\title{
The process of end-of-life decisions : regarding people with intellectual disabilities
}

Citation for published version (APA):

Wagemans, A. M. A. (2013). The process of end-of-life decisions : regarding people with intellectual disabilities. [Doctoral Thesis, Maastricht University]. Datawyse / Universitaire Pers Maastricht. https://doi.org/10.26481/dis.20131128aw

Document status and date:

Published: 01/01/2013

DOI:

10.26481/dis.20131128aw

Document Version:

Publisher's PDF, also known as Version of record

\section{Please check the document version of this publication:}

- A submitted manuscript is the version of the article upon submission and before peer-review. There can be important differences between the submitted version and the official published version of record.

People interested in the research are advised to contact the author for the final version of the publication, or visit the DOI to the publisher's website.

- The final author version and the galley proof are versions of the publication after peer review.

- The final published version features the final layout of the paper including the volume, issue and page numbers.

Link to publication

\footnotetext{
General rights rights.

- You may freely distribute the URL identifying the publication in the public portal. please follow below link for the End User Agreement:

www.umlib.nl/taverne-license

Take down policy

If you believe that this document breaches copyright please contact us at:

repository@maastrichtuniversity.nl

providing details and we will investigate your claim.
}

Copyright and moral rights for the publications made accessible in the public portal are retained by the authors and/or other copyright owners and it is a condition of accessing publications that users recognise and abide by the legal requirements associated with these

- Users may download and print one copy of any publication from the public portal for the purpose of private study or research.

- You may not further distribute the material or use it for any profit-making activity or commercial gain

If the publication is distributed under the terms of Article $25 \mathrm{fa}$ of the Dutch Copyright Act, indicated by the "Taverne" license above, 
THE PROCESS OF END-OF-LIFE DECISIONS regarding people with intellectual disabilities 
The research presented in this thesis was conducted at the Governor Kremers Centre (GKC) and the Department of Family Medicine of Maastricht University Medical Centre (MUMC ${ }^{+}$).

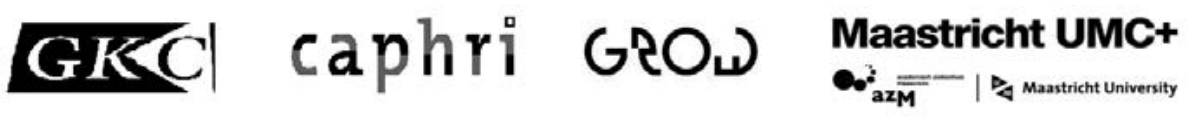

The studies presented in this dissertation were funded by the Koraal Groep and the Netherlands Organisation for Health Research and Development (ZonMw; project "Participatory research into quality of life of adults with intellectual disabilities", grant number 57000005).

\section{e? \\ Koraal Groep

De tekening op het omslag is gemaakt door een cliënt van De Blikvenger.

De Blikvenger is het kunstatelier van Maasveld (onderdeel van de Koraal Groep) waar cliënten terecht kunnen voor dagbesteding.

C Copyright Annemieke Wagemans, Maastricht 2013

Layout: Tiny Wouters

Production: Datawyse | Universitaire Pers Maastricht 


\title{
THE PROCESS OF END-OF-LIFE DECISIONS regarding people with intellectual disabilities
}

\author{
PROEFSCHRIFT
}

Ter verkrijging van de graad doctor aan de Universiteit Maastricht, op gezag van de Rector Magnificus, Prof dr. L.L.G. Soete

volgens het besluit van het College van Decanen, in het openbaar te verdedigen op donderdag 28 november 2013 om 16:00 uur

door

Annemieke Wagemans

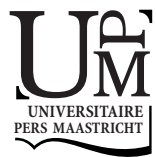




\section{Promotores}

Prof. dr. L.M.G. Curfs

Prof. dr. H.M.J. van Schrojenstein Lantman-de Valk (UMC St Radboud Nijmegen)

Prof. dr. J.F.M. Metsemakers

\section{Beoordelingscommissie}

Prof. dr. J.P.M. Geraedts (voorzitter)

Prof. dr. H.F.J.M. Crebolder

Prof. dr. H.M Evenhuis (Erasmus MC Rotterdam)

Prof. dr. T. van der Weijden 


\section{Contents}

$\begin{array}{lll}\text { Chapter } 1 \quad \text { General introduction } & 7\end{array}$

Chapter 2 End-of-life decisions: an important theme in the care for people 17 with intellectual disabilities

Chapter 3 The factors affecting end-of-life decision making by physicians of patients with intellectual disabilities in the Netherlands:

a qualitative study

Chapter 4 End-of-life decisions for people with intellectual disabilities, an interview study with patient representatives

Chapter 5 End-of-life decisions for people with intellectual disabilities, from the perspective of paid care staff

Chapter 6 Do-not-attempt-resuscitation orders for people with intellectual disabilities: dilemmas for physicians

Chapter 7 General discussion

Summary

Samenvatting

List of publications

Dankwoord

Curriculum Vitae 



\section{Chapter 1}

\section{General introduction}

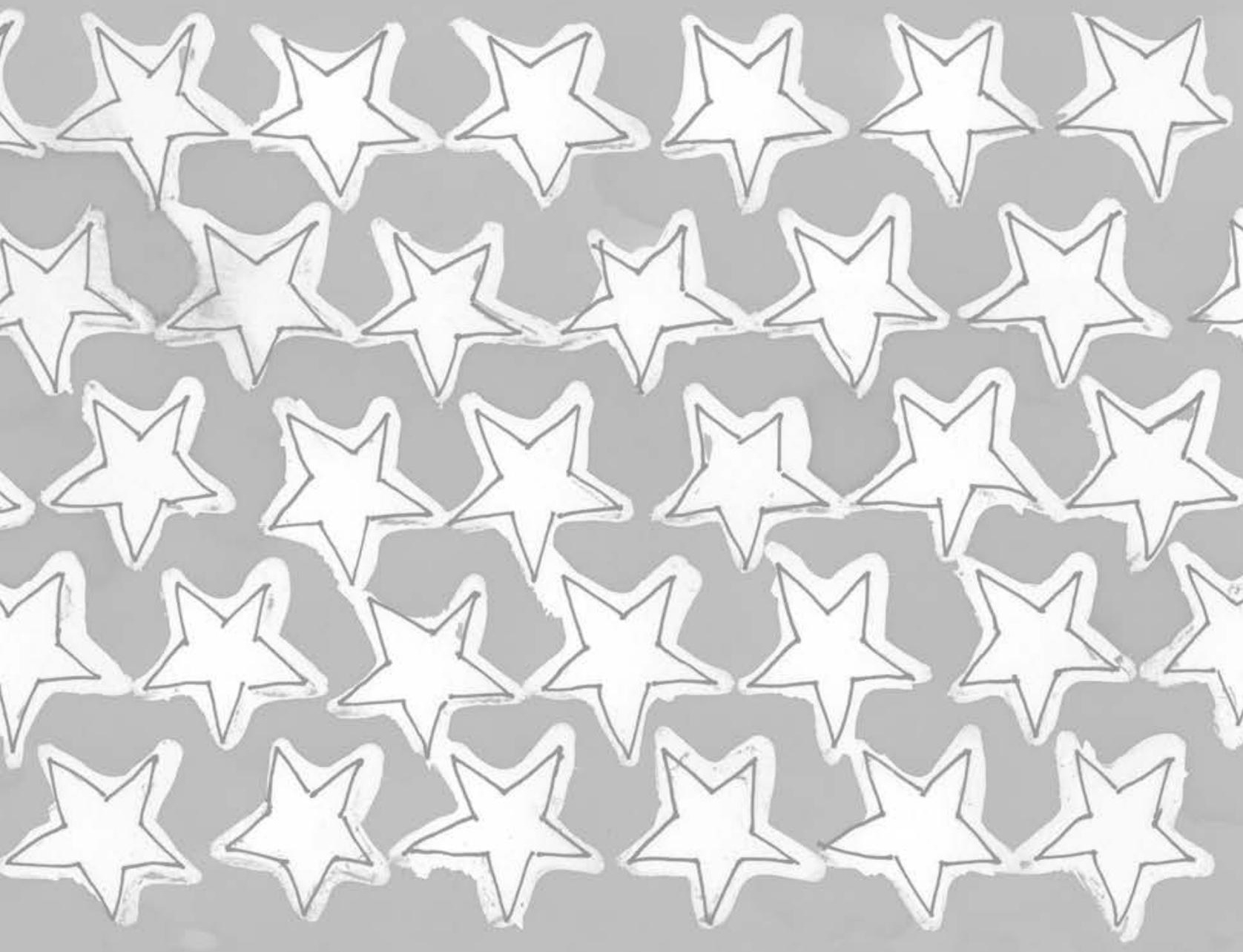


Chapter 1 


\section{General introduction}

\section{A narrative}

A 40-year-old man called John had a second episode of pneumonia. John had a profound intellectual disability (ID), was wheelchair-bound, could not sit or stand, and had to be fed. He probably had a swallowing disorder because of the neurological damage. He had spent three weeks in hospital during a first episode of infection and malaise, and then had returned to the group home where he lived. After two weeks, John was once again admitted to hospital and referred to a pulmonologist. After diagnostic investigations, the pulmonologist proposed to open his thorax and to drain the abscess which was probably causing the problems, an operation involving major risks for a patient with cerebral palsy, choking problems and epilepsy. John's mother was invited by the ID physician (physician for people with intellectual disabilities) to give her opinion and consent. As she knew that she would have to make a difficult decision, she brought along a daughter and two other sons for the discussion with the doctor. She felt that John's quality of life had diminished and that he had suffered enough. She asked the ID physician and paid care staff to do what they could without intrusive treatments and to get him out of hospital. The paid care staff of the group home, however, who had known him for more than five years, were not of the opinion that John had deteriorated or was suffering. His mother, who had known him all his life, had a different impression of John, who had been able to enjoy and love life in the past. According to her, John had lost his zest for life and she did not want him to suffer any longer. She asked for a treatment policy aimed at comfort and relief. John died four months later, after a period of palliative care in his own care home.

In this case, the mother felt that John had been suffering enough. The ID physician was not aware of the opinion of the family before the moment when serious health problems occurred, as mother and physician had never seriously discussed John's health status. The decision to make was an important one regarding John's life expectancy. Paid care staff did not realise how fragile John's health was. It turned out that the various participants in John's care had different views and opinions, and had never discussed the best options for John.

People with intellectual disabilities (IDs) (for a definition, see the Box below) are vulnerable as regards health problems and solutions. A recent study in the United Kingdom, involving patients' representatives, friends, paid care staff and physicians, revealed that the quality and effectiveness of health care given to people with IDs were insufficient. Forty-two percent of the deaths of people with IDs were considered premature, and the weakest link in the chain related to problems of diagnosis and treatment. ${ }^{1}$ People with IDs cannot always bear a major burden of diagnostic investigations and complex treatments. This limited ability to cope with normal health care solutions comes on top of more than average health problems and limited 
communication skills. People with IDs visit a doctor twice as often as the non-ID population and receive repeat prescriptions four times as often. ${ }^{2}$ They are highly dependent on others taking their complaints seriously ${ }^{3}$ and it is difficult to interpret what they want to tell us. ${ }^{4,5}$ People with IDs are sometimes highly inclined to give a desirable answer to please the interviewer, and they cannot always weigh up and predict the consequences of difficult health decisions. ${ }^{6,7}$

One of the characteristics of people with IDs is that they need support ${ }^{8,9}$ and often cannot make sound decisions by themselves. ${ }^{10}$ Parents have to make decisions for their children with IDs from the moment of birth onwards until the end of life, unlike for their other children, who take their lives in their own hands as they grow up.

The representational role of parents is often taken over by brothers and sisters later on in the life of someone with IDs and they are mostly deeply involved in the lives of their loved ones. Although parents and other next of kin are familiar with deciding for someone else, they often struggle to make a good decision. While different families may propose different solutions for the same health conditions and problems, it is ultimately the physician who is responsible for end-of-life decisions. Two approaches which can support the decision-making process are 'advance care planning' and 'shared decision making'. ${ }^{11-13}$

People with IDs are nowadays living longer ${ }^{14}$ and in terms of difficult health decisions, it is the end-of-life decisions that are especially burdensome to representatives. ${ }^{15}$ End-of-life decisions are often made in a palliative care setting (see the Box for definitions). Palliative care and end-of-life decisions are as important for people with IDs as they are for anyone. ${ }^{16-18}$ In fact, it may be argued that they are even more important, on the one hand because of the more frequent health problems and on the other hand because representatives are involved. Representatives play an important role in the making of health decisions for their loved ones. ${ }^{10}$ Despite all this, the available literature on palliative care for people with IDs ${ }^{18-21}$ and on end-of-life decisions ${ }^{22,23}$ provides no information on how representatives and other stakeholders fulfil their roles in the process of end-of-life decisions. Recently, ZonMw (The Netherlands Organisation for Health Research and Development) published a report on questions surrounding medical decisions at the beginning and end of life, which aims to contribute to the debate on the appropriateness of care at the end of life. ${ }^{23}$ In fact, this is the same question that John's mother asked: "Do we need to do everything that is possible?" The ZonMw report states that hardly anything is known about the way decisions are made at the end of life. 


\section{Box: Definitions}

\section{Definition of intellectual disabilities}

"Intellectual disability is a disability characterized by significant limitations both in intellectual functioning and in adaptive behaviour, which covers many everyday social and practical skills and is sometimes expressed in IQ points (from profound to mild, range 0-70 IQ points). This disability originates before the age of $18{ }^{\prime \prime} .^{24}$

\section{Definition of end-of-life decisions}

"End-of-life decisions are those decisions which can lead to or hasten death, whether intentionally or not. They include withdrawing or not starting medical treatment, pain treatment with possible life-shortening side-effects, and ending a patient's life with or without his or her request. These kinds of decisions are extremely important in the lives of most people, and are known to play a substantial part in the process of dying in half of the deaths in Western countries". ${ }^{25}$

\section{Definition of palliative care}

The World Health Organization gives a broad definition of palliative care ${ }^{26}$ : "Palliative care is an approach that improves the quality of life of patients and their families facing the problem associated with life-threatening illness, through the prevention and relief of suffering by means of early identification and impeccable assessment and treatment of pain and other problems, physical, psychosocial and spiritual. Palliative care:

- $\quad$ provides relief from pain and other distressing symptoms;

- affirms life and regards dying as a normal process;

- intends neither to hasten or postpone death;

- integrates the psychological and spiritual aspects of patient care;

- $\quad$ offers a support system to help patients live as actively as possible until death;

- offers a support system to help the family cope during the patient's illness and in their own bereavement;

- uses a team approach to address the needs of patients and their families, including bereavement counselling, if indicated;

- $\quad$ will enhance quality of life, and may also positively influence the course of illness; is applicable early in the course of illness, in conjunction with other therapies that are intended to prolong life, such as chemotherapy or radiation therapy, and includes those investigations needed to better understand and manage distressing clinical complications." 


\section{Research questions}

This study was initiated because we wanted to know more about the prevalence and nature of end-of-life decisions for people with IDs, but first and foremost because we wanted to improve the care at the end of life for people with IDs. For this reason we were interested in the way decisions are taken and whether and how they are shared between physicians, patients' representatives and paid care staff.

We decided to involve representatives and professionals in the study and to ask their viewpoints. People with IDs themselves were not included in this study, as their roles and contributions were deemed to be complex and delicate, and would need a separate, comprehensive study. Since we felt that the problem of issuing Do-NotAttempt-Resuscitation (DNAR) orders involved different features and problems than the other end-of-life decisions, this aspect was studied separately.

The research questions were:

- What is the prevalence and nature of end-of-life decisions for people with IDs?

- How does the process of end-of-life decisions work?

- Who plays what role?

- What considerations are important in the decision-making process?

- What are the problems and pitfalls regarding DNAR orders from the perspective of ID physicians?

\section{Outline of the thesis}

\section{Chapter 2}

Although end-of-life decisions are seen as an accepted part of dying, not much was known about these decisions as regards people with IDs when this research project started. Therefore chapter 2 discusses the prevalence and nature of end-of-life decisions. In a retrospective study, we investigated patient files of people with IDs who had died in a Dutch centre providing professional care, between January 2002 and July 2007. The numbers and categories of end-of-life decisions were studied and difficult cases were investigated and described.

The population which was studied in the next three chapters was that of physicians, representatives (mostly next-of-kin) and paid care staff involved in the processes surrounding the deaths of ten people with IDs. ID physicians, representtatives and most of the paid care staff involved were interviewed. Research questions 2 (How does the process of end-of-life decisions work?), 3 (Who plays what role?) and 4 (What considerations are important in the decision-making process?) were investigated separately for physicians (chapter 3 ), for representatives (chapter 4 ) and for paid care staff (chapter 5 ). 


\section{Chapter 3}

This chapter reports on a study into the contribution of physicians to the process of end-of-life decisions. The Dutch Association of ID physicians issued a guideline based on literature and consensus in 2008. This guideline was practice-oriented and needed evidence to support doctors (ID physicians, family doctors and medical specialists) in their work. $^{27}$

\section{Chapter 4}

The role of representatives in the process of end-of-life decisions for people with IDs had hardly been studied. We therefore wanted to know what role representatives played in the process of end-of-life decisions, and what influence they had on these decisions. Our study included only those processes in which representatives played an important role, which meant that the representatives could be interviewed in all cases.

\section{Chapter 5}

This chapter reports on a study into the role of the paid care staff in the end-of-life decision-making process. Paid care staff have often known the people with IDs for whom they care for a long time and are deeply involved in their lives. They know what the people they care for like, and what is important in their lives. Their contribution to the process of end-of-life decisions seemed very important and deserved a separate study. This chapter therefore examines the input of paid care staff in the process of end-of-life decisions.

\section{Chapter 6}

The question "What are the problems and pitfalls regarding the issuing of DNAR orders?" was examined in a separate study. A DNAR order is a special kind of end-oflife decision, as this decision is made in advance by a patient or physician, whereas when the decision comes into effect, it is often bystanders who have to decide what to do. DNAR was studied separately because the organizational context is important, the decision is made in advance and it is often bystanders and not the physicians who have to effectuate the DNAR decision.

\section{Chapter 7}

The final chapter discusses the findings of the above studies and offers recommendations for further research.

The thesis ends with a summary in English and Dutch. 


\section{References}

1. Heslop P. Confidential Inquiry into premature deaths of people with learing disabilities. Norah Fry Research Centre: Bristol UK, 2013.

2. Van Schrojenstein Lantman-de Valk HM, Walsh PN. Managing health problems in people with intellectual disabilities. BMJ 2008;337:a2507.

3. Wullink M, Veldhuijzen W, Van Schrojenstein Lantman-de Valk HM, et al. Doctor-patient communication with people with intellectual disability--a qualitative study. BMC Fam Pract 2009;10:82.

4. Meininger HP. Narrating, writing, reading: life story work as an aid to (self) advocacy. British Journal of Learning Disabilities 2006;34:181-8.

5. Widdershoven GAM, Berghmans RLP. Wilsbekwaamheid in de zorg voor mensen met een verstandelijke beperking (Competency issues in the care of people with intellectual disabilities). Nederlands Tijdschrift voor de Zorg aan mensen met verstandelijke beperkingen. 2004;30:166-80.

6. Welie JV, Welie SP. Patient decision making competence: outlines of a conceptual analysis. Med Health Care Philos 2001;4:127-38.

7. Welie SP. Criteria for patient decision making (in)competence: a review of and commentary on some empirical approaches. Med Health Care Philos 2001;4:139-51.

8. Herps MA, Buntinx WH, Curfs LM. Individual support planning: perceptions and expectations of people with intellectual disabilities in the Netherlands. J Intellect Disabil Res 2012; doi: 10.1111/j.1365-2788.2012.01598.x. [Epub ahead of print].

9. Bossaert G, Kuppens S, Buntinx W, et al. Usefulness of the Supports Intensity Scale (SIS) for persons with other than intellectual disabilities. Res Dev Disabil. 2009; 1306-16. doi: 10.1016/ j.ridd.2009.05.007. Epub 2009 Jun 17.

10. WGBO, Act of 17 November 1994 amending the civil code and other legislation in connection with the incorporation of provisions concerning the contract to provide medical treatment (Medical Treatment Contract Act). Staatsblad 837, 1994.

11. Kingsbury LA. People Planning Ahead. Washington: AAIDD, 2009.

12. Charles C, Gafni A, Whelan T. Shared decision-making in the medical encounter: what does it mean? (or it takes at least two to tango). Soc Sci Med. 1997;44:681-92.

13. Entwistle VA, Carter SM, Cribb A, et al. Supporting patient autonomy: the importance of clinicianpatient relationships. J Gen Intern Med 2010;25:741-5.

14. Patja K, livanainen $\mathrm{M}$, Vesala $\mathrm{H}$, et al. Life expectancy of people with intellectual disability: a 35-year follow-up study. J Intellect Disabil Res. 2000;44:591-9.

15. Dreyer A, Forde R, Nortvedt P. Autonomy at the end of life: life-prolonging treatment in nursing homes--relatives' role in the decision-making process. J Med Ethics. 2009;35:672-7.

16. Tuffrey-Wijne I. Living with Learning Disabilities, Dying with Cancer. first edition London UK: Jessica Kingsley Publishers, 2010.

17. Van Thiel GJ, Van Delden JJ, De Haan K, et al. Retrospective study of doctors' "end of life decisions" in caring for mentally handicapped people in institutions in The Netherlands. BMJ 1997;315:88-91.

18. Tuffrey-Wijne I. The palliative care needs of people with intellectual disabilities: a literature review. Palliat Med 2003;17:55-62.

19. De Veer AJ, Francke AL and Poortvliet EP. Nurses' involvement in end-of-life decisions. Cancer Nurs 2008;31:222-8

20. De Veer AJE, Francke A, Speet $M$, et al. Verpleegkundig zorg rondom het overlijden van mensen met een verstandelijke beperking (Nursing care at the end of life for people with intellectual disabilities). NTZ 2004;2:110-22.

21. Tuffrey-Wijne I. People with intellectual disabilities and their need for cancer information. European Journal of Oncology Nursing 2006;10:106-16.

22. Van Dartel JNGM. Handreiking (niet) reanimatie beleid in de zorg voor mensen met een beperking.[Suggestions for care policies on resuscitating, or refraining from resuscitating, people with intellectual disabilities.] Vereniging Gehandicaptenzorg Nederland, 2007. 
23. ZonMw, ed. Moet alles wat kan (Do we need to do everything that is possible?) Vagen rond medische beslissingen bij het begin en einde van het leven (Questions surrounding medical decisions at the beginning and the end of life). ZonMw: den Haag. 1-66, 2013

24. Schalock. Intellectual Disability: Definition, Classification, and Systems of Supports (Eleventh Edition). Washington American Association on Intellectual and Developmental Disabilities, 2011.

25. Van der Heide A, Deliens L, Faisst K, et al. End-of-life decision-making in six European countries: descriptive study. Lancet 2003;362:345-50.

26. http://www.who.int/cancer/palliative/definition/en/. [2013,cited 19 February].

27. NVAVG. Medische Beslissingen rond het levenseinde bij mensen met een verstandelijk handicapt (Medical end-of-life decisions for people with intellectual disabillities). Guideline 2008. 



\section{Chapter 2}

End-of-life decisions: an important theme in the care for people with intellectual disabilities

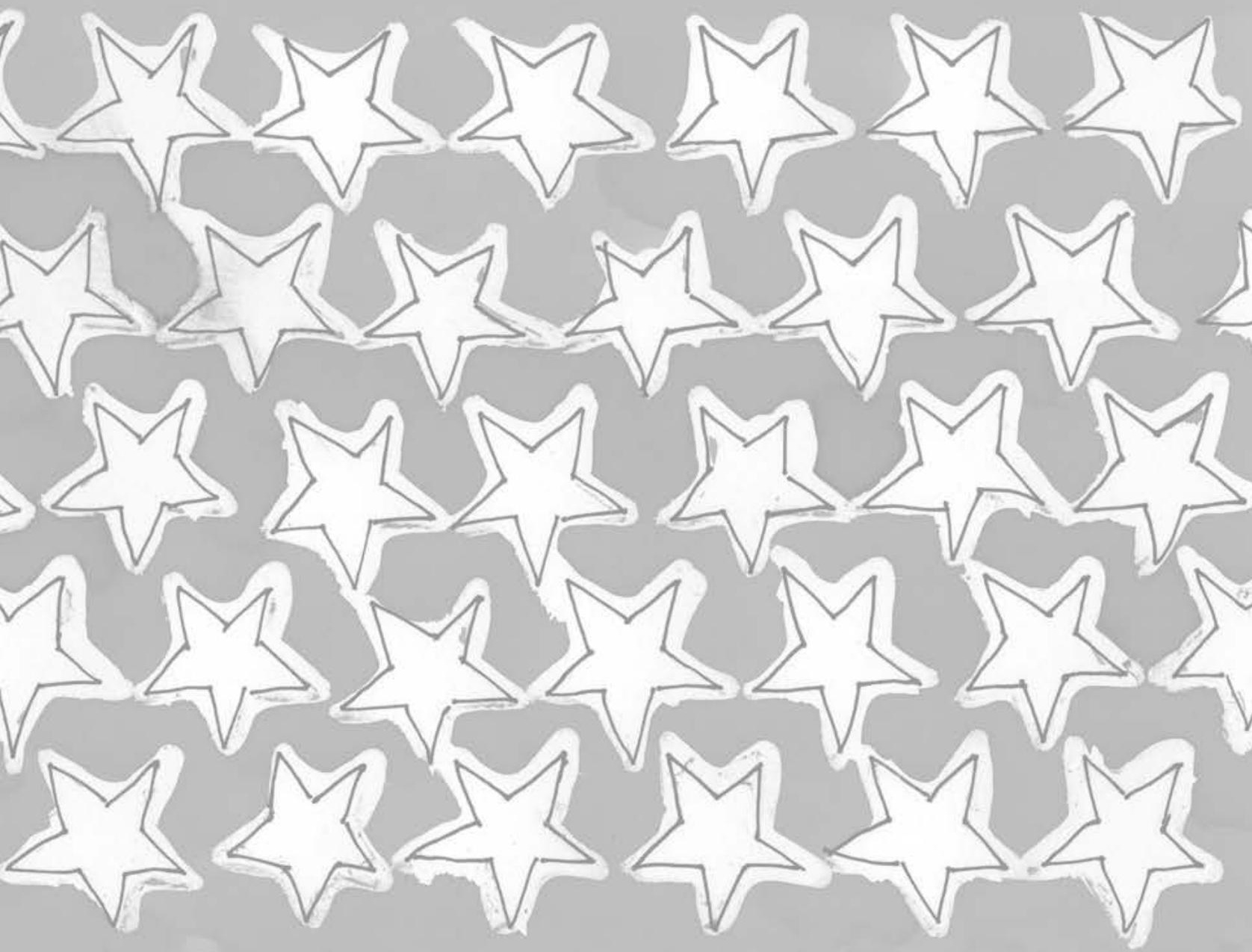

Wagemans AMA, van Schrojenstein Lantman-de Valk HMJ, I. Tuffrey-Wijne I, Widdershoven GAM, Curfs LMG 


\section{Abstract}

Background

Whilst end-of-life decisions in the general population have received attention in several countries, not much is known about this in people with intellectual disabilities.

Therefore the prevalence and nature of end-of-life decisions was investigated in a Dutch centre providing residential care for 335 people with intellectual disabilities.

Method

A retrospective study of medical files of people who died between January 2002 and July 2007.

Results

One or more end-of-life decisions were taken in 27 out of 47 cases. A non-treatment decision was taken for seven residents, possibly shortening life expectancy in some cases. The family was involved in decision making in half of the 27 cases. No information was found about the process of end-of-life decision making. There was no evidence in the notes that any of the people with intellectual disabilities was asked for his or her own opinion in taking an end-of-life decision.

\section{Conclusion}

This study demonstrates that medical end-of-life decisions played a part in significant numbers of people with intellectual disabilities who have died within this centre, but further studies are needed to establish decision making processes. 


\section{Introduction}

This paper considers end-of-life decisions for people with intellectual disabilities. Medical end-of-life decisions in Dutch health care include intensified alleviation of pain or symptoms with hastening of death as a possible side effect, abandoning potentially life-prolonging treatment, palliative sedation, ending of life without an explicit request of the patient, euthanasia and physician-assisted suicide. ${ }^{1}$

The wide range of intellectual disabilities from mild to profound means that there are considerable variations in how much people with intellectual disabilities can understand with regard to end-of-life decisions.

Advances in medicine have increased life expectancy for people with intellectual disabilities in Western countries and the dying process is changing from acute death to a more protracted process. ${ }^{2}$ In the past years, patient empowerment also developed within the care for people with intellectual disabilities. Consequently, endof-life decisions have gained more prominence.

\section{Dutch health care law regarding end-of-life decisions}

In Dutch health care law $^{3}$ the Contract of Medical Treatment Act uses a representational model. People who lack capacity in taking health care decisions often have a representative. Parents are supposed to represent their children until the age of 18 years if there is lack of capacity. Over 18 years a representative is informal (partner, children, parents, siblings) or has to be appointed by the court of justice (mentor or curator). The doctor holds ultimate responsibility for end-of-life decisions.

Health care professionals do not act as representatives. The representatives' role is to give their view on a particular decision. If consensus is not achieved, and if it is an important decision, the doctor has the right to overrule the representative. ${ }^{3}$

The ability of patients to take health care decisions themselves depends on their capacity. Assessment of the patient's capacity is primarily the responsibility of the attendant health care professionals, which will be the doctor in the case of end-of-life decisions. ${ }^{4-6}$ However there is some unclarity in the literature, and even more so among clinicians and in the law, as to what exactly is meant by patient decision making competence. ${ }^{7}$

The laws around capacity, consent and medical decision making vary in countries. $^{8,9}$

\section{Prevalence of end-of-life decisions}

End-of-life decisions are seen as an accepted part of dying. ${ }^{10} \mathrm{~A}$ descriptive study in six European countries $(\mathrm{N}=20,480)$ found that the proportion of deaths that were 
preceded by an end-of-life decision ranged from 23\% (Italy) to $51 \%$ (Switzerland). In all studied countries, death was sudden and unexpected in about a third of all cases. ${ }^{11}$

Van Thiel and colleagues ${ }^{12}$ did a retrospective study of doctors' end-of-life decisions in caring for people with intellectual disabilities in institutions in the Netherlands. There was an end-of-life decision in $44 \%$ of all reported deaths. The authors recommend reconsideration of the role of communication with clients, drawing attention to the expressions of people with intellectual disabilities who lack capacity.

A lack of capacity should not be assumed. Tuffrey-Wijne et al. ${ }^{13}$ found that health care professionals and daily care givers lacked skill and confidence in communicating about serious illness with people with intellectual disabilities. Family members and paid caregivers tended to withhold potentially upsetting information from people with mild and moderate intellectual disabilities in order to spare them distress. People with intellectual disabilities themselves wanted information when affected by cancer, and appeared to be capable of comprehending it. ${ }^{14}$

\section{Aims}

The aim of this study was to establish the prevalence and nature of end-of-life decisions in people with intellectual disabilities in a Dutch residential care centre. The objectives were to establish the following facts about residents who died between 2002 and 2007: the moment and place of death, aims of treatment, nature and amount of end-of-life decisions, involvement of family and caregivers in these decisions, frequency of second opinion at end-of-life, and the residents' capacity for making end-of-life decisions.

\section{Methods}

Data were collected in a Dutch centre providing residential care for 335 children and adults with intellectual disabilities. People lived in wards or group homes of four to 12 persons (mostly clustered together on a campus; most had lived together for many years). Some people had been cared for in this centre for decades. Health care was provided by a physician specialized in the care of people with intellectual disabilities, as is usual in the Netherlands.

The medical files of all residents who died between January 2002 and July 2007 were systematically reviewed with the use of a checklist. This checklist (Table 2.1) was developed by the current authors based on the existing literature about end-of-life decisions in people with intellectual disabilities ${ }^{12}$ and more general literature. ${ }^{1,11}$ 
After an iterative process of consultation of project members and experts the checklist was finalised. All required information could be traced in the files. Furthermore the files were kept on the basis of day to day care.

We thus concluded that the quality of the files was more than sufficient for this aim

Differences in frequencies were tested with the Chi square test.

The process of end of life decisions is illustrated by case scenarios.

Table 2.1 Checklist for screening medical files.

\begin{tabular}{ll}
\hline Gender & Male / Female \\
Age of dying & In decades \\
Place of dying & Residential setting / Hospital / At parental home \\
Death (un)expected & Yes / No \\
Focus of treatment plan & Cure / Comfort and symptom relief \\
Degree of intellectual disabilities & Mild / Moderate / Severe / Profound \\
Long lasting diseases & Chronic obstructive pulmonary disease / Heart failure / Cancer / \\
& Neurological diseases / Other \\
Cause of death & Pneumonia / Heart failure / Choking / Epileptic fit / Exhaustion / \\
& Other / Unknown \\
Underlying disease & Chronic obstructive pulmonary disease / Heart failure / Cancer / \\
& Neurological disease / Other \\
Disorder leading to EoL decision & Chronic obstructive pulmonary disease / Heart failure / Cancer/ \\
Neurological disease / Other \\
Nature of EoL decision preceding death & Intensified allevation of pain or symptoms / Abandoning \\
& potentially life prolonging treatment / Palliative sedation / \\
& Ending of life without an explicit request of the patient / \\
& Euthanasia / Physician-assisted suicide. \\
EoL influencing life expectancy & Yes / No \\
EoL improving the quality of life & Yes / No \\
Partners in decision & Patiënt / Representative / Nurses / Chaplain / Psychologist \\
Lack of capacity of the resident on EoL & Yes / No / Not recorded \\
Resident had influence on EoL decision & Yes / No / Not recorded \\
Second opinion sought & Geriatrician / Neurologist / Paediatrician \\
\hline
\end{tabular}

\section{Results}

Forty seven residents died during the study period (34 women and 13 men). More residents (19) died in their fifties than in any other decade of life. Overall, the age of death in the study population was lower than in the general Dutch population (Figure 2.1).

Residents with severe and profound intellectual disabilities died at a younger age than those with mild and moderate intellectual disabilities (Figure 2.2). 
The presumed causes of death were pneumonia (9), exhaustion (6), heart failure (3), peritonitis (3), epileptic seizure (2), cerebrovascular accident (2), choking (1), unknown (21).

Thirty-five residents died at their residential home or ward, ten in hospital and two at home with their family. Death was unexpected for 23 residents.

The treatment plan was either focused on cure (17 residents) or on comfort and relief (30 residents). In the comfort group death was expected significantly more often than in the cure group $(p<0.001)$. An end-of-life decision was taken for most residents in the comfort group. All residents whose death was expected had a treatment plan focused on comfort.

Reported causes of death can only be assumed to be correct, as none of the deceased had a post mortem.

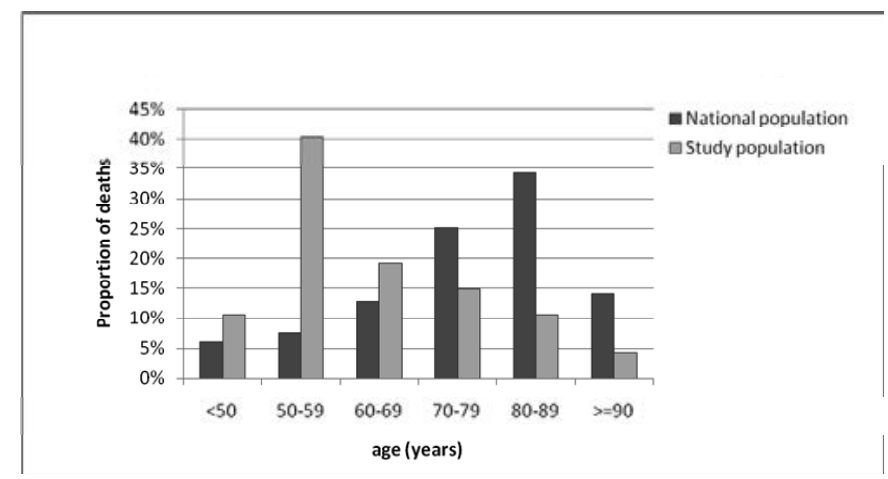

Figure 2.1 Age of death in the national population and in the study population.

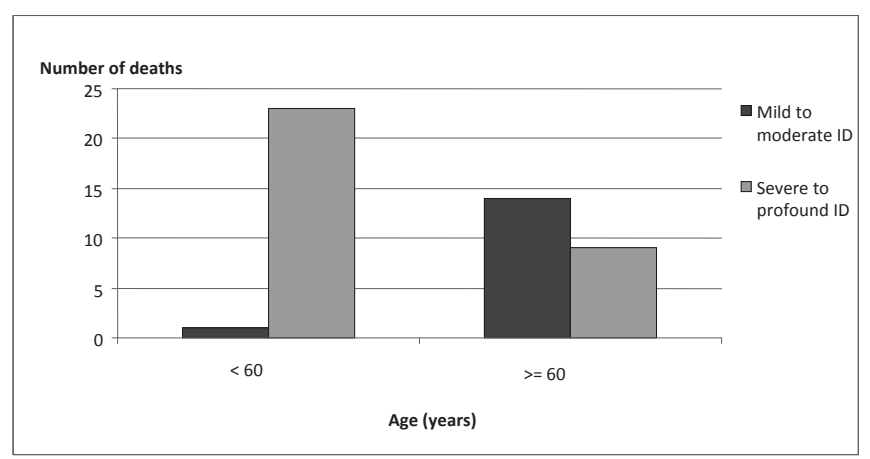

Figure 2.2 Age of death related to degree of ID in study population. 
An end-of-life decision was taken in 27 out of 47 deceased. There were no instances of euthanasia, assisted suicide or ending of life without an explicit request of the resident. All end-of-life decisions are listed in Table 2.2; while Table 2.3 shows the estimated effects on life expectancy.

Table 2.2 End-of-life decisions in study population

\begin{tabular}{|c|c|c|c|c|c|c|}
\hline & \multirow[b]{2}{*}{$\begin{array}{l}\text { Number of } \\
\text { Patients }\end{array}$} & \multicolumn{5}{|c|}{ Type of Decision } \\
\hline & & $\begin{array}{l}\text { Withholding } \\
\text { nasal feeding } \\
\text { tube }\end{array}$ & $\begin{array}{l}\text { Withholding } \\
\text { therapy }\end{array}$ & DNR & $\begin{array}{l}\text { Pain relief/ } \\
\text { Symptom } \\
\text { control }\end{array}$ & $\begin{array}{l}\text { Second } \\
\text { Opinion }\end{array}$ \\
\hline Dementia & 9 & 3 & 1 & 7 & 1 & 4 \\
\hline Cancer & 6 & 2 & 3 & 7 & 6 & 6 \\
\hline Heart Failure & 2 & & & 2 & 1 & 2 \\
\hline No lust for life & 2 & & & 2 & 1 & 2 \\
\hline Other & 8 & 3 & 3 & 7 & 3 & 7 \\
\hline Total & 27 & 8 & 7 & 25 & 12 & 21 \\
\hline
\end{tabular}

Table 2.3 Supposed effect on life expectancy

\begin{tabular}{lccccc}
\hline & \multicolumn{3}{c}{ Type of Decision } \\
\cline { 2 - 6 } & $\begin{array}{c}\text { Withholding } \\
\text { nasal feeding } \\
\text { tube }\end{array}$ & $\begin{array}{c}\text { Withholding } \\
\text { therapy }\end{array}$ & DNR & $\begin{array}{c}\text { Pain relief/ } \\
\text { Symptom } \\
\text { control }\end{array}$ & $\begin{array}{c}\text { Second } \\
\text { Opinion }\end{array}$ \\
\hline No influence on life expectancy & 6 & 4 & 24 & 12 & 0 \\
Possible influence on life expectancy & 2 & 3 & 1 & 0 & 0 \\
\hline
\end{tabular}

The family was involved in decision making in half of the cases. In the other half, the resident didn't have family involved, and had no other formal representative. This was almost always the case for the older residents, who mostly had no children, and whose siblings were not involved or had predeceased them. The nurses supporting the residents were involved in the end-of-life decision making process in all cases.

In 21 out of 27 residents with end-of-life decisions, a second opinion was sought from a physician other than the ID-physician, mostly a geriatrician or a neurologist. No second opinion was sought for five (out of nine) residents who had dementia (often in Down syndrome) and for whom an end-of-life decision was taken, possibly because the family and doctor had a long time to prepare for an expected death.

Twenty-six residents had a do-not-resuscitate order. This order was acted upon for one resident (see below).

A non-treatment decision was taken in a further seven of the deceased residents, details of end-of-life decisions are given below.

Nothing was noted in the files about the views of the residents themselves, nor about their capacity to take an end-of-life decision. 


\section{Cases}

\section{Non-resuscitation decisions}

A non-resuscitation order was activated in the case of a boy who died at the age of 15 from a not adequately treated epileptic seizure. The boy had a profound intellectual disability and West syndrome, a rare and difficult to treat syndrome with epileptic seizures. His parents had requested that no treatment would be offered in case of emergency, and asked the ID-physician and neurologist not to refer the boy to hospital when the epileptic seizures could not be managed. Although death had not been expected, the boy died in the centre following an epileptic seizure. His death appeared to be the result of following the do-not-resuscitate order. Only the do-notresuscitate order was recorded in the files, not the considerations of the parents or the doctors.

\section{Non-treatment decisions}

- A 15 year old boy with no verbal communicative skills had Hodgkin disease. His parents and pediatrician had decided to forgo treatment because of its complexity and the possibly life-threatening side effects. The treatment of Hodgkin disease generally has a high success rate. The parents were afraid they could not handle the medical problems on top of the boy's long-standing challenging behavior; he was subsequently admitted to the residential centre in this study. He died of Hodgkin disease within a year. At his parents request they took care of him at home during the last two weeks of his life.

- A 60 year old lady with mild intellectual disabilities had disseminated breast cancer. The oncologist did not consider any treatment options for her, noting in her hospital transfer letter that 'because of her intellectual disabilities, chemotherapy is not possible'. The diagnosis or prognosis was not discussed with this lady. After she was admitted to the residential centre, she was not informed at the request of her family, who wanted to protect her from distress. Although the caregivers at the centre believed it would be better for her to be informed about the expected end of her life, the family's wishes were respected.

- A 64 year old lady with moderate intellectual disabilities had a chronic neurological disease and serious signs of a neoplasm in abdomen. Her three brothers and the medical team felt there was a very severe decline in her quality of life during the last years. The relatives, the neurologist, the ID-physician and the geriatrician discussed the situation, and they all agreed not to trace the neoplasm. The most important reason for not starting a diagnostic pathway was the client's perceived increasingly poor quality of life. She was not informed about this decision by either family or by professionals. 
- Parents had previously requested for their 15 year old son not to be treated in case of medical decline. When the son developed an umbilical rupture, they changed their mind and asked to refer their son to hospital for surgical intervention. He died from complications following the intervention. For the parents it was difficult to stick to their former decision.

- A 65 year old lady with Down syndrome had dementia. She had been treated for pneumonia repeatedly and with increasing frequency, and died of a final episode of pneumonia which was left untreated. The patient was choking on her own saliva, and at this stage treatment was considered to be futile. For the involved representative it was very difficult to discuss this complicated situation with the other family members. Finally he agreed with the doctor's proposal of nontreatment.

\section{Removal of nasogastric feed tube}

Two residents with Down syndrome and dementia returned from hospital with a nasogastric tube.

- One woman with symptoms of an extensive cerebral vascular stroke removed the tube herself. As the attendant doctor, caregivers and family thought the cerebral damage was very extensive, they decided it was in her best interest not to give her another tube.

- A 52 year old man went to hospital at the end of life because of an epileptic seizure, and a nasogastric tube was inserted. The hospital medical team did not discuss the benefit of the tube for this resident with the relatives. At the residential centre, the focus of the treatment plan had been discussed with his relatives several months earlier. They agreed with the proposal not to give fluid by nasogastric tube if oral intake would diminish. After his return from hospital the tube was removed, in line with former agreements, because relatives and caregivers felt it would not improve his quality of life. Not the length of life but the quality of life was the most important focus in the terminal phase.

It is possible that the removal of the nasogastric tubes shortened life expectancy.

\section{Euthanasia request}

An older mother requested euthanasia for her 50 year old son who she felt had a poor quality of life. In his youth, this man was able to communicate more clearly, to walk and cycle, and to work in a sheltered workshop. Over the years there was a very serious decline of his physical health. He was wheelchair-dependent and was fed by his caregivers. He remained in bed for most of the day. Repeated medical examinations did not reveal the cause of his progressive deterioration. As the man himself could not express his thoughts or indicate the severity of his complaints, the 
doctor could not agree to the mother's request. In Dutch legislation only a person himself can request for euthanasia, no other person can do so, even not parents.

\section{Discussion}

Notwithstanding increasing longevity in people with intellectual disabilities, they still die at a younger age than the general population ${ }^{15}$. People with severe and profound intellectual disabilities have more physical and health problems, which will shorten life expectancy even more ${ }^{2}$.

Half of the residents died unexpectedly. Sixty percent of the deceased residents in the study population had a recorded end-of-life decision, including those who died suddenly. In the Dutch general population, the total frequency of end-of- life decisions between June 2001 and February 2002 was 44\% in non-sudden deaths. ${ }^{11}$ End-of-life decisions occurred in $70 \%$ of all deaths in a prospective cohort study in long-term care patients with a life-expectancy of six weeks in 16 nursing homes representative for the Netherlands. ${ }^{16}$ This higher percentage is not surprising, given that the prognosis was only six weeks. The percentage found by Van Thiel in people with intellectual disabilities ${ }^{12}$ was $44 \%$, which did not include residents who died in hospital. It could be that the percentage in our study is relatively high because in this particular residential care centre, discussions with representatives often start early in the course of a disease. The advantages are not only that advance directives are in place, but also that relatives are more accepting of the dying process, even though death remains unexpected at times. The fact that half of the deaths studied were expected, reveals that end-of-life decisions and end-of-life care are a key issue for research and service providers.

A non-treatment decision was taken in seven of the deceased residents, possibly shortening life expectancy in some cases. In the Netherlands a study in the general population demonstrated that end-of-life decisions only have a small influence on life expectancy. ${ }^{17}$ There are no reasons to presume that this is different in the care for people with intellectual disabilities. ${ }^{12}$ On the other hand, young people with a disease like Hodgkin are routinely offered curative treatment. In the case described, the decision by doctors and parents not to treat the 15-year-old boy was not based on his medical condition, but on the fact that he had challenging behaviour and was unable to understand the burden of treatment and its side effects. This decision resulted in his death a year later.

The example of the 60 year old lady with breast cancer shows a lack of deliberation between doctors, family and patient whether there should follow (palliative) treatment at end-of-life. It seems clear that the doctors in both cases made 
a non-treatment decision on the basis of their intellectual disabilities, rather than their physical illness.

The cases illustrate that advance planning, for example through do-notresuscitate orders, seems to give certainty. In the absence of such planning, decisions are taken at the moment they are required, a time when emotions can run high and decision making can be more difficult.

As illustrated in this study, parents have a very important voice in taking end-oflife decisions, particularly for young people. It is difficult for anyone but the person him- or herself to judge quality of life. Parents know their children intimately and will have a distinct opinion on the child's quality of life, but there is a worrying possibility that a parent's assessment of poor quality of life leads to discriminatory or even unethical practice if it is not also carefully considered by a range of carers and professionals. The doctor has to consider the medical facts and not presumed quality of life. It is clear that end-of-life decisions, particularly if quality-of-life assessments are involved, present complex problems that need to be negotiated with care.

Doctors will generally seek consensus with representatives and other caregivers. In a qualitative, ethnographic study in two nursing homes in the Netherlands an attempt was made to clarify the decision making process when withholding the artificial administration of fluids and nutrition in patients who lacked capacity. ${ }^{18}$ One of the conclusions was that doctors tried to create the broadest possible basis for the decision making process and its outcome, mainly by involving family.

However, not every person with intellectual disabilities has family involved. In a retrospective study in a long-term residential care centre in the USA, only $20 \%$ of the 850 people with severe disabilities had family involved in their welfare decisions. ${ }^{19}$ Half of the residents in our study had family involved in end-of-life decisions, which can be seen as a more favorable situation. In the other half, some family lived far away and rarely visited the resident. In those cases, it seems appropriate to involve distant family members in some way, but not to base end-of-life decisions solely on the opinion of relatives who may not know the resident very well. ${ }^{20}$

Communication between doctor and patient took place in only 38 percent of endof-life decisions in the Netherlands in $2005 .{ }^{17}$ In our study population discussions between the resident and the doctor never occurred, or at least were not recorded in the files. However in half of the deceased there was a discussion with the representatives. Hardly anything was recorded about the process of decision making, nor about the diverse roles of the people involved.

Seeking consent is a fundamental part of good practice in the care for people with intellectual disabilities. ${ }^{6}$ Health care professionals should be trained to give information in an adequate way. ${ }^{14}$ As Van Thiel concluded, it may be that health-care professionals too often presume a lack of capacity in people with intellectual disabilities, without actually testing this. ${ }^{12}$ 
The capacity of residents to take a health-care decision was not recorded in their files, which leads us to assume that it was never assessed. It seems that end-of-life decisions were not discussed with the residents, nor were they informed about this after the decision was taken. The physician and the family didn't want to discuss endof-life decisions with the resident probably because they supposed the resident couldn't understand the message and because they wanted to protect him or her.

Finally a few limitations should be noted.

This study was carried out in only one service center with 335 clients. This is a small and not representative proportion of the total Dutch population of people with intellectual disabilities (estimated to be about 111,000 people ${ }^{21}$ ).

Causes of death recorded were all presumed. In the Netherlands, postmortem is not common practice in cases of natural death.

The results were further limited by the fact that this was not a prospective study, but a retrospective review of files; the considerations of those involved in decision making were not written down in any detail.

\section{Conclusions and recommendations for further study}

This study has demonstrated that medical end-of-life decisions played a part in significant numbers of people with intellectual disabilities who died within a residential care setting. The decision-making process was not clear from their medical files, and further research is needed to establish this. In particular, it would be important to investigate to what extent people with intellectual disabilities and their representatives are involved in such decision making. The views of the representatives were important as demonstrated in some of the cases. This raises the question whether it is right that the opinion of the representative carries so much weight. As this is by no means a one-off occurrence in practice, it needs to be addressed. A further, more comprehensive study of decision-making processes in the end-of-life care for people with intellectual disabilities would be important in order to understand the thought processes and influence of various stakeholders, including people with intellectual disabilities themselves, families, doctors, nurses and other carers. Guidelines should be developed and implemented to support policy makers and practitioners in this important aspect of care for people with intellectual disabilities. 
End-of-life decisions: an important theme in the care for people with intellectual disabilities

\section{References}

1. Onwuteaka-Philipsen B. Evaluatie Wet toetsing levensbeëindiging op verzoek en hulp bij zelfdoding (The termination of life on request and assisted suicide act evaluated). ZonMw, den Haag. 2007.

2. Patja K, Molsa P, livanainen M. Cause-specific mortality of people with intellectual disability in a population-based, 35-year follow-up study. J Intellect Disabil Res 2001;45:30-40.

3. Welie SP, Dute J, Nys H, Van Wijmen FC. Patient incompetence and substitute decision-making: an analysis of the role of the health care professional in Dutch law. Health Policy 2005;73:21-40.

4. Ministerie van Justitie. Handreiking voor de beoordeling van wilsbekwaamheid (Assistance to assessment of lack of capacity). Available at: http://www.justitie.nl/images/Handreiking\%20 beoordeling\%20wilsonbekwaamheid\%20dec2006_tcm34-34470.pdf (2007, retrieved 20 May 2008).

5. Widdershoven G, Berghmans RP. Wilsbekwaamheid in de zorg voor mensen met een verstandelijke beperking (Competency issues in the care of people with intellectual disabilities). Nederlands Tijdschrift voor de Zorg aan mensen met verstandelijke beperkingen 2004;30:166-80.

6. Department of Health, Social Services \& Public Safety. Seeking consent: working with people with learning disabilities. Available at: www.dhsspsni.gov.uk/consent-guidepart4.pdf (2003,retrieved 1 July 2008).

7. Welie JV, Welie SP. Patient decision making competence: outlines of a conceptual analysis. Med Health Philos 2001;4:127-38.

8. Ministry of Justice. Mental Capacity Act 2005:Code of Practice. In Department for Constitutional Affairs (Ed., London: The Stationary Office). Availible at: http://www.opsi.gov.uk/acts/acts2005/ ukpga_20050009_en_1 (2007,retrieved 12 May 2009).

9. Ministry of Justice. Adults with an incapacity (Scotland) In Department for Constitutional Affairs (Ed., London: The Stationary Office). Availible at: http://www.opsi.gov.uk/legislation/scotland/acts2000/ asp_20000004_en_1 (2000,retrieved 12 May 2009).

10. Onwuteaka-Philipsen BD, Van Der Heide A, Koper D, Keij-Deerenberg I, Rietjens JA, Rurup ML, Vrakking AM, Georges JJ, Muller MT, Van Der Wal G, Van Der Maas PJ. Euthanasia and other end-oflife decisions in the Netherlands in 1990, 1995, and 2001. Lancet 2003;362:395-9.

11. Van der Heide A, Deliens L, Faisst K, Nilstun T, Norup M, Paci E. et al. End-of-life decision-making in six European countries: descriptive study. Lancet 2003;362:345-50.

12. Van Thiel GJ, Van Delden JJ, De Haan K, Huibers AK. Retrospective study of doctors' "end of life decisions" in caring for mentally handicapped people in institutions in the Netherlands. BMJ 1997; 315:88-91.

13. Tuffrey-Wijne M, Bernal J, Hubert J, Butler G, Hollins S. People with learning disabilities who have cancer: and ethnographic study. Br J Gen Pract 2009;59:503-9.

14. Tuffrey-Wijne I. People with intellectual disabilities and their need for cancer information. Eur J Oncol Nurs 2006;10:106-16.

15. Hollins S, Attard M, von Franhofer N, McGuigan S, Sedwick P. Mortality in people with learning disability: risk, causes, and death certification findings in London. Developmental Medicine \& Child Neurology 1998;40:50-6.

16. Brandt HE. Palliative care in Dutch nursing homes. University Medical Center VU Amsterdam, 2007.

17. Prins K, Deerenberg I, Onwuteaka-Philipsen B, Van der Heide A. Medische beslissingen rond het levenseinde nauwelijks van invloed op de levensverwachting (Medical end-of-life decisions hardly influence life expectancy). Bevolkingstrends 2007;55:17-35.

18. The AM, Pasman R, Onwuteaka-Philipsen B, Ribbe M, Van der Wal G. Withholding the artificial administration of fluids and food from elderly patients with dementia: ethnographic study. BMJ 2002;325:1326.

19. Lohiya GS, Tan-Figueroa L, Kohler H. End-of-life decisions in a developmental center: a retrospective study. West J Med 2002;176:20-2.

20. Tuffrey-Wijne I. Living with learning disabilities, dying with cancer: thirteen personal stories. Jessica Kingsley Publishers, London, 2010. 
Chapter 2

21. Wullink M, Van Schrojenstein Lantman-De Valk HM, Dinant GJ, Metsemakers JF. Prevalence of people with intellectual disability in the Netherlands. J Intellect Disabil Res 2007;51:511-9. 


\section{Chapter 3}

The factors affecting end-of-life decision making by physicians of patients with intellectual disabilities in the Netherlands: a qualitative study

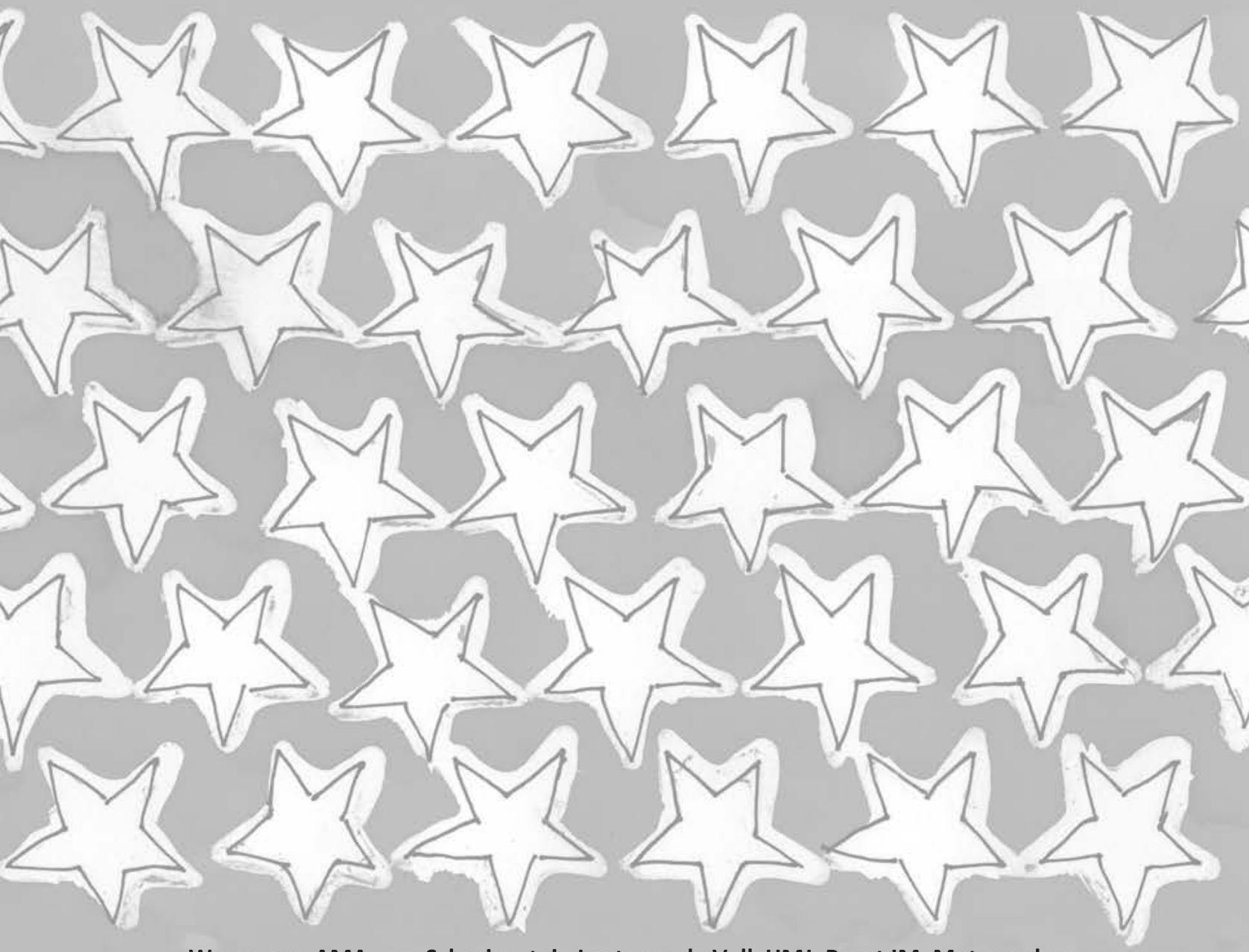

Wagemans AMA, van Schrojenstein Lantman-de Valk HMJ, Proot IM, Metsemakers

J, Tuffrey-Wijne I, Curfs LMG

J Intellect Disabil Res. 2013;57:380-389. 


\section{Abstract}

\section{Background}

The aim of this study was to investigate the process of end-of-life decision-making regarding people with intellectual disabilities (ID) in the Netherlands, from the perspective of physicians.

\section{Method}

This qualitative study involved nine semi-structured interviews with ID physicians in the Netherlands after the deaths of patients with ID that involved end-of-life decisions. The interviews were transcribed verbatim and analysed using Grounded Theory procedures.

Results

Four main contributory factors to the physicians decision making process were identified, three of which are related to the importance of relatives' wishes and opinions: (1) Involving relatives in decision making. As they had assessed their patients as lacking capacity, the physicians gave very great weight to the opinions and wishes of the relatives and tended to follow these wishes. (2) Delegating quality of life assessments to relatives. Physicians justified their end-of-life decisions based on their medical assessment, but left the assessment of the patients' quality of life to relatives, despite having their own implicit opinion about quality of life. (3) Good working relationships. Physicians sought consensus with relatives and paid care staff, often giving greater weight to the importance of good working relationships than to their own assessment of the patient's best interest. (4) Knowledge of the patient's vulnerabilities. Physicians used their intimate, long-standing knowledge of the patient's fragile health.

\section{Conclusion}

In order to take a more balanced decision, physicians should seek possibilities to involve patients with ID themselves and other stakeholders which are important for the patients. Physicians who have known the patient over time should rely more on their own knowledge of the patient's needs and preferences, seek the input of others, and openly take the lead in the decision making process. 


\section{Introduction}

In the process of end-of-life decisions for people with intellectual disabilities (ID), physicians struggle with the roles and tasks of themselves and other caregivers and representatives. End-of-life decisions are those decisions which can hasten death, whether intentionally or not. They include withdrawing or not starting medical treatment, pain treatment with possible life-shortening side-effects, and ending a patient's life with or without his or her request. These kinds of decisions are extremely important, and are known to play a substantial part of the process of dying in half of the deaths in Western countries. ${ }^{1}$ End-of-life decisions are just as relevant for people with ID as for the general population. ${ }^{2,3}$

Normally, patients should play a key role in any decision-making process that affects their lives, but people with ID are sometimes unable to do so. Assessment of someone's capacity to decide is a part of the decision-making process and is often not straightforward. In the Netherlands, it is the responsibility of the relevant health care professionals to assess this capacity where health care decisions are concerned ${ }^{4}$ and to consult with the patient's representative as stipulated in the Contract of Medical Treatment. ${ }^{5}$ A "representative" (often a close or distant relative) is a legal entity carrying the power of substituted decision making for patients who lack capacity, although the roles and responsibilities of representatives in end-of-life decision making are not clearly defined. For example, physicians can disregard the wishes of representatives about medical decisions; but they would need to have clear reasons for doing so, such as their assessment that the course of action proposed by the representative would be harmful to the patient ${ }^{5}$. England and Wales has a model where medical decisions for those who lack capacity are based on an assessment of 'best interest' rather than on substituted decision making; it gives the explicit opportunity to take into account a broad range of views. ${ }^{6,7}$

In both the Dutch and the UK models, relatives of the individual with ID have the important task of giving advice and especially of taking into account the patient's quality of life. Ultimately, however, it is the ID physician who is responsible for end-oflife decisions, not the representative. ${ }^{5}$

Knowledge about the process of decision-making regarding people with ID, and knowledge about quality of life as a contributing factor in end-of-life decisions, is very scarce. Some studies have examined end-of-life decisions in nursing homes for the general population. ${ }^{8}$ General palliative care literature shows that clear decisionmaking is an important component among the factors contributing to a good death. ${ }^{9}$

The aim of this study was to investigate how physicians make end-of-life decisions for patients with ID, and in particular, what factors affect the process of decision making. 
In this paper we use the term 'patients' (rather than 'clients' or 'people') with ID to reflect their physical life-limiting conditions; they were under the medical care of the ID physicians who use the term 'patients' for people on their caseload.

\section{Methods}

\section{Setting and sample}

In the Netherlands, ID physicians are medical physicians who have undertaken a three-year vocational training, whose caseload consists exclusively of people with ID. In the Netherlands people with ID live at home with their family, in small living facilities or on a larger campus, and are under the care of family physicians (GPs: 'General Practitioners') or ID physicians. ID physicians care mostly for people with profound, severe and moderate ID; GPs care mostly for people with mild ID.

A group of 12 ID physicians were invited to participate in a research project about end-of-life decisions. Their patients with ID were living in small facilities in the community or on a larger campus. They were part of a group that met for peer review six times a year and had known each other for a long time, in most cases more than ten years. The first author had been part of this group from the start.

In 2008 she asked the peer review group to select any of their patients who met the following inclusion criteria: (a) died in the past year (excluding sudden deaths); (b) after a process of end-of-life decisions; and (c) involving representatives who agreed to participate in the study. Six ID physicians identified eight patients who met these criteria, and these physicians all agreed to participate. They contacted the representatives involved in their patient and in the decision making process, and asked if they would agree to a face to face interview. All agreed and the ID physician, the most significant paid care staff and the representative were interviewed separately by the first author. As all but one of these representatives were the patients' relatives, the term "relative" will be used in the rest of this paper.

Because the deceased patients were initially sampled by convenience through the ID physicians and most had lived in institutional settings (seven on a larger campus and three in small living facilities), there were only two people with mild ID out of the first eight deceased patients proposed. A purposive sampling method was used to find two further patients with a mild cognitive impairment. People with mild ID often live in small homes in the community, supported by paid care staff, with medical care provided by a GP. We used a short paper in a bulletin of the Department of General Practice at Maastricht University to invite GPs to report the deaths of people with mild ID. As no GPs responded, ID physicians who were known to have had patients with mild ID were approached. This resulted in two additional cases of patients with mild ID who had deceased, and their relatives, with one doctor ultimately refusing to 
participate in an interview (ten patients, seven physicians, nine interviews with physicians).

Interviews were held between November 2008 and June 2010. This paper reports the viewpoints of the physicians on end-of-life decisions for people with ID. The findings of the interviews with the relatives and paid care staff will be reported separately.

\section{Ethical approval}

The Ethics Committee of University Hospital Maastricht and Maastricht University approved the study.

\section{Data collection and analysis}

\section{Data collection}

An interview guide was developed, as no questionnaire on the end-of-life decisions preceding the deaths of people with ID was available. The interview guide was based on concepts found in the literature, discussions with the project members and a pilot interview with an ID physician, and was reviewed by experts (a professor of health law, a professor of ethics of health care and a senior researcher in palliative care). The guide was piloted in two interviews not used for the final sample, and encompassed four topics and probing questions about the participants and their roles, the considerations which were used, the concept of quality of life and the decision-making process (for details see Appendix 3.1).

All interviews were recorded on a digital voice recorder and transcribed verbatim. The names and other personal details of the participants were removed and replaced by a code. After each interview, field notes were kept to record impressions of the interviewees and their environment and to note certain important statements, often made after the taped conversation had ended. Interview guides were adapted to reflect emerging themes, following Grounded Theory principles.

\section{Analysis}

The interviews were analysed following the procedures of Grounded Theory, a qualitative research method used to develop an inductively derived theory about a phenomenon (Strauss, 1990). ${ }^{10}$ The grounded theory approach uses a constant comparative method in the analysis process, with open, axial and selective coding. The first six interviews were open-coded, which yielded a list of key words and associated concepts. These words and associated concepts were grouped into a structure. After six interviews, data saturation was reached. The seventh to ninth interviews were axially coded, which means that the concept structure was 
broadened and concepts were defined in more detail. Selective coding was used to identify a core category, after which the other major categories were linked to this core category. The results of the selective coding process were checked by rereading all nine interviews which had been used for open and axial coding. Triangulation of data was achieved by interviewing different sets of stakeholders (physicians, relatives and paid care staff). The computer program NVivo was used to store and organise the data.

Member check took place by presenting the results of the open coding at a meeting of the peer review group of ID physicians, where no new points of view were expressed.

All interviews were coded by the first author. In addition, each interview was also analysed by one of the other members of the project group or a physician interested in end-of-life decisions (researcher triangulation). The first author wrote overall instructions for open and axial coding for the researchers involved in the analysis process.

\section{Results}

Patients were six women and four men, ranging in age from 40 to 78 years. Three patients died of cancer, two of dementia, two patients had a progressive neurological disease, two had an unspecified health decline and one patient died of a chronic pulmonary condition (see Table 3.1).

The nine interviews with physicians ultimately yielded four categories, each of which represents an important factor that contributed to their processes of end-of-life decision making for patients with ID (see Figure 3.1).

Table 3.1 Age of dying, level of intellectual disability and cause of dying.

\footnotetext{
Patient 1, $78 \mathrm{yr}$, mild ID, series of strokes causing serious cognitive decline

Patient 2, $40 \mathrm{yr}$, mild ID, cancer

Patient 3, $50 \mathrm{yr}$, severe ID, Parkinson's disease

Patient 4, $43 \mathrm{yr}$, profound ID, feeding problems, bowel obstruction

Patient 5, $57 \mathrm{yr}$, severe ID, Down's syndrome, dementia

Patient 6, $51 \mathrm{yr}$, severe ID, feeding problems, general decline, sudden death

Patient 7, 66 yr, profound ID, neurological decline with serious hypothermia

Patient 8, $47 \mathrm{yr}$, moderate ID, cancer

Patient 9, $73 \mathrm{yr}$, mild ID, COPD (chronic obstructive pulmonary disease)

Patient 10, 68 yr, mild ID, cancer
} 


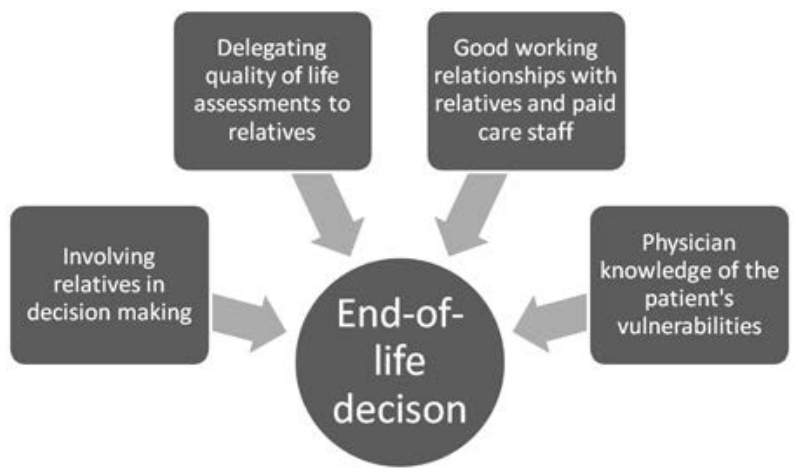

Figure 3.1 Factors affecting the end-of-life decision making by physicians for patients with intellectual disabilities.

\section{Involving relatives in decision making}

The participants involved in the process of end-of-life decisions were physicians, relatives and paid care staff, and in exceptional cases other professionals.

In all nine cases, the physicians reported that they had not consulted or involved their patients in the decision making process. In some cases there was a very clear lack of capacity, as in that of a patient with Down syndrome and dementia, or that of a patient with profound ID. Each physician who was interviewed about a patient with moderate or mild ID was convinced that their specific patients had been unable to understand the consequences of a choice and could not comprehend the process of decision-making. As one physician said:

No, she was not mentally competent. She might have a mild intellectual disability as regards verbal intelligence, and she had considerable practical skills, as she was able to play the piano, read music, and read articles in The Watchtower [a magazine], but her emotional development was at a much lower level (MD 9)

About the choice of starting palliative chemotherapy, another physician said:

No, we didn't consult $A$ about this, as we thought that $A$ did not possess the required level to understand this. This idea of "what if...". A simply wasn't up to that. (MD8) 
As they had assessed their patients as lacking capacity, the physicians gave very great weight to the opinions and wishes of the relatives and followed these wishes in all but one of the cases. In fact, they made implicit suggestions to the relatives that they (relatives) had the right to decide upon the treatment policy. Despite this, the physicians saw themselves as the person who made the necessary medical decisions and took responsibility for their decisions.

Her sister said explicitly that she appreciated the fact that she was given this information, but that I took full responsibility for the management. Well, the management basically consisted of pain control using a morphine plaster, and if she regained some consciousness, we would see if we could offer her some liquids. (MD7)

The relatives quickly became convinced that there was no remedy for her. ... So the relatives immediately clearly stated that they wanted no palliative chemotherapy, nothing that would put an additional burden to her; they didn't want to torment her (MD8).

The considerations used for the decisions were developed in a complex and often protracted process, in which participants discussed the direction of the further treatment policy, a policy that could change over time depending on changes in health issues. One doctor, discussing the relatives of a patient with a neurological disease, said:

It's a process in which everyone involved gradually moves towards a decision. The relatives' wishes carry a lot of weight. (MD3).

The one case where the physician acted against the relative's wishes involved a family asking for palliative sedation for their relative with ID. The physician felt strongly that this was not in the patient's best interest and did not comply with the family's request, although he found not following their wishes a very difficult thing to do.

Physicians preferred to discuss end-of-life decisions in a stable and calm situation, when emotions were under control and enough time could be spent on a sensible discussion. Nevertheless, the physicians also reported that they did not always avail themselves of the opportunities that came along in everyday care situations.

When you see people deteriorate over a period of six months or so, you start to look ahead, to see how far you will go, where does it end, and then you discuss this with the relatives. But if it's someone where there's no clear 
deterioration in the course of two or three years, no, I don't think it would be discussed. But I'm only guessing, of course. There are some people where you will do this. As soon as someone from the team or a relative happens to mention it, or a related topic, you tend to think, "yes, we really ought to discuss this sometime." (MD6)

The physicians did not mention the weight they gave to the contribution of paid care staff in the decision making process. It may be of interest here to report that these paid staff (who were also interviewed as part of the overall study) themselves felt that they did have an important contribution to make.

The role of the paid care staff, as seen by physicians, is to inform them about symptoms and signs they notice in the patients and to test the considerations and grounds which contribute to a decision for a particular patient.

\section{Delegating quality of life assessments to relatives}

None of the physicians introduced the concept of quality of life in their description of the decision-making process, but in all nine cases they were asked if an assessment of quality of life affected their end-of-life decision. They seemed to have an opinion about this theme but did not put it into words. Physicians were inclined to leave it to relatives to evaluate the patients' quality of life, and as has already been described, the relatives' evaluation and opinion about their loved ones' quality of life carried great weight. The physicians themselves only gave their medical considerations as explicit contributions to the decision. They were reluctant to discuss their own opinions of their patients' quality of life. When asked whether they had views on quality of life, physicians did not deny this, but added that they were not entitled to use this in treatment decisions.

However, it seemed that the physicians' own assessment of the patients' quality of life did contribute to their end-of-life decisions in an implicit way. Off the record, they certainly had their own opinion about the quality of life of patients whom they had often known for many years. The account of one physician illustrates this implicit opinion:

I find it hard to comment on that [quality of life]. Whether life ... I do think that if you see someone go from an independent, mobile woman with her own clear opinions deteriorating into a kind of vegetable over a period of seven years. Although there were good moments, that's true. But then I think, 'Let her go. Just let her go.' It's actually a hopeless situation. It's just a case of prolonging a miserable life, even though it had its valuable moments. I don't 
want to be judgmental. You often hear specialists say, 'Is this life still worth living?' or things like that. That makes me think, 'Who am I? God?' (MD1)

Another physician said:

I think that, as we had concluded in the earlier conversation, that his quality of life had rapidly deteriorated. And of course we restarted oral feeding, but it was all of course just little morsels. And he kept choking on the food. It was ... well. So that was based on the talk we had in October, when the relatives felt that his quality of life had become very low compared to the previous situation. (MD3)

\section{Good working relationships}

According to the physicians, good working relationships with relatives and paid care staff were the most important contributing factor to ensure an effective process of decision making. The "working relationship" with relatives refers to that part of a professional's relationship with relatives that facilitated the process of decisionmaking. In this process, the importance of developing a good relationship and work towards consensus seemed to be given greater weight by the physicians than the importance of arriving at a decision that was in the patient's best interest. This was a negotiation process with a degree of give and take, and sometimes physicians 'gave in' to the relatives against their own better judgement.

We agreed at that time to administer a nasogastric tube, even though I did not agree with that at all. But the relatives were particularly worried about one thing, the familiar story: 'If they become dehydrated, they get terrible thirst. That's such a torment.' However often I told them that this wasn't true, I think I just didn't get through to them. So I agreed that a nasogastric tube would be applied if there were signs of dehydration. (MD1)

Paid care staff included mostly nurses and trained support workers with a background in social care. A good relationship with paid care staff was necessary for the physicians because paid care staff could often provide them with detailed information and knew how to interpret the signals given by patients. Physicians were able to see the main health problems, but subtler changes in physical wellbeing might escape their notice, as most patients did not complain. They therefore depended on paid care staff for the interpretation of these signals and for knowledge about patient's wishes and preferences. In cases where the patient's health declined gradually, it was often the paid care staff who noticed the decline, rather than the doctor or relatives. 
Well, it was especially the signals I got from the nursing staff, who of course had got to know him pretty well by then. And they told me: 'We find it very difficult. We see no ... we never really see him happy.' It was often little things that they noticed that showed them 'he's OK for now.' But most of the time he was actually not OK. Those were the signals I got. (MD3)

\section{Knowing the patients' vulnerabilities}

The fact that the physicians often knew their patients very well, having cared for them for many years (from two up to 25 years), resulted in a patient-centered management strategy based on intimate knowledge about the lives of their patients and their families. The considerations used in end-of-life decisions were rooted in the vulnerability of the people with ID, whose lives, especially in terms of health issues, were often highly fragile. However, the physicians in this study seemed to find it difficult to give rational explanations for their medical decision making, and the considerations they used to explain the decisions seemed to be identified in retrospect. At first, physicians tended to offer rather vague reasons for their decisions.

What we did agree on was that, well, her situation was so unfortunate and that her prospects for recovery to a normal situation were so poor that we had to let her go. And of course that is what happened. (MD8).

The health situation of the patients involved in this study had been mostly stable but vulnerable; many patients had feeding disorders and epileptic seizures. In this fragile state, some of the patients had experienced a distinct health decline. End-oflife decisions were made following a health event which was considered serious and important. Death often came months or years after these health issues were discussed, probably because it is not always possible to foresee how physical conditions will progress.

We made agreements as to what had to be done in case of a recurrent stroke, or a pneumonia, what to do if she refused to eat or to drink. And those agreements did not have to be activated for the next two years. (MD1)

Considerations to come to a decision were more implicit than explicit. The following quote is from a doctor talking about a 50 year old patient who was unable to move or to speak, with a progressive neurological disease and recurrent pneumonias, who had been fitted with a gastric tube the year before. The doctor recognised the medical benefits of sending the patient for repeated hospital admissions, but was worried about how this affected the patient: 
If I think of the number of times he was hospitalised... And after each time he returned in a much worse condition. Or well, ... much worse? Of course he would have recovered from his pneumonia, or the gastric tube would work properly again. But after each hospitalisation it was just ... he had lost so much ground. He would be physically much more tired. And pressure sores, pressure sores everywhere. (MD3).

\section{Discussion}

One of the most striking findings of this study is the weight given to the opinions of relatives in physicians' end-of-life decision making processes. Three of the four main contributing factors are related to the importance of relatives' wishes and opinions. This may be in part a result of the Dutch legal system, where 'patient representatives' are substituted decision makers for patients who lack capacity. Looking at the factors influencing physicians' end-of-life decision making, several important factors were not prominent, notably including the perspectives of the patients themselves. A more balanced assessment of "best interest" (including the perspectives of a wider range of involved parties) was also lacking.

Physicians felt responsible for the end-of-life decision and sought consensus with relatives and paid care staff. However, this was not "shared decision making" in the sense described by Charles et al. ${ }^{11}$, who states that key characteristics of "shared medical decision-making" include that at least two participants are involved (physician and patient), share information, and take steps to achieve consensus about the preferred treatment. According to the physicians in our study, they shared the end-oflife decisions with relatives and paid care staff, but not with patients.

Within the concept of shared decision-making, a distinction must be made between the process of involvement and the final decisional responsibility. Practitioners can focus on the process of involving patients rather than considering who actually makes the decision ${ }^{12}$. In our study, physicians did indeed involve the relatives and did take responsibility for the final decision, but where no consensus could be reached, it was often the relatives' wishes that influenced the decision most strongly. Physicians found it very difficult to go against the families' wishes, although there was one example where this did happen.

One consequence of physicians' strong inclination to accommodate the relatives' wishes was that they were not explicit about how their own non-medical reasons influenced their decision. This included their own opinion about the patient's quality of life.

Evaluating the quality of life of another person is not easy, and substantial evidence is available for a lack of agreement between self-reports and proxy reports, 
including the self-reports of people with ID. ${ }^{13}$ Evidence has been found that proxies cannot predict the preferences of those they represent regarding end-of-life decisions. $^{14}$

Although the physicians we interviewed knew their patients intimately, the category of "Knowing the patients vulnerabilities" did not contribute accordingly to the decision-making process. In line with our findings, Dreyer et al. ${ }^{8}$ found that it appeared to be difficult for physicians to explicitly describe their practices regarding to end-of-life decisions and the values and justifications on which these practices were based. Physicians should be trained to describe more explicitly their reasons for a particular decision (including their value based judgements), and habitually discuss ethical issues to sustain the decision-making process. ${ }^{15}$ They should also document the process of decision-making explicitly. ${ }^{16}$

The authors of this paper argue that if a patient is unable to contribute in a meaningful way to the assessment of his or her quality of life, it is best to involve as many people as possible in such an assessment. This includes family, friends, paid and unpaid carers, and members of the medical team who know the patient. Although the most important role of a physician in this process is to contribute his or her medical opinion and to outline the pros and cons of proposed treatments (or withholding of treatments), it is important that a physician, like all other involved parties, is able to contribute his or her thoughts on the patient's quality of life and to let this be one part of the decision making process. If the opinion of only one set of stakeholders (in this case, the representatives/relatives) is given such heavy weight, there is a danger that this leads to a less balanced representation of the patient's own preferences.

In the Netherlands, this should include ID physicians and GPs if they have known the patients and their families over time. The Dutch situation, where many people with ID have been well known to their physicians for many years, may be unique. However, there may be similar situations in other countries, for example with regards to children and young people with profound and multiple ID and their families.

The capacity of the patients to participate in end-of-life decisions was judged to be insufficient, even if they had a mild level of ID. The non-involvement of vulnerable groups in medical end-of-life decisions is not unique to people with ID; children, for example, seem also not to be involved in medical end-of-life decisions. ${ }^{17,18}$ Other studies have found that people with mild and moderate ID are capable of giving their views on end-of-life care ${ }^{19}$, and that the end-of-life experiences and preferences of people with severe and profound ID can be obtained through careful listening and observation. ${ }^{20}$ However, this does not often happen, and health care professionals have been found to be unaware of the emotions of their patients with ID, including anxiety and fear. ${ }^{21}$ Physicians and other involved parties should therefore carefully assess patient's opinions on end-of-life decisions, even if the patient fails the test for mental capacity; often, such opinions are expressed without words. In the position statement "Caring at the End of Life" the AAIDD ( American Association on Intellectual 
and Developmental Disabilities) states that people with ID should make their own decisions, as much as possible. ${ }^{22-24}$

"Good working relationships" with relatives and paid care staff supported physicians in their decision-making tasks. If it was difficult to reach a consensus, the physicians tried to achieve consensus by taking time to discuss the issues with relatives. The et al. ${ }^{25}$ and colleagues found the same in research among nursing home physicians, who also sought consensus with relatives about end-of-life decisions. In a qualitative study in 10 nursing homes in Norway, interviews revealed that the nurses and physicians were more focused on the relationship with the relatives, sometimes at the expense of respecting the patient's wishes or best interest. ${ }^{8}$

Within the Dutch legal system the ID physicians in this study tried their very best to make a good decision for their patients. If the opinions of physicians and the relatives differ, the physicians struggle with their role and the possibilities they have for overruling the relatives in favour of their patients. This can be a lonesome position and perhaps best interests models give better opportunities to involve views and opinions of important stakeholders than the representational model.

\section{Strengths and limitations}

This is the first study about end-of-life decisions for patients with ID in which physicians were interviewed about the way they actually functioned in the decisionmaking process. The physicians cooperated freely and generously in cases which were often complex and controversial. They were open about their shortcomings and doubts and deserve respect for this attitude. The physicians in this study did not differ from the total group Dutch ID physicians so we feel that they represent the ID physicians in the Netherlands. As this study did not include GPs or medical specialists, the findings are not representative of them.

As the patients had died during a period of one year preceding the interviews, it may have been difficult for the physicians to recall the detailed considerations leading to a decision. Previous research has found that the process of end-of-life decisions is recorded only briefly in patients' files. ${ }^{16}$ If the research had been done prospectively, considerations and motives might have been formulated more in detail.

\section{Conclusion and implications for research and practice}

Three of the four main contributing factors are related to the importance of relatives' wishes and opinions. In order to take a more balanced decision, physicians should seek possibilities to involve patients with ID themselves and other stakeholders which are important for the patients. Physicians who have known the patient over time should rely more on their own knowledge of the patient's needs and preferences, 
seek the input of other carers and paid care staff as well as relatives and openly take the lead in the decision making process.

Further analysis of our work should yield information about the needs of relatives and paid care staff. Future research should focus on the needs and views of people with ID themselves, and we are obliged to think carefully about the most adequate procedures. The ultimate goal of our project is to involve all major stakeholders in developing a guideline to support end-of-life decisions for people with ID including first and foremost people with ID themselves. 


\section{Appendix 3.1}

List of topics, with interview themes, about end-of-life decisions for people with intellectual disabilities

\section{Roles}

The roles of the different participants in the decision-making process. Who made the end-of-life-decisions, who influenced this process? Was the patient with ID involved? What was the link with the patient's capacity to decide, including the level of ID? Did the paid care staff play a part in this process?

Quality of life

The quality of a patient's life and its influence on the decision-making process. Did the relatives have a clear idea about their quality of life, and on what aspects of the life of their loved one was this based? Did the physician take the quality of life into account?

\section{Considerations}

The considerations which led to an end-of-life decision. Did only medical considerations play a role, or were the patient's verbal or non-verbal expressions taken into account? Was there an immediate reason to make the end-of-life decision? Process: we asked which aspects made this process good or bad. 


\section{References}

1. Van Der Heide A, Deliens L, Faisst K, Nilstun T, Norup M, Paci E, Van Der Wal G, Van Der Maas PJ. Endof-life decision-making in six European countries: descriptive study. Lancet 2003;362:345-50.

2. Onwuteaka-Philipsen BD, Van Der Heide A, Koper D, Keij-Deerenberg I, Rietjens JA, Rurup ML, Vrakking AM, Georges JJ, Muller MT, Van Der Wal G, Van Der Maas PJ. Euthanasia and other end-oflife decisions in the Netherlands in 1990, 1995, and 2001. Lancet 2003;362:395-9.

3. Van Thiel GJ, Van Delden JJ, De Haan K, Huibers AK. Retrospective study of doctors' "end of life decisions" in caring for mentally handicapped people in institutions in The Netherlands. BMJ 1997;315:88-91.

4. WGBO. Act of 17 November 1994 amending the civil code and other legislation in connection with the incorporation of provisions concerning the contract to provide medical treatment (Medical Treatment Contract Act). Staatsblad 1994.

5. Welie SP, Dute J, Nys H, Van Wijmen FC. Patient incompetence and substitute decision-making: an analysis of the role of the health care professional in Dutch law. Health Policy 2005;73:21-40.

6. Department for Constitutional Affairs. Mental Capacity Act 2005: Code of Practice London, The Stationery Office. 2007.

7. Joyce T. Best Interests, Guidance on determining the best interests of adults who lack the capacity to make a decision (or decisions) for themselves (England and Wales). The British Psychological Society. Leicester UK 2010.

8. Dreyer A, Forde R, Nortvedt P. Life-prolonging treatment in nursing homes: how do physicians and nurses describe and justify their own practice? J Med Ethics 2010;36:396-400.

9. Steinhauser KE, Clipp EC, Mcneilly M, Christakis NA, Mcintyre LM, Tulsky JA. In search of a good death: observations of patients, families, and providers. Ann Intern Med 2000;132:825-32.

10. Strauss (Ed.) Basics of Qualitative Research, Grounded Theory Procedures and Techniques, Sage Publications 1990.

11. Charles C, Gafni A, Whelan T. Shared decision-making in the medical encounter: what does it mean? (or it takes at least two to tango). Soc Sci Med 1997;44:681-92.

12. Edwards A, Elwyn G. Inside the black box of shared decision making: distinguishing between the process of involvement and who makes the decision. Health Expect 2006;9:307-20.

13. Verdugo MA, Schalock RL, Keith KD, Stancliffe RJ. Quality of life and its measurement: important principles and guidelines. J Intellect Disabil Res 2005;49:707-17.

14. Seckler AB, Meier DE, Mulvihill M, Paris BE. Substituted judgment: how accurate are proxy predictions? Ann Intern Med 1991;115:92-8.

15. Hermsen $M$, Ten Have $H$. Decision-making in palliative care practice and the need for moral deliberation: a qualitative study. Patient Educ Couns 2005;56:268-75.

16. Wagemans A, Van Schrojenstein Lantman-De-Valk H, Tuffrey-Wijne I, Widdershoven G, Curfs L. Endof-life decisions: an important theme in the care for people with intellectual disabilities. J Intellect Disabil Res 2010;54:516-24.

17. Pousset G, Bilsen J, Cohen J, Chambaere K, Deliens L, Mortier F. Medical end-of-life decisions in children in Flanders, Belgium: a population-based postmortem survey. Arch Pediatr Adolesc Med 2010;164:547-53.

18. Vrakking AM, Van Der Heide A, Arts WF, Pieters R, Van Der Voort E, Rietjens JA, Onwuteaka-Philipsen BD, Van Der Maas PJ, Van Der Wal G. Medical end-of-life decisions for children in the Netherlands. Arch Pediatr Adolesc Med 2005;159:802-9.

19. Tuffrey-Wijne I, Bernal J, Butler G, Hollins S, Curfs L. Using Nominal Group Technique to investigate the views of people with intellectual disabilities on end-of-life care provision. J Adv Nurs 2007;58: 80-9.

20. Tuffrey-Wijne I. Living with Learning Disabilities, Dying with Cancer: Thirteen Personal Stories. Jessica Kingsley Publishers, London 2010.

21. Tuffrey-Wijne I, Bernal J, Hubert J, Butler G, Hollins S. People with learning disabilities who have cancer: an ethnographic study. Br J Gen Pract 2009;59:503-9. 
Chapter 3

22. AAIDD. Caring at the End of Life. Available at: http://www.aamr.org/content_170.cfm?navID=56 (retrieved 2 August 2011). 2005.

23. AAIDD. People Planning Ahead: Communicating Healthcare and End-of-Life Wishes, American Association on Intellectual and Developmental Disabilities, Washington, US 2009..

24. AAIDD. End-of-Life Care for Children and Adults with Intellectual and Developmental Disabilities, American Association on Intellectual and Developmental Disabilities, Washington, US 2010.

25. The AM, Pasman R, Onwuteaka-Philipsen B, Ribbe M, Van Der Wal G. Withholding the artificial administration of fluids and food from elderly patients with dementia: ethnographic study. British Medical Journal 2002;325:1326. 


\section{Chapter 4}

End-of-life decisions for people with intellectual disabilities, an interview study with patient representatives

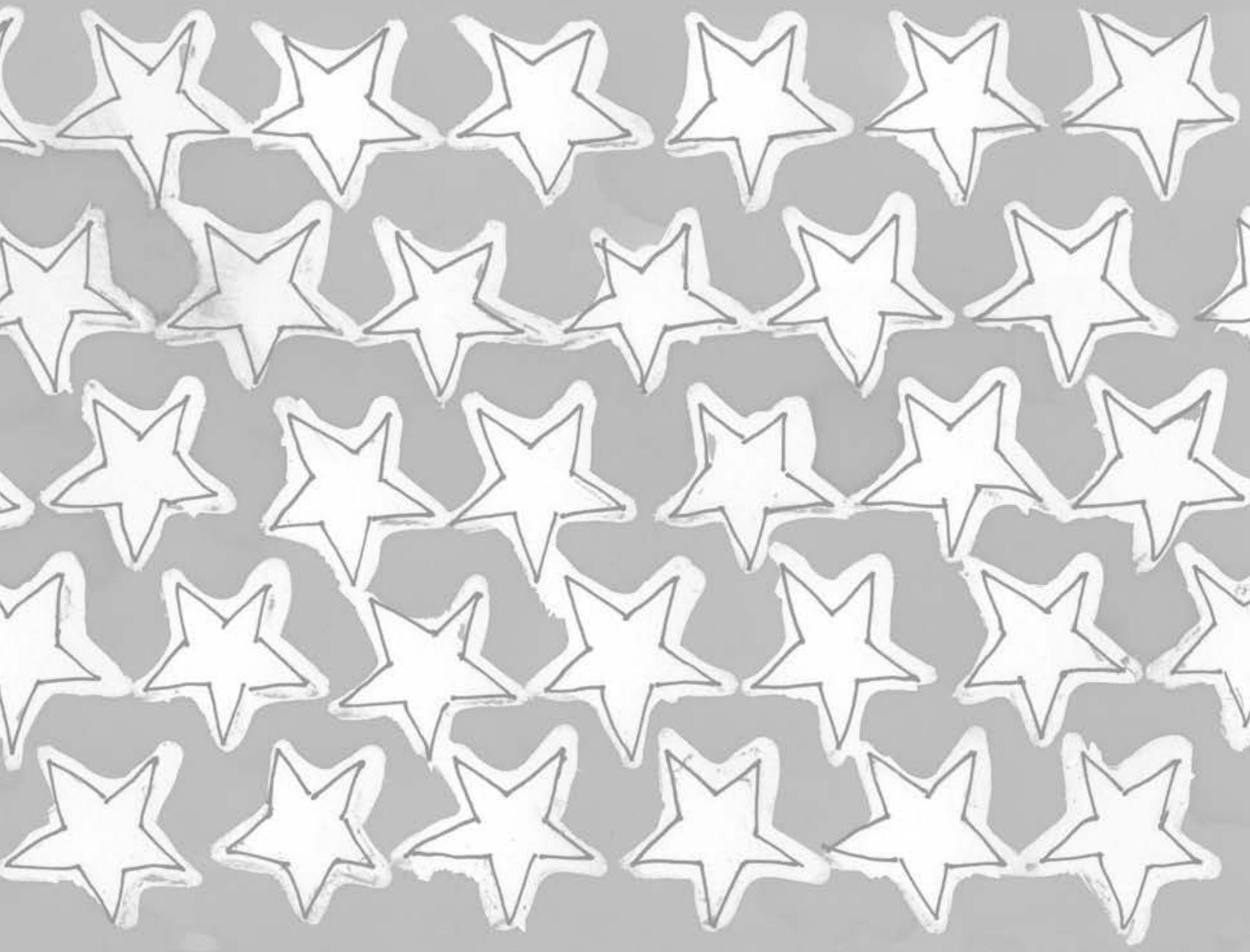

Wagemans AMA, van Schrojenstein Lantman-de Valk HMJ, Proot IM, Metsemakers J, Tuffrey-Wijne I, Curfs LMG 


\section{Abstract}

Background

Not much is known about the process of end-of-life decision making for people with intellectual disabilities.

Aim

To clarify the process of end-of-life decision making for people with intellectual disabilities, from the perspective of patient representatives.

\section{Design}

A qualitative study based on semi-structured interviews, recorded digitally and transcribed verbatim. Data were analysed using Grounded Theory procedures.

\section{Participants}

We interviewed 16 patient representatives after the deaths of ten people with intellectual disabilities in the Netherlands.

Results

The core category "Deciding for someone else" describes the context in which patient representatives took end-of-life decisions. The patient representatives felt highly responsible for the outcomes. They had not involved the patients in the end-of -life decision making process, nor any professionals other than the doctor. The categories of "Motives" and "Support" were connected to the core category of "Deciding for someone else". "Motives" refers to the patient representatives' ideas about quality of life, prevention from suffering, patients who cannot understand the burden of interventions, and emotional reasons reported by patient representatives. "Support" refers to the support that patient representatives wanted the doctors to give to them in the decision-making process.

Conclusion

From the perspective of the patient representatives, the process of end-of-life decision making can be improved by ensuring clear roles and an explicit description of the tasks and responsibilities of all participants. Regular discussion between everyone involved including people with intellectual disabilities themselves can improve knowledge about each other's motives for end-of-decisions and can clarify expectations towards each other. 


\section{Introduction}

End-of-life decisions are extremely important in the lives of most people, and are a major aspect of the process of dying in half of the deaths in Western countries, ${ }^{1}$ in the general population as well as for people with intellectual disabilities. ${ }^{2,3}$ An intellectual disability is characterised by significant limitations both in intellectual functioning and in adaptive behavior, originating before the age of $18 .^{4}$

Legal frameworks vary from the best interests model (England and France) to the representational or substituted judgement model (the Netherlands, Germany, Belgium and USA). Although the legal circumstances are clear, there are significant cultural differences between countries. ${ }^{5,6}$ In the Dutch system the doctor needs consent from the patient or the representative (often close relatives like parents, adult children, or adult siblings). The representative has to act as a good and careful representative, but cannot refuse a necessary treatment nor enforce tests or treatment. Other health care professionals like nurses or social workers have no legal role in end-of-life decisions. ${ }^{7}$ Health professionals for people with intellectual disabilities tend to allocate an important role to the patient representatives, who are obliged to involve the patient and consider carefully his quality of life. ${ }^{8}$ Ultimately, however, it is the ID physician (physician for people with intellectual disabilities) who has the medical responsibility for end-of-life decisions in the Dutch system. ${ }^{8}$

Despite this responsibility the doctor, the patient with intellectual disabilities and the patient representative have to prepare end-of-life decisions together, to share decision making and to make treatment decisions. ${ }^{9}$ Insights into the process of shared decision making are growing, ${ }^{10}$ and the importance of clinician-patient relationships with regard to supporting patient autonomy and hence shared decision making has become more fully recognised. ${ }^{11}$ The participation of patient representatives makes the treatment decisions even more complex.

The role and influence of patient representatives in the process of making end-oflife decisions for people with intellectual disabilities have not been clearly described. Who feels responsible, who takes responsibility, and do representative, patient and doctor share the decision? Does quality of life play an important role? What are important considerations in the decision making process? What makes the process a good process? The aim of the present study was to clarify the process of end-of-life decision making for people with intellectual disabilities as seen through the eyes of the patient representatives. 


\section{Methods}

\section{Setting and sample}

In the Netherlands people with intellectual disabilities live at home with their family, in small living facilities or on a larger campus, and are under the care of family physicians or ID physicians (physicians exclusively caring for people with intellectual disabilities).

The ID physicians working in different residential settings for people with intellectual disabilities were asked to select any of their patients who had died in the past year (excluding sudden deaths). The patient representatives in this study were contacted by phone by the ID physicians who had cared for the patients toward the end of their lives. None of the representatives refused to participate.

Representatives were invited for a one-hour interview about the process of endof-life decisions, to be held at a place of their own choice. Subsequently, the representative, the ID physician and the most closely involved professional care provider were interviewed separately by the first author. The involvement of a representative was an inclusion criterion, as we were interested specifically in their contribution. Written informed consent was obtained before the interviews were conducted.

Of the first eight deceased patients who were included, two had a profound intellectual disability, four had a severe and one a moderate intellectual disability (intellectual disability range 0-70 IQ points, profound, severe, moderate, mild). To include more patients with mild intellectual disabilities, we approached more ID physicians. This resulted in two additional cases of patients with mild intellectual disabilities (Table 4.1).

Between November 2008 and June 2010, ten cases were included, and semistructured interviews were held by the first author (an experienced female ID physician who worked at a residential setting not included in this study). This paper reports the views of the patient representatives about end-of-life decisions for people with intellectual disabilities.

\section{Ethical approval}

The Ethics Committee of University Hospital Maastricht and Maastricht University approved the study. 


\section{Data collection and analysis}

\section{Data collection}

An interview guide was developed, as no existing questionnaire was available. The interview guide was based on concepts found in the literature, discussions with the project members and a pilot interview, and was reviewed by experts ( a professor of health law, a professor of ethics of health care and a senior researcher in palliative care). This resulted in four topics about the respondents and their roles, the considerations which were used, the concept of quality of life and the decision-making process (for details see Appendix 4.1). Topics and probing questions were piloted in two interviews with patient representatives, who were not included in the final sample.

Interviews were conducted at home, in some cases with more family members present. The interviewees knew that the interviewer was an ID physician. Field notes were made to record impressions of the interviewees and their environment, for example the prominent place of a photograph of the deceased. In these field notes certain important statements, often made after the recorder had been stopped were noted with consent of the interviewees. All interviews were recorded on a digital voice recorder and typed out verbatim.

Table 4.1 Study population (patients and representatives).

\begin{tabular}{|c|c|c|c|c|}
\hline $\begin{array}{l}\text { Case } \\
\text { number }\end{array}$ & $\begin{array}{l}\text { Age } \\
\text { (years) }\end{array}$ & $\begin{array}{l}\text { Level } \\
\text { intellectual } \\
\text { disability }\end{array}$ & of Medical problems/cause of dying & $\begin{array}{l}\text { Family member/ Legal } \\
\text { Representative }\end{array}$ \\
\hline 1 & 78 & Mild & $\begin{array}{l}\text { Physical and mental deterioration } \\
\text { due to multiple strokes }\end{array}$ & Brother, his spouse and a sister \\
\hline 2 & 40 & Mild & Cancer & $\begin{array}{l}\text { Two volunteers: legal } \\
\text { representatives }\end{array}$ \\
\hline 3 & 50 & Severe & Parkinson's Disease & Sister \\
\hline 4 & 43 & Profound & $\begin{array}{l}\text { Feeding problems, bowel } \\
\text { obstruction }\end{array}$ & Mother and Father \\
\hline 5 & 57 & Severe & Down's syndrome, dementia & Sister \\
\hline 6 & 51 & Severe & $\begin{array}{l}\text { Feeding problems, general decline, } \\
\text { sudden death }\end{array}$ & Mother and Sister \\
\hline 7 & 66 & Profound & $\begin{array}{l}\text { Neurological decline, serious } \\
\text { hypothermia }\end{array}$ & Sister \\
\hline 8 & 47 & Moderate & Cancer & Two Sisters \\
\hline 9 & 73 & Mild & $\begin{array}{l}\text { COPD (chronic obstructive } \\
\text { pulmonary disease) }\end{array}$ & Brother \\
\hline 10 & 68 & Mild & Cancer & Nephew \\
\hline
\end{tabular}




\section{Analysis}

The interviews were analyzed following the procedures of Grounded Theory, a qualitative research method. This method is used to develop a theory about a phenomenon, ${ }^{12}$ featured by a constant comparative method with open, axial, and selective coding phases. The first six interviews were open-coded, which yielded a list of key words and associated concepts. After six interviews, data saturation in the open coding phase was reached. On the basis of the axial coding phase (seventh to tenth interviews), we defined a core category, after which the other major categories were linked to this category. The NVivo computer program was used to store and organise the data.

All interviews were coded by the first author and analysed by one of the other members of the project group (researcher triangulation) or a doctor interested in endof-life decisions (peer debriefing). The codes were discussed and if necessary rearranged and refined and new concepts were added on the basis of these discussions. Data from interviews with doctors and caregivers were used to refine the analysis of the data of patient representatives (data triangulation). ${ }^{13}$

\section{Results}

The ten interviews with patient representatives ultimately yielded three categories, each of which is discussed below. The core category was that of "Deciding for someone else", which identifies the context in which patient representatives make end-of-life decisions. The categories of "Motives" and "Support" were connected to "Deciding for someone else". "Motives" refers to prevention from suffering, patients who cannot understand the burden of interventions, emotional reasons and ideas about quality of life. "Support" refers to the support which doctors are supposed to give to patient representatives in the decision-making process.

\section{Deciding for someone else}

Deciding for someone else involves at least two participants, the person who decides and the person for whom a decision is made. The person who felt responsible for deciding was mostly a family member who was the legal patient representative (Table 4.1).

Most patient representatives had known their loved ones for a lifetime and based their decisions on an intimate knowledge of the patient. A suitable decision did justice to their loved one, fitted in with their life story and did not harm them. The patient representatives had to decide between various options, such as forgoing treatment (e.g. antibiotics or chemotherapy) or continuing certain treatments (e.g. gastric tube, 
hospital admission) and felt highly responsible for the outcomes. The discussions frequently involved do-not-attempt-resuscitation (DNAR) decisions. As the patient representatives wanted to avoid any suffering for their loved ones, they tended to decide to withhold or withdraw tests or treatment, especially if they felt these might be futile.

(Respondent 6) Sister: but I was like: if she has to go through all that too, with this minimum of life she has left. And then all this pain on top of that. I felt, well, ... that wouldn't do. So we were like: let's just let her life go the way it's going now, without interventions.

Deciding to start tube feeding was very difficult for one sister because she knew eating was one of the few small pleasures for her brother.

(R3) But that was the hardest part, I thought, I found that very hard indeed: [name of patient] was someone who was profoundly disabled, to put it in everyday terms. So he had few hobbies, in fact none. And eating was one of the things he really loved... And well, this eating was now being taken away from him [by the introduction of a gastric tube]. That's what it came down to. And that was really tough for me.

The patient representatives were not sure about the boundaries and limitations of deciding for someone else, not sure about the relevant legislation, but felt morally responsible for the decisions, just as the doctors were legally responsible. As one patient representative said:

(R7) My brother and sister felt that I was the one taking the decision, and they wondered whether I had the right to do that. I then said, well, the doctor is supporting me. The doctor left the decision to me. It would have been easier for me if things had been clearer. The doctor might have been clearer. ... I was never told that it's the doctor who is actually responsible.

According to the patient representatives even patients with moderate or mild disabilities were unable to make choices, such as whether or not to start chemotherapy or be admitted to a hospital for aggravating treatments. As a brother said:

(R9) Yes, you're right, [my sister's] is a doubtful case. She knows very well what dying means, what being ill means. But if she's really ill, the capacity for rational thinking in her situation becomes very difficult..... She would probably 
have said no, no pain. As she hated pain...She would probably have said well, if I'm going to heaven anyway, then let it be like this, that sort of thing.

A couple (where the woman was the representative) said:

(R2) M(an): That ... was really impossible. But he was good at certain things, like telling the time and that sort of thing.

W(oman): Computers, technology.

I(nterviewer): But you never discussed with him whether he wanted to be resuscitated?

W: No.

M: No.

W: Death was a topic we never raised with A. We talked about it indirectly, when others... But not with A himself.

M: I think ... you couldn't discuss that with him, resuscitation.

W: He would totally panic. He couldn't deal with that.

M: No, but then he couldn't really understand what it was.

Apart from the doctors, no other professional care providers, such as nurses, social workers, or priests, played a role in the decision-making process, although patient representatives appreciated their help and involvement in the end-of-life care.

(R2) I: Well, have you had any support apart from... I gather that one of the doctors at the institute and the doctor at the hospital gave you support, and also supported you in taking decisions. Is that right?

W: Yes.

M: Yes.

I: Did the nurses have a part to play in that?

M: No. Not really.

\section{Motives}

The main consideration in the decision-making process was "we couldn't go on like that", based on ideas about quality of life and weighed against the decline in the life of the loved ones. The quality of life was often described as very basic, enjoying food, holding someone's hand, sunshine, playing on a trampoline, foot massage, drinking advocaat liqueur. At the time of decision making, patient representatives felt that the quality of life was only just acceptable and should not be reduced any further. The following quote is from a representative of a man with mild intellectual disabilities and severe physical impairments who had bladder cancer. 
(R2) So we knew what operation A would have to undergo, and we gave permission for it. And we had also agreed with the urologist, and had it entered into the file, that if anything should go wrong during the operation, the surgeon would make the decision in such a way that $A$ would not come out of surgery even more impaired, even less than what he has and can do now. We didn't want that to happen to him .

In most of the cases, there was time to think about future health care decisions. Prevention from (further) suffering was an important motive in the decision-making process.

(R7) S(ister): Before May there were still periods when I thought she seemed content. You could tell that from the way she looked. She couldn't say anything, but she'd be sucking things or playing with those towels. But after May she'd just be lying there and I couldn't think of anything to make her happy. So I thought this will only get worse.

The patient representatives felt that their loved ones could not understand the burden of interventions, whether diagnostic or therapeutic. Two sisters expressed it this way:

(R8) S(ister)1: The next time I went with her alone, yes. And then he [the gynaecologist] came back, the gynaecologist said that there were still opportunities for treatment. So I said, what would we be treating? Yes, but he still had some expectations. And when we saw how fast it went, we were, like, what would we be doing to her? How can we explain to her that she'll have chemotherapy, that her hair will fall out.

S2: We wanted to maintain that tiny bit of quality of life she still had as best we could.

Some motives were more emotional than others, as was illustrated by a mother who hesitated about surgery for a gastric stoma because she was not allowed to accompany her daughter:

(R6) I: I hear you were reluctant about this PEG tube, and also about further examinations. Can you explain why you were so reluctant about that? What was the reason for that?

Mother: Well, these things couldn't be done here, or where I could accompany her. I would have to hand over my child, and I just knew she'd come out worse. 
One representative said about a sister (a person who never spoke) that she would not have wanted to be resuscitated.

(R5) Yes/ I thought it, ... it's what [name of patient] would not have wanted, this resuscitation. It would then be OK for a while and then she'd have to go through it all again. I didn't want that.

\section{Support}

The patient representatives appreciated the doctor's support in the process of decision making. The doctors should be closely involved in the process of decision making, be empathic and give the patient representatives time to think and deliberate. Nevertheless some representatives did not want the doctor to influence them in what they thought was important for their loved ones.

(R3) Sister: I got the feeling that she [the doctor] did have an opinion about it, but she never really expressed it. At least not as far as I can remember. And I actually liked that. As it would probably influence me. So she never said, like: 'I'd do this or that', or 'Are you sure about that?' She never said things like that.

Other patient representatives wanted the doctors to give personal advice.

(R5) Did the doctor support you?

S: Yes, she did, actually. If I proposed something, she might say that she [the doctor] might do the same, you know, about the decision I made. And I did feel that was ... since you have to make the decision all on your own... My sister would say: 'you should do what you think is best, you only want what's best for her'. And if I discussed it with my sister, she might say: 'Yes, that's what I would do too'. But it's good to hear that from a doctor. That she [the doctor] takes the same view.

The doctor should know the family and the different roles in the family, and positively value the role of the patient representatives.

(R3) Sister: I think she was very thoughtful in the way she dealt with the family. With the family's wishes, but also with the family as a family. She knew exactly that someone was the mother or a brother, and she kept that very much in mind. 
Some patient representatives had not visited their loved ones very often, which gave them a less prominent position in the decision-making process. As a brother said about his contribution to the process:

(R9) B(rother): Well, I really have to say they did an excellent job.

I: And you feel you've been given the position that you were entitled to in this kind of process?

B: Yes, I think it would have been a bit arrogant of me to suddenly play the older brother who's calling the shots.

Reassurance was an important part of the support.

(R5) Then I'd call one of them, and they'd immediately take it up. They'd immediately report it to doctor B. And she'd come round - well not immediately, that wouldn't be possible of course - but she'd come round at least the next day. To see what the situation was like. If there was anything, doctor $B$ would always phone me at home. I really appreciated that.

The support failed when there was a conflict of opinion between a doctor and a patient representative, as it emerged that the doctor was in the position to make the decision,.

(R8) I: And how did you feel about that? What was your impression of the doctor at that moment?

S2: Reluctant.

S1: Yes, distant.

S2: And also, like, I'm the one to decide and this is how we're going to do it.

S1: I'll do this, and I'm the one to decide. And he really made it very clear that there was this difference.

The patient representatives were not aware that it was possible to discuss decisions other than the DNAR with the doctor. This left them feeling un-supported.

(R6) I: ... we sometimes call that a minimal intervention policy. My question is whether you ever considered trying to come to an agreement with the doctor about that.

Sister: I think we said that but I wouldn't know... I think that if that's the usual procedure I'd almost say that the signal should have come from the doctor or the nurse, ... Well ... now I'm hearing this, that you could write down more about that ... I wouldn't have known about that myself. 


\section{Comments made after the interview had ended}

After the recording had been stopped and the session ended with a brief review of what had been said in the interview, one patient representative started to cry when she understood that the doctor had been responsible for the end-of-life decisions. Deciding for her sister had been a burden to her, notwithstanding the fact that she was convinced that the decisions had been correct. Another respondent said afterwards that she would have preferred to talk about more than a DNAR agreement and regretted the fact that nobody had informed her about the end-of-life issues that she could have discussed with the doctor. She felt it was important to discuss nontreatment decisions and pain relief, and to draw up written advance directives in order to ensure implementation in the future.

\section{Discussion}

The patient representatives in this study felt highly responsible for the end-of-life decisions and were passionately involved in the process because they were not able to consult with the patient. Patient representatives had ideas about quality of life, prevention from suffering, and patients who cannot understand the burden of interventions. They sometimes had emotional reasons for their decision. They wanted the doctor to support them in the decision making process.

The results of the present study are limited by the fact that it only included those deceased patients whom the patient representatives had known intimately throughout their lives. The study followed a qualitative design and explored the endof-life decision process around ten patients in detail. Member checks have not been conducted because we felt a second exposure would be burdensome for the participants who often expressed strong emotions during the interviews. Nonetheless, the study has offered important insights into issues that are relevant to patient representatives in making decisions for their loved ones.

The burden of responsibility when making decisions for their loved ones was heavy for the patient representatives, who were unaware that doctors are ultimately responsible for end-of-life decisions after careful consideration with patient representatives. In a systematic review on the effect on patient representatives of making treatment decisions for others (elderly and ICU patients), negative emotional burden was reported. ${ }^{14}$ In Norwegian nursing homes the position of representatives regarding to end-of-life decisions was unclear and complex. ${ }^{15}$ The process of decision making for incapacitated adults with intellectual disabilities has not been studied.

The patient representatives in our study doubted very much whether their loved ones had the competence to decide about their own health, which implies the capacity to judge health-related interests and to make a suitable decision. ${ }^{16,17}$ The 
American Association on Intellectual and Developmental Disabilities states that careful observation and interaction over time will clarify what a person with intellectual disabilities considers important. Although our data did not include life story work, its use would seem to be a tool that could be used in future. Life stories can help those patients who lack capacity to provide information about their own beliefs in health and treatment. ${ }^{18,19}$ Strategies for assisted and shared decisionmaking, life planning, and more careful communication could improve decision making. $^{20-22}$

Decline and deterioration of health and well-being were an important consideration for the patient representatives to make an end-of-life decision for their loved ones. The concept of quality of life is not only related to the life story of the person who is represented, but also to the life story of a family -family being one of the domains of quality of life. ${ }^{23}$

The doctor's support was important for the representative and this outcome corresponds with the ideas currently being developed in the world of informed shared decision making, about the importance of relationships between clinicians and patients. ${ }^{11,24}$ Professional views and advice were helpful for patient representatives in end-of-life decisions for people with dementia. ${ }^{25}$ Competent patients and families wanted relationships with health care providers that affirm a more encompassing view on death and dying. ${ }^{26}$ The influence of relationships and the strategies for shared decision making have not been studied for people with intellectual disabilities.

From the perspective of the patient representatives, the process of end-of-life decisions could be improved by defining clear roles and responsibilities of all participants involved. If possible people with intellectual disabilities themselves should be involved in the decision making process. Knowledge of their needs and preferences, quality of life and life stories could improve the decisions. Regular discussion between everyone involved will improve the understanding of each other's role in the process. Further research is needed to study the process of decision making for people with intellectual disabilities. An important goal could be to develop and implement effective written information and decision aids for patient representatives and people with intellectual disabilities. 


\section{Appendix 4.1}

\section{List of interview topics about end-of-life decisions for people with intellectual disabilities}

\section{Roles}

The roles of the different participants in the decision-making process. Who did take the end-of-life-decisions, who influenced this process? Was the person with intellectual disabilities involved? What was the link with the patient's capacity to decide, including their level of intellectual disability? Did a professional care provider play a part in this process?

\section{Quality of life}

The quality of a patient's life and its influence on the decision-making process. Did the patient's representative have a clear idea about the quality of life of their loved one, and on what aspects of their life was this based? Did the patient representative take the quality of life into account?

\section{Considerations}

The considerations which led to an end-of-life decision. Did only medical considerations play a role, or were the patient's verbal or non-verbal expressions taken into account? Was there an immediate reason to make the end-of-life decision? Process: which aspects made this process good or bad in the eyes of the different participants? 


\section{References}

1. Van der Heide A, Deliens L, Faisst K, Nilstun T, Norup M, Paci E, Van der Wal G, Van der Maas PJ; EURELD consortium. End-of-life decision-making in six European countries: descriptive study. Lancet 2003;362:345-50.

2. Onwuteaka-Philipsen BD, Van der Heide A, Koper D, Keij-Deerenberg I, Rietjens JA, Rurup ML, Vrakking AM, Georges JJ, Muller MT, van der Wal G, van der Maas PJ. Euthanasia and other end-oflife decisions in the Netherlands in 1990, 1995, and 2001. Lancet 2003;362:395-9.

3. Van Thiel GJ, Van Delden JJ, De Haan K, Huibers AK. Retrospective study of doctors' "end of life decisions" in caring for mentally handicapped people in institutions in The Netherlands. BMJ 1997; 315:88-91.

4. Schalock. Intellectual Disability: Definition, Classification, and Systems of Supports (Eleventh Edition). Washington American Association on Intellectual and Developmental Disabilities, 2011.

5. Joyce T, Best Interests, Guidance on determining the best interests of adults who lack the capacity to make a decision (or decisions) for themselves (England and Wales), in The British Psychological Society. Leicester UK, 2010

6. Buiting HM, Clayton JM, Butow PN, Van Delden JJ, Van der Heide A. Artificial nutrition and hydration for patients with advanced dementia: perspectives from medical practitioners in the Netherlands and Australia. Palliat Med 2011;25:83-91.

7. WGBO, Act of 17 November 1994 amending the civil code and other legislation in connection with the incorporation of provisions concerning the contract to provide medical treatment (Medical Treatment Contract Act). Staatsblad 837, 1994

8. Welie SP, Dute J, Nys H, Van Wijmen FC. Patient incompetence and substitute decision-making: an analysis of the role of the health care professional in Dutch law. Health Policy 2005;73:21-40.

9. Charles C, Gafni A and Whelan T. Shared decision-making in the medical encounter: what does it mean? (or it takes at least two to tango). Soc Sci Med. 1997;44:681-92.

10. Edwards A and Elwyn G. Inside the black box of shared decision making: distinguishing between the process of involvement and who makes the decision. Health Expect. 2006;9:307-20.

11. Entwistle VA, Carter SM, Cribb A, et al. Supporting patient autonomy: the importance of clinicianpatient relationships. J Gen Intern Med 2010;25:741-5.

12. Corbin J and Strauss A. Basics of Qualitative Research: Techniques and Procedures for Developing Grounded Theory. Los Angeles/London: Sage Publications. 379, 3th ed. 2008,

13. Tong A, Sainsbury P and Craig J. Consolidated criteria for reporting qualitative research (COREQ): a 32item checklist for interviews and focus groups. Int J Qual Health Care 2007;19:349-57.

14. Wendler D and Rid A. Systematic review: the effect on surrogates of making treatment decisions for others. Ann Int Med 2011;154:336-46.

15. Dreyer A, Forde R and Nortvedt P. Life-prolonging treatment in nursing homes: how do physicians and nurses describe and justify their own practice? J Med Ethics 2010;36:396-400.

16. Welie JV and Welie SP. Patient decision making competence: outlines of a conceptual analysis. Med Health Care Philos 2001;4:127-38.

17. Welie SP. Criteria for patient decision making (in)competence: a review of and commentary on some empirical approaches. Med Health Care Philos 2001;4:139-51.

18. AAIDD. Caring at the end of life. http://www.aaidd.org/content_170.cfm?navID=31 (2005 accessed April 5th 2011)

19. Meininger HP. Narrating, writing, reading: life story work as an aid to (self) advocacy. British Journal of Learning Disabilities 2006;34:181-8.

20. Kingsbury LA. People Planning Ahead. Washington: AAIDD, 2009,

21. Stein GL and Kerwin J. Disability perspectives on health care planning and decision-making. J Palliat Med 2010;13:1059-64.

22. Tuffrey-Wijne I. A new model for breaking bad news to people with intellectual disabilities. Palliat Med. 2013;27:5-12. 
Chapter 4

23. Verdugo MA, Schalock RL, Keith KD, Stancliffe RJ. Quality of life and its measurement: important principles and guidelines. J Intellect Disabil Res. 2005;49:707-17.

24. Entwistle VA, Prior M, Skea ZC, Francis J. Involvement in decision-making: a qualitative investigation of its meaning for people with diabetes. Soc Sci Med. 2008;66:362-75.

25. Livingston G, Leavey G, Manela M, Livingston D, Rait G, Sampson E, Bavishi S, Shahriyarmolki K, Cooper C. Making decisions for people with dementia who lack capacity: qualitative study of family carers in UK. BMJ 2010;341:c4184..

26. Steinhauser KE, Christakis NA, Clipp EC, McNeilly M, McIntyre L, Tulsky JA. Factors considered important at the end of life by patients, family, physicians, and other care providers. JAMA 2000;284: 2476-82. 


\section{Chapter 5}

End-of-life decisions for people with intellectual disabilities, from the perspective of paid care staff

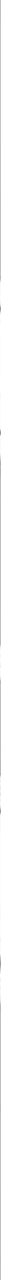

Wagemans AMA, van Schrojenstein Lantman-de Valk HMJ, Proot IM, Metsemakers J, Tuffrey-Wijne I, Curfs LMG 


\section{Abstract}

Background

Not much is known about the involvement of paid care staff in the process of making end-of-life decisions for people with intellectual disabilities (IDs).

Design

A qualitative interview study.

Settings

Small residential facilities for people with IDs in the community or on a larger campus in the Netherlands.

Participants

Nine members of the paid care staff, all but one ID nurses.

Aim

The aim of this study was to clarify the decision-making process in medical end-of-life decisions regarding people with IDs, from the perspective of paid care staff.

Method

This qualitative study involved nine semi-structured interviews with paid care staff held after the deaths of patients with IDs in the Netherlands. The interviews were transcribed verbatim and analysed using Grounded Theory procedures.

Results

The core characteristic of the position of the paid care staff and of the way they supported the patient was "Being at the centre of communication". Related categories of topics emerging from the interviews were "Having a complete picture of the patient", "Balancing involvement and distance", "Confidence in one's own opinion" and "Knowledge about one's own responsibility", all of which were focused on the patient. This focus on the patient with IDs might explain why the paid care staff could contribute to such an important subject as end-of-life decisions. People with IDs themselves were not involved in the decisions. The paid care staff were not always aware who was ultimately responsible for the end-of-life decisions.

Conclusion

Paid care staff is in a unique position to support the process of end-of-life decision making. It is important to use their knowledge and give them a stronger position in this decision-making process. It should be clear to all involved who is ultimately responsible for making the end-of-life decision. 


\title{
Introduction
}

End-of-life care for people with intellectual disabilities (IDs) (Box 5.1) is a part of general health care, but also has some special features. Communication is the most striking characteristic, including on the one hand the communication with people with IDs themselves and on the other hand the communication within their network of relatives and paid care staff. Communicating with people with IDs in a palliative care setting is not always easy. ${ }^{1,2}$

Box 5.1 Definition of intellectual disabilities and definition of end-of-life decisions.

\begin{abstract}
"Intellectual disability is a disability characterized by significant limitations both in intellectual functioning and in adaptive behaviour, which covers many everyday social and practical skills and is sometimes expressed in IQ points (from profound to mild, range 0-70 IQ points). This disability originates before the age of $18^{\prime \prime} .^{3}$

"End-of-life decisions are those decisions which can lead to or hasten death, whether intentionally or not. They include withdrawing or not starting medical treatment, pain treatment with possible lifeshortening side-effects, and ending a patient's life with or without his or her request. These kinds of decisions are extremely important in the lives of most people, and are known to play a substantial part in the process of dying in half of the deaths in Western countries" ${ }^{4}$
\end{abstract}

Normally, patients should play a key role in any decision-making process that affects their lives, but people with IDs are sometimes unable to do so. Assessment of someone's capacity to decide is a part of the decision-making process and is often not straightforward. In the Netherlands, it is the responsibility of the relevant health care professionals to assess this capacity where health care decisions are concerned ${ }^{5}$ and to consult with the patient's representative, as stipulated in the Contract of Medical Treatment Act. ${ }^{6}$ England and Wales have a model where medical decisions for those who lack the necessary mental capacity are based on an assessment of "best interest", rather than on substituted decision making; it offers the explicit opportunity to take into account a broad range of views. ${ }^{7,8}$ In the Dutch legal system, paid care staff, like trained ID nurses, have no formal part in the decision process, even though they have often cared for the patients for a very long time. Ideally, the relatives, the paid care staff and the physician will work together in the daily end-of-life care for people with IDs, listen to each other and try to come to a sensible policy for the palliative care trajectory.

The paid care staff's contribution to end-of-life care for people with IDs is usually important and intensive. ${ }^{9,10}$ They have often been involved in the lives of these people for many years, caring for them on a daily basis. In these years they have learnt a great deal about their needs and preferences and often know them more intimately than some (often distant) relatives. As a consequence, they would seem to be well 
equipped to support the people with IDs, as well as the doctors and relatives, when difficult end-of-life decisions (Box 5.1) are required. This position may be unique compared to that of nurses in hospitals and nursing homes, who care for patients over a shorter period. The balance between involvement and emotional distance can be difficult for paid care staff in ID care.

A study among Irish paid care staff for people with IDs found that they thought end-of-life care was an important part of their work, and they sometimes experienced being pushed aside by relatives who re-establish contact at the end-of-life and make decisions for their loved ones without listening to staff. ${ }^{11}$ Although staff found making decisions about end-of-life care issues difficult and stressful, they also felt that they had in-depth knowledge of the people with IDs and as a consequence could contribute to the process. A study among nurses involved in palliative terminal care found that nurses working in psychiatric care had a greater desire to be involved in end-of-life decisions than those working in other health care sectors. ${ }^{12}$

Nurses at an intensive care unit in England saw their role in end-of-life decision making as supporting the family, being an advocate for the patient and helping the medical staff to establish the right moment to withdraw treatment. ${ }^{13}$ In another study nursing roles were described as presenting the "big picture" of the patient's deterioration and acting as the nodal point for exchange of information. ${ }^{14}$

Not being involved in end-of-life decisions can cause feelings of anger, frustration and powerlessness among paid care staff. ${ }^{15}$ Belgian nurses felt that they could make important contributions to end-of-life decisions. ${ }^{16}$ In a systematic review of the literature about end-of-life decision making in acute care, three nursing roles emerged, the first being that of information broker, the second that of supporter and the third that of advocacy (for patients and relatives). ${ }^{17}$

In geriatric care, the opinion of nurses turned out to be important, as nurses were consulted about Do Not Attempt Resuscitation (DNAR) in up to $72 \%$ of cases. ${ }^{18}$ Finnish nurses also offered their opinion on the appropriateness of a DNAR order for a particular patient. $^{19}$

Although it may be clear from these examples that nurses want to be involved in end-of-life decisions, many aspects of the role and influence of paid care staff in the process of making end-of-life decisions for people with IDs have not been studied before. Who feels responsible, who takes responsibility, and do the patient's representative, the patient and the doctor share the decision? This study set out to explore these themes as seen through the eyes of the paid care staff. 


\section{Methods}

\section{Setting and sample}

In the Netherlands, people with IDs may live at home with their family, or may live in small residential facilities or on larger campuses. They get medical care from family physicians (general practitioners or GPs) or ID physicians (physicians whose caseload consists exclusively of people with IDs).

The present study was part of a research project about end-of-life decisions, in which a group of 12 ID physicians were invited to participate. Their patients with IDs were living in small residential facilities in the community or on a larger campus. The ID physicians were part of a group that met for peer review six times a year and had known each other for a long time, in most cases more than ten years. The first author had been part of this group from the start.

In 2008 she asked the peer review group to select any of their patients who met the following inclusion criteria: (a) died in the past year (excluding sudden deaths); (b) after a process of end-of-life decisions; and (c) involving relatives who agreed to participate in the study. Six ID physicians identified eight patients who met these criteria, and these physicians all agreed to participate. The ID physicians contacted the relatives and the most significant paid care staff and asked if they would agree to a face-to-face interview.

Since the deceased patients were initially sampled by convenience through the ID physicians and most had lived in institutional settings (on a larger campus or in small residential facilities), the first eight deceased patients proposed by the physicians included only two people with mild ID. A purposive sampling method was used to find two further patients with mild cognitive impairment. This resulted in two additional cases of patients with mild ID who had deceased, bringing the total sample to ten patients.

All but one (a social worker) of the ten paid care staff were ID nurses. Such nurses have completed a three-year vocational training course in ID care, including health care.

As one nurse left her job, nine interviews were held between November 2008 and June 2010. This paper reports the viewpoints of the paid care staff on end-of-life decisions for people with IDs.

\section{Ethical approval}

The Ethics Committee of University Hospital Maastricht and Maastricht University approved the study. 


\section{Data collection and analysis}

\section{Data collection}

Since no questionnaire on the end-of-life decisions preceding the deaths of people with IDs was available, we developed an interview guide, based on concepts found in the literature, discussions with the project members and a pilot interview with an ID physician. The guide was reviewed by experts (a professor of health law, a professor of ethics of health care and a senior researcher in palliative care). The guide was piloted in two interviews, which were not used for the final sample, and encompassed four topics and probing questions about the participants and their roles, the considerations they had used, the concept of quality of life and the decision-making process (for details see Appendix 5.1).

All interviews were recorded on a digital voice recorder and transcribed verbatim. The names and other personal details of the participants were removed and replaced by a code. After each interview, field notes were made to record impressions of the interviewees and their environment and to record certain important statements, often made after the taped conversation had ended. The interview guide was adapted to reflect emerging themes, following Grounded Theory principles.

\section{Analysis}

The interviews were analysed following the procedures of Grounded Theory, a qualitative research method used to develop an inductively derived theory about a phenomenon. ${ }^{20}$ The Grounded Theory approach uses a constant comparative method in the analysis process, with open, axial and selective coding. Open coding is a process of exploring the text and selecting words and concepts which are connected with the questions and themes of the study. ${ }^{20}$ The first five interviews were open-coded, and yielded a list of key words and associated concepts. These words and associated concepts were grouped into a structure. After five interviews, data saturation was reached in the open coding phase.

The sixth to ninth interviews were axially coded, which means that the concept structure was broadened and concepts were defined in more detail. Selective coding was done by rereading all nine interviews with the aim of identifying the core category, after which the other major categories were linked to this core category. Triangulation of data (using other sources to broaden the view and to prevent a restrictive perspective) was achieved by interviewing different sets of stakeholders (physicians, relatives and paid care staff). The Nvivo computer program was used to store and organise the data. ${ }^{21}$

All interviews were analysed by the first author. In addition, each interview was also analysed by one of the other members of the project team or a physician interested in end-of-life decisions (researcher triangulation). The first author wrote 
overall instructions for open, axial and selective coding for the researchers involved in the analysis process.

\section{Results}

The nine interviews with paid care staff ultimately yielded five categories of topics, each of which is discussed below. The core category we identified was "Being at the centre of communication", which describes the core business of paid care staff in the process end-of-life decisions. This core category was supported by "Having a complete picture of a patient", "Balancing involvement and distance", "Confidence in one's own opinion" and "Knowledge about one's own responsibility".

\section{Being at the centre of communication}

The paid care staff felt that they were at the centre of communication around the patient at the end of life. They cared for the patient, saw and interpreted complaints and symptoms, and subsequently informed the doctor and the relatives.

(Paid Care Staff [PCS]1) Well, we usually sit around the table (in the patient's apartment): the doctor will be there, I will be there, the relatives are there. And the doctor explains the medical situation. And we usually, if the relatives want us to, add information from the nursing group: how do we perceive the patient through the day? Is she in pain for instance? What aspects of behaviour do we notice? Does she eat and drink well? You see, the doctor wouldn't know as much about that as we do. And so together we fill in ... you get the complete picture.

The paid care staff seemed to be used to this position and were involved in endof-life care. They gave the relatives enough space to make the end-of-life decisions and in the meantime used their position and knowledge to influence both the doctor and the relatives.

(PCS 3) Well yes, we had a good working relationship with the doctor in this period, where we were able to say anything we wanted: what we thought, our feelings about it. And the doctor definitely listened to what we said. Yes, absolutely.

The working relationship with the doctor was taken for granted, but the relationship with relatives needed more care and took time and effort. The paid care 
staff tried to cooperate with relatives in an open relationship and intended to support them, and also felt supported by relatives.

(PCS 5) As staff we knew that her sister would miss her very much, as she was very closely involved with her. You hardly ever see that, that someone is so intensely involved with a relative with Down syndrome. ... And we very much respected her for it, being so intensely involved with her sister. And she respected us for doing our best to care for [name of patient] when she wasn't around.

\section{Having a complete picture of the patient}

The paid care staff tried to present a realistic overall picture of the patient's health situation to their relatives. In many cases, this was based on having known the patient for years, allowing the staff to detect their gradual deterioration.

It was this deterioration which caused them to contact relatives and doctors in order to get together for the purpose of end-of-life planning. In some cases, the paid care staff had known the patient for more than a decade and they had clear ideas about the patient's needs and wishes, beyond the health situation, including quality of life.

(PCS 7) She'd been deteriorating for a number of years. So yes, you get to a stage where, well, if you, err, I wouldn't say measure the quality of life, but when you see that her quality of life is much lower than it used to be. ... Then yes I think it's our duty to do something about it. As they can't do anything themselves.

The paid care staff believed that they sometimes knew more about the health situation of the person they cared for than the relatives, as they saw the patient more often than the relatives and consequently could gauge the situation on a more solid daily basis.

(PCS 3) Well, yes, you could put it like that. But of course it's a matter of providing information. The relatives would come and visit for an afternoon once every so many weeks. And then they see [name of patient] at that particular moment, and they develop their own idea of the situation. The nursing staff see [name of patient] every day. And the doctor, especially when they're ill, also sees them every week, or even several times a week. And then it's easier to realistically evaluate their situation than as a relative who only comes round every few weeks. 
The paid care staff felt that the patients themselves were not fully capable of making their own end-of-life decisions, like the decision to forgo treatment. Consequently, they felt obliged to stand up for their patients and give their own opinion. At this point, tensions, or even a sense of competition, could enter into the relationship with relatives, if they had different views on the patient's needs and wishes. For instance, two sisters of a patient with ID wanted and asked for palliative sedation for their sister, who had cancer, while the paid care staff and the doctor thought this was not indicated at that moment.

(PCS 8) But on the other hand we figured well if these sisters insist on this decision, they will go through with it, and then that's the decision that will be made. Then we'll have to be prepared to accept it. And that meant, that's a sort of acceptation. A sort of feeling that this is the decision made by these two sisters. And that means that as an organisation, you're more or less ignored.

\section{Balancing involvement and distance}

Involvement with the lives of the people with IDs for whom they cared was a matter of course for the paid care staff.

(PCS 7) Well yes, it won't be very long before this person is no longer there. And what does that mean to me, as someone who basically cares for them 24 hours a day? Well, I do notice that it causes certain feelings to emerge among the staff. You notice that when you talk about it with colleagues.

The combination of being involved with the life of a patient and not becoming emotional about it was difficult, and paid care staff felt that keeping too much distance would not contribute to good care.

(PCS 4) And that's why you feel heavily involved with these people. ... And this involvement, you sometimes get reproached for that; that you're too much involved, or too closely tied to them. Because you're supposed to adopt a socalled professional attitude, but if I have to adopt an attitude of remaining at a distance, then I can't do my job.

\section{Confidence in one's own opinion}

The paid care staff developed a complete picture of a patient, and had clear ideas about what was important in their client's life, based on their daily care. Paid care 
staff were confident regarding their knowledge about the client's wants and needs and even about their quality of life.

(PSC 9) My impression was always that she actually really enjoyed life, but was also very much bothered by her impairment, both physically and mentally. She had a good quality of life until the very end. Yes, I think I can really say that.

End-of-life care was a normal and important part of their work, and as a result the paid care staff had an opinion about what constituted good care at the end of life, including the nature of end-of-life decisions.

(PSC 7) Well, yes, you do have a kind of controlling role there. ... You just discuss it with the doctor at that stage. And you gradually come to a conclusion, which the doctor thinks is justified and that we as paid care staff can agree with. And on the basis of that you discuss it with the relatives.

\section{Knowledge about one's own responsibility}

Paid care staff knew that they could not take, and did not even need to take responsibility for end-of-life decisions, and this position meant that they could freely discuss ideas about a patient's quality of life, knowing that they were not responsible for the decision. Although they knew that they were not responsible, however, they did feel obliged to stand up for their patients.

(PSC 4) And that's different from a home for the elderly, where there are also people dying every day. As it's really essential that these people can't do anything for themselves. You are their senses, their eyes, you're everything for them. One moment of inattention can have disastrous consequences.

Paid care staff had specific ideas about the needs and preferences of their patients, and tried to influence the end-of-life trajectory. They felt that it was the responsibility of the relatives to decide, not that of the physician.

(PSC 7) As nurses, we don't have the authority to decide. We can make suggestions for what we ... would wish to be done for this person. But in the end it's always the relatives or a legal representative who decides. But you do discuss it with them on a regular basis. And in that respect it's very important that the doctors and the nursing staff are in agreement, as I think it would be very frustrating for the nursing staff if a policy is adopted that not all of the staff can agree with. Since we're the ones who have to carry it out. 
The do-not-attempt-resuscitation decisions were considerably more important for the paid care staff than other end-of-life decisions, probably because they expected to be directly involved in situations in which resuscitation was needed. Their influence was so important that in one case the paid care staff convinced the relatives to reconsider and change the do-not-resuscitate order. As one of them expressed it:

(PSC 6) I clearly indicated this to them. I said: "Well, I have serious doubts about this." And the relatives understood that: "Yes, we can imagine." But you also have to think of the relatives. What are you doing when you do resuscitate? You might actually make things worse. That's why it's such a difficult choice. What decision are you going to make?

\section{Discussion}

This study found that paid care staff in ID care were at the centre of communication, and were able to shape end-of-life care and influence end-of-life decisions. As they often had known and cared for the people with IDs for more than a decade, they had clear ideas about the patient's needs and preferences and showed confidence in their own opinion. Above all, they felt responsible for a good end-of-life process.

From our study a picture emerged of a group of professionals who are involved in end-of-life care, are confident about their role in such care and are convinced of their knowledge about the lives, needs and preferences of the people they care for. In an informal way, they give direction to the end-of-life care, including end-of-life decisions, while knowing that they are not responsible for the decision. Many of them are convinced that relatives are responsible (even though this is formally the responsibility of the physicians). In countries where health care is organised in a different way, paid care staff are less confident about their own capacity to support clients with IDs in end-of-life care. ${ }^{10,22}$ A possible explanation could be that paid care staff in Dutch residential care are specially trained for ID care and sometimes have had supplementary training courses on end-of-life care.

The paid care staff in our study felt that the people with IDs they cared for were themselves unable to contribute to the end-of-life decisions, even though some of them had only mild IDs. As they knew the persons with ID very well, their opinion seems important and should be taken seriously. Nevertheless it seems important to involve people with IDs themselves in end-of-life decisions. ${ }^{1,2}$ Paid care staff in our study had a clear overall picture of their patients and were often the one to detect deterioration, which then led to discussions with relatives and physicians. The ID physicians also indicated deterioration as the reason to talk with relatives about endof-life care. $^{23}$ 
Studies in other health care settings have shown that important goals for nurses are those of supporting the relatives and helping the medical staff make decisions. ${ }^{13,16}$ The paid care staff in our study did not always seem to know that it is the physicians and not the relatives who are ultimately responsible for end-of-life decisions. Paid care staff and physicians have different roles in end-of-life decisions: the physicians have to make the decisions, the paid care staff have to accept them. ${ }^{24}$ As the paid care staff expected that they would be the ones who had to implement the decisions, it was especially the DNAR decisions which seemed important to them. The relatives of one patient in our study changed their preference for a DNAR to one of resuscitation because the most closely involved nurse felt that she could not implement a DNAR decision.

The position of the paid care staff in this trajectory is not one of formal responsibility, making them vulnerable in case of problems of communication. It might be better if the paid care staff had a stronger position in the trajectory of endof-life decisions, as one of the important stakeholders, enabling them to provide their own input for the decisions. Dutch paid care staff are often in a unique position to contribute to end-of-life decisions for persons who are not fully capable of deciding for themselves, as they know the patients and their relatives over a long period. In our study, paid care staff mostly felt supported by relatives, but in one case a conflict arose when relatives decided without consulting the staff and the ID physician. In an ideal world, relatives and paid care staff respect each other, knowing that both are needed and irreplaceable, but in practice there can be tension between these parties. ${ }^{25}$

Our study was limited by the fact that we interviewed paid care staff in Dutch ID care, but not nurses in other settings. Nurses in hospitals and nursing homes care for their patients for much shorter periods, and do not know as much about the needs and preferences of their patients. In addition, we only examined those processes of end-of-life decision making in which relatives were involved. Paid care staff will have a different, and probably stronger position in situations not involving relatives.

In conclusion, we advocate a suitable and clear position for paid care staff in guidelines for end-of-life decisions. These guidelines should be based on the literature and supported by opinions of patients, relatives, paid care staff and physicians. The results of our study underline the importance of the position of the paid care staff in supporting patients and relatives. 


\section{Appendix 5.1}

\section{List of interview topics about end-of-life decisions for people with intellectual disabilities}

\section{Roles}

The roles of the different participants in the decision-making process. Who made the end-of-life-decisions, who influenced this process? Was the patient with ID involved? What was the influence of the patient's capacity to decide, including the level of ID? Did a professional care provider play a part in this process?

\section{Quality of life}

The quality of a patient's life and its influence on the decision-making process. Did the patient's representative have a clear idea about their quality of life, and on what aspects of the life of their loved one was this based? Did the patient representative take the quality of life into account?

\section{Arguments}

The arguments which led to an end-of-life decision. Did only medical arguments play a role, or were the patient's verbal or non-verbal expressions taken into account? Was there an immediate reason to make the end-of-life decision?

\section{Process}

Which aspects made this process good or bad in the eyes of the different participants? 


\section{References}

1. Tuffrey-Wijne I, McEnhill, L. Communication difficulties and intellectual disability in end-of-life care. Int J Palliat Nurs. 2008;14:189-94.

2. Tuffrey-Wijne I. A new model for breaking bad news to people with intellectual disabilities. Palliat Med. 2013;27:5-12.

3. Schalock. Intellectual Disability: Definition, Classification, and Systems of Supports (Eleventh Edition), American Association on Intellectual and Developmental Disabilities, Washington 2011.

4. Van der Heide A, Deliens L, Faisst K, Nilstun T, Norup M, Paci E, Van der Wal G, Van der Maas PJ. Endof-life decision-making in six European countries: descriptive study. Lancet 2003;362:345-50.

5. WGBO. Act of 17 November 1994 amending the civil code and other legislation in connection with the incorporation of provisions concerning the contract to provide medical treatment (Medical Treatment Contract Act). Staatsblad 837, 1994.

6. Welie SP, Dute J, Nys H, Van Wijmen FC. Patient incompetence and substitute decision-making: an analysis of the role of the health care professional in Dutch law. Health Policy 2005;73:21-40.

7. Department for Constitutional Affairs. Mental Capacity Act 2005: Code of Practice. London, The Stationery Office, 2007.

8. Joyce T. Best Interests, Guidance on determining the best interests of adults who lack the capacity to make a decision (or decisions) for themselves (England and Wales). In: The British Psychological Society. Leicester UK, 2010.

9. De Veer AJE, Francke A, Speet M, Poortvliet EP. Verpleegkundige zorg rondom het overlijden van mensen met een verstandelijke beperking [Nursing care at the end of life for people with intellectual disabilities]. NTZ 2004;2:110-122.

10. Wiese M, Stancliffe RJ, Balandin S, Howarth G, Dew A. End-of-life care and dying: issues raised by staff supporting older people with intellectual disability in community living services. J Appl Res Intellect Disabil 2012;25:571-83.

11. Ryan KGS. Dodd P, McEvoy J. End-of-Life Care for People with Intellectual Disabilities: Paid Carer Perspectives. J Appl Res Intellect Disabil., 2011;24:199-207.

12. De Veer AJ, Francke AL, Poortvliet EP. Nurses' involvement in end-of-life decisions. Cancer Nurs 2008;31:222-8.

13. McMillen RE. End of life decisions: nurses perceptions, feelings and experiences. Intensive Crit Care Nurs 2008;24:251-9.

14. Liaschenko J, O'Conner-Von S, Peden-McAlpine C. The "big picture": communicating with families about end-of-life care in intensive care unit. Dimens Crit Care Nurs 2009;28:224-31.

15. Yang $\mathrm{MH}$, Mcllfatrick S. Intensive care nurses' experiences of caring for dying patients: a phenomenological study. Int J Palliat Nurs 2001;7;435-41.

16. Inghelbrecht E, Bilsen J, Mortier F, Deliens L. Nurses' attitudes towards end-of-life decisions in medical practice: a nationwide study in Flanders, Belgium. Palliat Med. 2009;23:649-58.

17. Adams JA, Bailey DE Jr, Anderson RA, Docherty SL. Nursing Roles and Strategies in End-of-Life Decision Making in Acute Care: A Systematic Review of the Literature. Nurs Res Pract. 2011;2011:527834.

18. De Gendt C, Bilsen J, Van Den Noortgate N, Lambert M, Stichele RV, Deliens L. Prevalence of patients with do-not-resuscitate status on acute geriatric wards in Flanders, Belgium. J Gerontol A Biol Sci Med Sci. 2007;62:395-9.

19. Hilden HM, Louhiala P, Honkasalo ML, Palo J. Finnish nurses' views on end-of-life discussions and a comparison with physicians' views. Nurs Ethics. 2004;11:165-78.

20. Corbin J, Strauss A. Basics of Qualitative Research: Techniques and Procedures for Developing Grounded Theory.Sage Publications, Los Angeles/London, 2008.

21. Bazeley P. Qualitative data analysis with Nvivo. Sage Publications, London, 2007.

22. Tuffrey-Wijne I. Living with Learning Disabilities, Dying with Cancer. Jessica Kingsley Publishers, London UK, 2010. 
23. Wagemans A, Van Schrojenstein Lantman-de Valk H, Proot I, Metsemakers J, Tuffrey-Wijne I, Curfs L. The factors affecting end-of-life decision-making by physicians of patients with intellectual disabilities in the Netherlands: a qualitative study. J Intellect Disabil Res. 2013;57:380-9

24. Oberle K, Hughes D. Doctors' and nurses' perceptions of ethical problems in end-of-life decisions. J Adv Nurs 2001;33:707-15.

25. Tuffrey-Wijne I, Bernal J, Hubert J, Butler G, Hollins S. Exploring the lived experiences of people with learning disabilities who are dying of cancer. Nurs Times 2010;106:15-8. 



\section{Chapter 6}

Do-not-attempt-resuscitation orders for people with intellectual disabilities: dilemmas for physicians

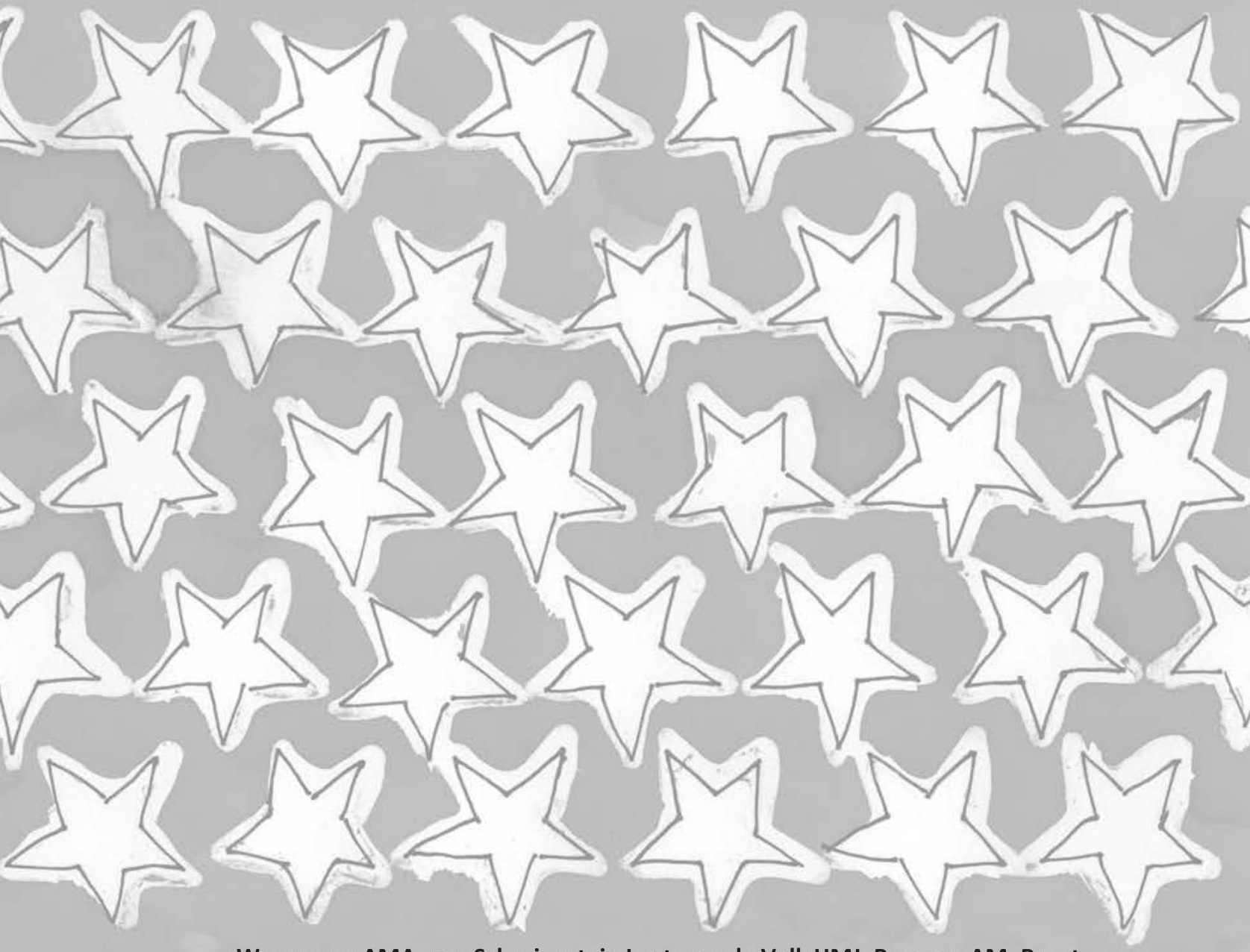

Wagemans AMA, van Schrojenstein Lantman-de Valk HMJ, Bressers AM, Proot IM, Metsemakers J, Tuffrey-Wijne I, Curfs LMG Submitted 


\section{Abstract}

Background

Not much is known about the process of Do-Not-Attempt-Resuscitation (DNAR) decision making for people with intellectual disabilities (IDs).

Aim

To clarify the problems and pitfalls of DNAR decision making for people with IDs, from the perspective of physicians.

Design

A qualitative study based on semi-structured interviews, recorded digitally and transcribed verbatim. Data were analysed using Grounded Theory procedures.

Participants

40 physicians were interviewed about problems and pitfalls of DNAR decision making for people with IDs in the Netherlands.

Results

The core category identified was "Considerations when issuing DNAR orders", while "Medical considerations" was the main contributory factor for the ID physicians. The evaluation of quality of life and suffering due to challenging behaviour was left to the representatives and was sometimes a cause of conflicts between physicians and representatives. At this point, physicians felt vulnerable and wanted a firmer and clearer legal position. The category of "Accepting the consequences of the role of decision maker" was as important as "The decision procedure in an organisational context". The procedure of issuing a DNAR decision and the embedding of this procedure in the health care organisation were important for the physicians.

Conclusion

A guideline is needed, as well as training for physicians to deal with uncertainties regarding DNAR decision making. Health care organisations should implement a procedure on DNAR decision making. An instrument needs to be developed to evaluate the quality of life of people with IDs who cannot express themselves. 


\section{Introduction}

ID physicians (i.e. physicians who take care of the medical needs of people with intellectual disabilities) are often asked by representatives (mostly relatives) to issue Do-Not-Attempt-Resuscitation (DNAR) orders for people with intellectual disabilities (IDs) long before the terminal phase. DNAR orders are part of a broader range of endof-life decisions and fit into the concept of advance care planning, ${ }^{1}$ which is important for people who need support. End-of-life decisions including DNAR are relevant to significant numbers of people with $\mathrm{IDs}^{2}$ as well as to the general Dutch population, as they are involved in 40 to $58 \%$ of all deaths between 1990 and 2010 . $^{3}$ Parents and other next-of-kin have questions about treatment decisions for those people with IDs who depend on others for daily care and who suffer from multiple conditions like epilepsy, osteoporosis and dysphagia. It should be clear to representatives that the ultimate DNAR decision is made by a doctor and that they do not need to carry the burden of such a decision. ${ }^{4}$ The position of Dutch physicians is described in the Contract of Medical Treatment Act (WGBO). ${ }^{5}$ In most European countries, physicians are responsible for DNAR orders for people who are incapacitated to decide for themselves. ${ }^{6,7}$

Physicians can follow different paths in their decision making, such as informing representatives and asking for permission, or only informing them or giving them the decisive voice, ${ }^{8}$ depending on the content of the decision. There is not always a dialogue between physicians and relatives about decisions for incompetent patients, and relatives were bypassed by physicians in $5-37 \%$ of DNAR orders. ${ }^{9}$ Although survival rate has a prominent place in discussions, DNAR decisions are made on the basis of problems at a given moment, rather than on the basis of expected survival. ${ }^{10}$ In everyday life, resuscitation attempts are unsuccessful in $70-98 \%$ of cases and effects after successful intervention are not clear. ${ }^{4}$ Whether resuscitation is futile or not is difficult to establish, as the concept of futility is very subjective. ${ }^{11}$ Since the survival probability is uncertain, there is little opportunity for physicians to be certain about a DNAR decision and little room for decision making without consulting patient or representatives. ${ }^{12}$ Health care organisations need to be sure whether they should organise resuscitation courses for paid care staff and provide Automated External Defibrillator (AED) units. ${ }^{13}$ Last but not least, the paid care staff needs to know what to do if they find someone who may need to be resuscitated.

This study set out to clarify the process of DNAR decisions for people with IDs from the point of view of ID physicians in the Netherlands. As these physicians are very experienced regarding medical care for people with IDs, this study focused on their views. What are the considerations to make a DNAR decision? Does quality of life play a role? Who influences the decision? What are the problems and pitfalls for the physician? The ultimate goal of this project is to develop a guideline for DNAR decisions for people with IDs. 


\section{Methods}

\section{Setting and sample}

The ID-physicians were invited either for an individual interview or for a focus group interview on the problems with DNAR decisions for people with IDs. Participants were recruited through a request at the annual meeting of the NVAVG (Dutch Association for ID Physicians) followed by an email. Seventeen ID physicians responded. Since trainee ID physicians were poorly represented, another focus group was recruited from the Dutch vocational training programme for ID physicians. To fit in with the schedules at the university, three trainee ID physician groups were formed. At the end of the data-gathering process, an expert meeting was held. Thus, four individual interviews, five focus group interviews and one expert meeting were held, with a total of 40 physicians.

\section{Data collection}

Since no existing questionnaire was available, an interview guide was developed, based on concepts found in the literature, discussions with the project members and a pilot interview. The guide was reviewed by experts (a professor of health law, a professor of ethics of health care and a senior researcher in palliative care). This resulted in four topics, namely the considerations used, the decision-making process, the participants and their roles, and the pitfalls (for details see Appendix 6.1). ${ }^{14}$ The topic list was piloted in two interviews with a senior ID physician and a trainee physician, who were not included in the final sample. Semi-structured interviews were conducted in the work settings or at the university from December 2009 till June 2012, individual or in focus groups. ${ }^{15}$

After the individual interviews, focus group interviews were held because we wanted to know how professionals discuss the whys and hows of DNAR with each other. All individual and focus group interviews were recorded on a digital voice recorder and transcribed verbatim. The individual interviews were conducted by one of the authors, while the focus group interviews had an independent moderator assisted by one or two of the co-authors.

\section{Analysis}

All interviews were analyzed following the procedures of Grounded Theory, a qualitative research method. ${ }^{16}$ This method is used to develop a theory about a social phenomenon, based on data from daily life (experiences), characterised by a constant comparative method with open, axial and selective coding phases. The qualitative analysis involves examining and interpreting data to elicit meaning, gain understanding, and develop empirical knowledge. ${ }^{16}$ The four individual interviews 
were open-coded, yielding a list of key words and associated concepts. The analysis of the first focus group interview ended in data saturation in the open coding phase. At this point it became clear that challenging behaviour was sometimes a contributing factor for DNAR, so we decided to hold a second focus group session with experienced physicians to put more emphasis on this aspect and to ensure that all important considerations and problems emerged. Of the three focus group interviews with trainee ID physicians, only one was used for axial coding because no new information emerged during focus groups four and five.

The third focus group was used to continue axial coding. The axial coding was used to define a core category, and to explore the relationships between the core category and the other major categories. Selective coding took place by rereading all the focus group interviews, and confirmed the major categories selected in the axial coding phase and their relationships.

In May 2012, the results of the analyses were presented at an expert meeting with a broad range of the Dutch ID physicians (board of NVAVG, continuous education group, ethical committee, vocational training programmes). The experts were asked if they recognised the outcomes and whether important themes had been omitted. The expert meeting was used to assess the categories and define them more clearly. No new categories emerged.

All interviews were analyzed by the first author and one of the other members of the project group, or a doctor interested in end-of-life decisions (researcher triangulation). The codes were discussed by the two researchers involved in the analysis of a particular interview. If necessary, codes were rearranged and refined and new concepts were added on the basis of these discussions. The NVivo computer program was used to store and organise the data. ${ }^{17}$

\section{Results}

The core category was found to be "Considerations when issuing a DNAR order" and was linked to two other categories "Accepting the consequences of the role as decision maker" and "The decision procedure in an organisational context".

\section{Considerations when issuing DNAR orders}

The most important considerations for physicians when issuing a DNAR order were longstanding chronic medical conditions. Considerations like congenital physical defects, epilepsy, diminished life expectancy, advance age and severe decline in health status were often mentioned. 
"My experience especially with clients with profound and multiple intellectual disabilities is that you often start such a discussion when they're poorly. It doesn't mean they're terminally ill, but it's more that he has pneumonia or he's ill, and the expectation is often that it will recur. Then it's good to discuss this and see what's to be done in this kind of situation. And that often includes whether to resuscitate or not, that's part of it." (Focus Group M)

Physicians felt that concepts like futility of resuscitation were very confusing and not practical to use.

"In any case, we said that if she starts to experience real impairments, starts to lose functions, that's when the DNAR policy will be effectuated. As it is, the relatives feel she has a comfortable life, so if anything were to happen, they'd prefer .. [resuscitation]. And as a doctor you then have to estimate whether that would constitute a meaningful medical intervention." (HJ)

Although they were unsure about the evidence, the ID physicians estimated the success rate of resuscitation to be very low, in the general population as well as for people with multiple disabilities. The whole process of resuscitation and recovery was seen as very burdensome and not suitable for those people who could not go through the whole trajectory into Intensive Care and further treatments. In addition, they expected a diminished quality of life afterwards. As one ID physician said about a successful resuscitation:

"The effect was that she ended up at a lower level. So you could ask yourself if it had had an effect. Well, it had an effect: she was still alive, but at a lower level." (Focus Group N)

Profound or severe intellectual disability was considered to contribute to a DNAR decision, because of brain damage after resuscitation coming on top of existing brain problems. Physicians also felt that people with profound and severe IDs were more vulnerable and that quality of life is lower for them.

"Of course he had a very low intellectual level, I'd say severely to profoundly disabled. So that means, and I discussed this with his parents of course, that the chances of successful resuscitation are naturally much lower." (Focus Group N)

Quality of life was difficult for ID physicians to use as a reason for issuing DNAR orders, and ID physicians tended to leave the judgment to the representatives. 
"To what extent are they suffering? That's often very difficult to say, especially if someone can't communicate." (HJ)

The quality of life of some relatives was reduced by the need to support the person with IDs. Physicians struggled with this knowledge but felt that it should not be used as an argument in decisions:

"However, I think there's a sliding scale of quality of life of the clients, but also that of relatives, who may be so burdened by having a child with ID that they feel like, if something should happen and he should die of it..." (Focus Group N)

The physicians reported several important considerations being mentioned by the representatives, such as "he has suffered enough" and "let my child die before I die". According to the physicians, declining health status was an important reason for representatives to ask for DNAR. Sometimes, very challenging behaviour was a reason for parents to ask for a DNAR order. Physicians hesitated about challenging behaviour as an argument for DNAR, but some physicians could understand the parents' wish and would issue such an order.

"If the boy hadn't exhibited this highly problematic autistic behaviour, I probably wouldn't have agreed (to issue a DNAR order)." (Focus Group N)

Suffering as a result of challenging behaviour in a situation without prospects of improvement and without quality of life contributed to the issuing of DNAR orders, although this argument was often complicated by the burden this situation put on the parents.

"So, erm, anyway, on one occasion I did agree to it. Not so much based on, let's put it clearly, medical indication, but on a very different, well ... lack of prospects in this whole complex of behavioural problems. And well, the parents themselves also mentioned this to some extent. And that's always a dilemma I think. Anyway, in the end I, I also thought that was a .... We then decided together that this [i.e. not to resuscitate] might be a good option." (Focus Group N)

\section{Accepting the consequences of the decision maker role}

The situation of the physician vis-à-vis the impact of the ideas and opinions of the representatives was unclear. Could a representative decide whether or not a DNAR order would be issued, especially if no urgent medical reasons existed? People with 
IDs who lacked the capacity to make their own end-of-life decisions were not involved in the DNAR order.

“There are extreme cases where someone who's admitted here, that there's a written statement from a lawyer, sometimes even a notary public, with stamps and signatures of erm..., saying the client must not be resuscitated. So I then always explain that that has no legal validity..." (WK)

The ID physicians wanted to prevent conflicts with representatives, especially regarding quality of life. An ID physician who wanted to make a DNAR decision said:

"If the parents might feel we have a very good rapport with our child. And we still see her smile, don't we? Someone with a very low intellectual level, and if I should then present them with a DNAR order, that would create a problem with the parents. As that person still functions within their social environment." (Focus Group M)

And the opposite situation:

"An excellent representative. But then she also wanted us to ... erm, although this person was in reasonable health ... to refrain from resuscitation. Though there was no medical reason." $(\mathrm{HJ})$

Some physicians asked the relatives to sign the DNAR order, to confirm that they had seen or approved it. Other physicians did not ask this, because they felt it was the doctor's professional decision and they did not want to burden the representative with this.

"Sometimes, at the start of the consultation, relatives say: now I'm the one who has to decide. So that's a reason for me to explain again ... that it's not their decision, but that we just want their opinion as one of the arguments to consider. And I've never heard about anyone finding it difficult to sign it. ... And personally, I also think well at least then it's clear that they were present at the consultation and ... okay, I think we're not officially obliged to." (KB)

Specialists in hospitals were less strict about issuing a DNAR order, because they had other ideas about quality of life. As one ID physician expressed it:

"At the hospital they look downwards from the top of the scale, while we look upwards from the bottom end. What can they do? While they look at what 
someone can't do. So they start talking about non-resuscitation at a far earlier stage." (Focus Group N)

Representatives were important as partners in the DNAR process because they know the patient well. As one doctor said:

"Yes, he had this deformed thorax. Well, if that boy had very severe intellectual disabilities, and, and, erm ... well, what would be reasons for me not to do it? No, I think the view, the relatives' view would carry great weight." (KB)

The views of paid care staff were also important, but they mostly had the same opinions as the doctors.

\section{The decision procedure in an organisational context}

The DNAR orders were a part of a more comprehensive set of end-of-life decisions, even if the end of life was not necessarily imminent.

"It's usually not purely about resuscitating or not. It's always about a much wider set of decisions of various kinds, and resuscitation is only one area." (Focus Goup M)

The physicians felt that it was not easy to find the right moment to discuss a DNAR order with representatives. At the same time, hospitals and paramedics in ambulances ask for clarity and want written instructions. Suitable occasions for talking about DNAR were reported to be the time when the person with IDs moves into a residential setting, or at a care plan meeting, or when a severe decline occurs in the client's health status. The physicians perceived an increasing tendency for representatives to ask for a DNAR order earlier in the life of their loved ones, even though no life-threatening medical problems existed. The physicians thought it was important to start discussing DNAR in good time.

"What I've noticed in recent years is that some families want to get these decisions on paper at an early stage. At a time when you think, well, this client is still in good health. But in many cases, something has happened in the family which meant that they had to make such a decision about their father, mother, grandfather or grandmother." (Focus Group M)

Most physicians thought choking was an accident, and should be treated as a nonnatural death, implying that the person should be resuscitated even if a DNAR order 
had been issued. In some health care organisations this was formally recorded in writing as an exception in the DNAR guideline.

"Resuscitation is assumed to apply only in a situation of natural death. Anything beyond that, for instance someone threatening to die as a consequence of choking on something, you'll have to try your very best to revive them or keep them alive." (WK)

The status of the order was not clear, because while the attending physician might have issued an order in advance, at the moment when the order should be effectuated, bystanders might start resuscitation and another doctor in charge would make the ultimate decision to continue or terminate the resuscitation. The respondents therefore felt that the ultimate outcome of the decision process could be different from that planned in advance.

"In any case, the order always states that the doctor treating the client at that moment... that they can make their own decision. And though that doctor can fall back on the carefully considered DNAR order, they also have the authority to deviate from it." (WK)

The physicians reported that, on the one hand, DNAR is a medical end-of-life decision, but on the other hand, at the moment the decision should be put into effect, it is often the paid care staff who have to decide whether or not to start resuscitation.

"Doctors may say it's a medical decision, but we're not present at the crucial moment and someone else has to make the decision." (Expert Meeting)

\section{Discussion}

This study generated three major categories of considerations: patient-related considerations as interpreted by the physicians; the way physicians fulfil their role as decision makers; and the organisational context in which ID physicians issue a DNAR order. All three categories were characterised by uncertainty. Firstly, with regard to patient-related considerations, the most commonly used arguments were the medical ones, although aspects like futility of resuscitation, success rate and challenging behaviour were difficult contributing factors. Quality of life was an important argument in decisions, but also difficult to predict. ID physicians tended to leave evaluating the quality of life to the representatives. In this respect, however, the procedure was prone to conflicts, and physicians were unsure of their role. Secondly, 
regarding their role in the process, ID physicians would prefer a clearer legal position vis-a-vis the representatives. Thirdly, organisational aspects like the status of a DNAR order, who signs the order and what is the right moment to discuss such an order remain to be resolved. The moment when bystanders have to decide whether to start resuscitation or not was regarded as the most vulnerable part of the decision-making process, and the ultimate test for the procedure.

In this study we interviewed ID physicians and not medical specialists or general practitioners. Given the fact that the ID physicians are the most trained and experienced physicians for a considerable proportion of the people with IDs, this study has provided important insights into DNAR decision making. However, it would be important to also survey the views, experiences and practices of physicians not specialised in ID, as they are often the ones responsible for DNAR decisions in both primary and secondary healthcare settings. Many countries outside the Netherlands do not have specially trained ID physicians. The extent to which perceived quality of life influences their decision has been an issue of concern in the UK, where cases haven been highlighted of inappropriate DNAR orders for people with IDs. ${ }^{18}$

The ID physicians in our study felt unsure about evaluating medical conditions against unknown and non-evidence-based chances of survival. Respondents had their own ideas about quality of life, like the view that people with profound and severe IDs have a lower quality of life, but they were not sure whether they could express and use this in the decision-making process. Clients showing challenging behaviour, as reported by representatives, was the most doubtful and problematic argument when it came to quality of life. There are no instruments to measure quality of life for those who cannot speak for themselves. ${ }^{19}$

The Dutch ID physicians felt insecure about their position vis-à-vis the patient and representatives as described in the Contract of Medical Treatment Act (WGBO). ${ }^{5}$ In the current legal situation, it might be important for physicians to accept the consequences of the role of decision maker and to make the decision, together with the patient (if capacitated) or representative (if the patient is incapacitated). ${ }^{20}$

As regards health care organisations, each organisation should describe, train and implement the DNAR procedure, while delineating professional responsibilities. The most vulnerable part of the whole process seems to be the moment the DNAR order is to be effectuated. Is the order immediately available and clear to bystanders and paramedics? The person standing by at a moment of collapse is often a member of the paid care staff. They have to decide immediately whether or not resuscitation is to be started, and they need optimal support and clarity from the organisation they work for. Currently some hospitals are introducing red DNAR bracelets and studying the outcomes of their use. ${ }^{21}$ Some health care organisations have indicated death by choking as an exception in their DNAR policy, because choking is seen as a non-natural death. It is becoming increasingly clear that choking is inextricably linked to dysphagia problems in many people with IDs ${ }^{22}$. To the extent that choking problems are part of 
the specific epidemiology of this group, it seems unreasonable to treat choking as an exception in a protocol for DNAR orders.

We can conclude that an instrument to evaluate the quality of life in those people with IDs who cannot express themselves needs to be developed and implemented in DNAR policy. Furthermore, for various reasons, physicians feel unsure about DNAR decisions for people with IDs. Important uncertainties relate to patient-related considerations (including quality of life), the position of the physician vis-à-vis the representatives and uncertainties about policies in their organisation. Physicians should express these uncertainties and, within their professional organisation, develop a guideline based on these uncertainties and on the literature. While this guideline is being implemented, physicians should be systematically trained in deciding in situations of uncertainty and accept their role in the deciding process, rather than postpone decisions. Research is needed to study the use of the DNAR guideline and the training of physicians. The procedures within an organisation should be subject of further research in which they are described, implemented and evaluated.

People with IDs who live their fragile lives with various conditions are unknown and unseen, although most physicians probably have such a patient among their patient population. It is important for patients and their next-of-kin to give proper attention to the difficult health decisions to be made. 


\section{Appendix 6.1}

\section{List of interview topics about DNAR decisions for people with intellectual disabilities}

\section{Considerations}

The considerations which lead to a DNAR decision. Do only medical considerations play a role, or are there other considerations, like quality of life? What was the immediate argument to make the DNAR decision?

Process

What aspects make this a good or a bad process?

\section{Participants}

Who makes the DNAR decision, who influences this process? Is the person with intellectual disabilities involved? Does paid care staff play a part in this process?

Pitfalls

What are the pitfalls and problems for the physician who has to make a DNAR decision? 


\section{References}

1. Kingsbury LA. People Planning Ahead. Washington: AAIDD, 2009.

2. Wagemans A, Van Schrojenstein Lantman-de-Valk H, Tuffrey-Wijne I, et al. End-of-life decisions: an important theme in the care for people with intellectual disabilities. J Intellect Disabil Res 2010;54: 516-24.

3. Onwuteaka-Philipsen BD, Brinkman-Stoppelenburg A, Penning C, de Jong-Krul GJ, Van Delden JJ, Van der Heide A. Trends in end-of-life practices before and after the enactment of the euthanasia law in the Netherlands from 1990 to 2010: a repeated cross-sectional survey. Lancet 2012;380:908-15.

4. Lippert FK, Raffay V, Georgiou M, Steen PA, Bossaert L. European Resuscitation Council Guidelines for Resuscitation 2010 Section 10. The ethics of resuscitation and end-of-life decisions. Resuscitation 2012;81:1445-51.

5. WGBO, Act of 17 November 1994 amending the civil code and other legislation in connection with the incorporation of provisions concerning the contract to provide medical treatment (Medical Treatment Contract Act).Staatsblad 837, 1994.

6. Welie SP, Dute J, Nys H, Van Wijmen FC. Patient incompetence and substitute decision-making: an analysis of the role of the health care professional in Dutch law. Health Policy 2005;73:21-40.

7. Joyce $T$, Best Interests, Guidance on determining the best interests of adults who lack the capacity to make a decision (or decisions) for themselves (England and Wales), in The British Psychological Society. Leicester UK, 2010.

8. De Vos MA, Van der Heide A, Maurice-Stam H, Brouwer OF, Plötz FB, Schouten-Van Meeteren AY, Willems DL, Heymans HS, Bos AP. The process of end-of-life decision-making in pediatrics: a national survey in the Netherlands. Pediatrics 2011; 127:e1004-12.

9. Van Delden JJ, Löfmark R, Deliens L, Bosshard G, Norup M, Cecioni R, Van der Heide A; EURELD Consortium. Do-not-resuscitate decisions in six European countries. Crit Care Med. 2006;34:1686-90.

10. De Vos R, Koster RW and De Haan RJ. Impact of survival probability, life expectancy, quality of life and patient preferences on do-not-attempt-resuscitation orders in a hospital. Resuscitation Committee. Resuscitation. 1998;39:15-21.

11. Stewart CL. A defence of the requirement to seek consent to withhold and withdraw futile treatments. Med 2012;196:406-8.

12. De Vos R. To be resuscitated or not: the concepts in decision making. J Cardiovasc Nurs. 2001;16:21-7.

13. Van Dartel, ed. Guideline for (Do-Not-) Resuscitate in the Care for People with Disabillities. VGN: Utrecht, 2006.

14. Lindlof TR and Taylor BC. Qualitative Communication Research Methods (second ed).Thousand Ouaks, Canada: Sage Publications, 2002.

15. Kitzinger J. Qualitative research. Introducing focus groups BMJ 1995;311:299-302.

16. Corbin J and Strauss A. Basics of Qualitative Research: Techniques and Procedures for Developing Grounded Theory. 3th ed. Los Angeles/London: Sage Publications. 2008,.

17. Bazeley P, ed. Qualitative data analysis with Nvivo. Sage Publications: London, 2007.

18. Meikle J, Family of Down's patient sue hospital over DNR order, in The Guardian. 13 September 2012.

19. Townsend-White C, Pham AN and Vassos MV. Review: a systematic review of quality of life measures for people with intellectual disabilities and challenging behaviours. J Intellect Disabil Res 2012;56: 270-84.

20. Wagemans AM, Van Schrojenstein Lantman-de Valk HM, Proot IM, Metsemakers J, Tuffrey-Wijne I, Curfs LM. End-of-life decisions for people with intellectual disabilities, an interview study with patient representatives. Palliat Med 2013;27:765-71.

21. Van Beelen A. Patiënten moeten een rood polsbandje om als ze niet gereanimeerd willen worden (Patients should wear a red bracelet if they want not to be resuscitated). Mednet 2012;5:13.

22. Chadwick DD, Jolliffe J and Goldbart J. Carer knowledge of dysphagia management strategies. Int J Lang Commun Disord. 2002;37:345-57. 


\section{Chapter 7}

\section{General discussion}

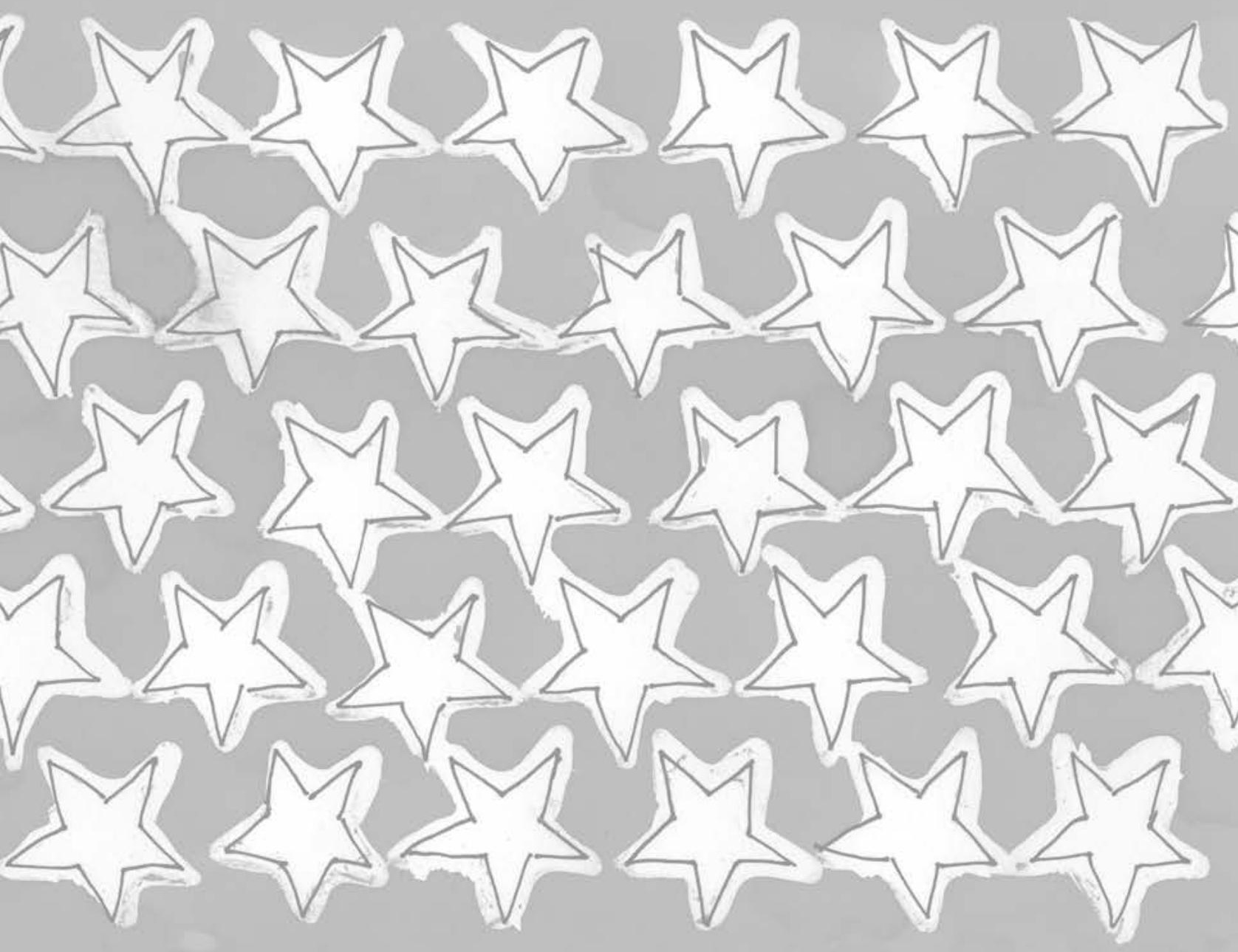


Chapter 7 


\section{Introduction}

End-of-life decisions are an important theme in the lives of all people, and even more so in the lives of people with intellectual disabilities (IDs). The aim of this thesis is to contribute to a better understanding of the process of end-of-life decision making for people with IDs. They are often unable to decide for themselves, so the decisions involve parents and other next-of-kin as representatives.

Our studies on end-of-life decision making addressed the following research questions:

- What is the prevalence and nature of end-of-life decisions for people with IDs?

- How does the process of end-of-life decisions work?

- Who plays which role in the process?

- Which considerations are important in the decision-making process?

- What are the problems and pitfalls regarding the issuing of Do Not Attempt Resuscitation (DNAR) orders from the perspective of ID physicians?

This general discussion chapter first presents a brief overview of the main results regarding the prevalence and nature of end-of-life decisions for people with IDs, the process of end-of-life decisions from different perspectives and problems and pitfalls of issuing DNAR orders. It then discusses the findings in a broader perspective, under the heading of Reflections. The chapter ends with recommendations for further research and suggestions for clinical practice.

\section{Findings}

\section{Research question 1: Prevalence and nature of end-of-life decisions for people with IDs}

A retrospective study of the medical files of people who died in a Dutch centre providing residential care for people with IDs demonstrated that an end-of-life decision had been recorded for 27 out of 47 (57\%) of the deceased. Dutch physicians caring for people with IDs reported end-of-life decisions for $44 \%$ of their patients in $1995^{1}$, whereas the prevalence of end-of-life decisions in the general population varies from $23 \%$ (Italy), to $44 \%$ (the Netherlands) and 51\% (Switzerland) ${ }^{2}$. The end-oflife decisions in our study were mainly decisions on withholding and withdrawing treatment. Decisions on ending a life with or without request were not found. The process of end-of-life decisions (what happens in the decision-making process) was not described in these records and there was no evidence that any of the people with IDs were themselves involved in the end-of-life decisions. These findings and the cases 
described demonstrate that end-of-life decisions are an important issue in the care for people with IDs, but leave open many questions as to what happens in the process of decision-making.

Research questions 2, 3 and 4: Roles, perspectives and considerations in the process of end-of-life decisions

These characteristics of the end-of-life decision-making process have been studied from the perspectives of ID physicians, representatives and paid care staff. This qualitative study, carried out in the Netherlands, involved semi-structured interviews with all three categories, discussing the deaths of ten patients with IDs that had involved end-of-life decisions.

\section{The perspective of the physicians}

The physicians reported that it was important to involve the relatives in the end-of-life decision-making process, to delegate the assessment of the quality of life to the relatives, to have good working relationships with relatives and paid care staff and to be aware of the patient's vulnerabilities. Physicians were inclined to give relatives the lead in the decision-making process for those patients who lack the capacity to make their own decisions. In doing so, they tended to be vague about their own responsibility in the decision process, although they viewed themselves as the professionals who actually took the decisions.

\section{The perspective of the representatives}

The patient representatives felt highly responsible for the end-of-life decisions they thought they had to make. They did not involve the persons they were representing in the end-of-life decision-making process, nor any other professionals than the doctor. During the years in which they fulfilled their role, patient representatives had developed perceptions about the quality of life, about prevention of suffering and about the ability of their loved one to understand the burden of possible interventions. They reported that they expected support from the ID physicians and regretted that they had not been aware that it was the ID physicians who were ultimately responsible for the end-of-life decision. Making an end-of-life decision for somebody else was a burden to most representatives.

\section{The perspective of the paid care staff}

The position of the paid care staff was characterized by the fact that they considered themselves to be at the centre of the communication network during the end-of-life period of the people with IDs they cared for. They were confident about their own opinion as they knew the patient's life story and his or her needs and preferences. 
They did feel responsible for the end-of-life care, but not for the end-of-life decisions. The balance between involvement and distance was not always easy to find. Their focus on the patient with IDs might explain why the paid care staff were able to contribute to such an important subject as end-of-life decisions. The paid care staff reported not to be sure who was actually responsible for the end-of-life decisions.

\section{Research question 5: Problems and pitfalls of issuing a DNAR order for people with IDs, from the viewpoint of ID physicians}

For the ID physicians, medical considerations were the main contributory factors to the process of deciding about DNAR orders, rather than the expected success rate of resuscitation. The evaluation of the patient's quality of life and possible suffering due to challenging behaviour was left to the representatives and was sometimes a cause of conflicts between physicians and representatives. At this point, physicians felt vulnerable and wanted to prevent conflicts with representatives. They therefore said that they wanted a more solid and more clearly defined legal position. The procedure of issuing a DNAR order and the embedding of this procedure in the health care organization were important for the ID physicians. They felt that the DNAR decision should be clearly communicated with the paid care staff to avoid unwanted resuscitation being initiated by staff or a bystander.

\section{Strengths and limitations}

The most important strength of this research project was that a difficult and sensitive topic was explored and its clinical relevance determined from the perspectives of the ID physicians, representatives and paid care staff. The files kept by the care facility provided a clear picture of the prevalence and offered thorough insights into the difficulty of these cases. The inclusion of the ID physician, representative and most closely involved paid care staff to discuss the death of a person with IDs was a successful approach. The physicians were experienced and open and did not hesitate to contribute to this study, even providing input about cases in which their own role had been questioned by the representatives. ID physicians also contributed just as willingly to the study on DNAR order issuing.

Although only ten cases were studied, they were studied in-depth, and the findings obtained from the different stakeholders complemented each other. It is still to a large extent unclear what exactly happens in all decision-making processes at the end of life in all care settings. Our findings are in agreement with the limited literature that is available on the process of decision making. Comparisons should be made with caution, but the results can be used for a broad range of people who lack the capacity to make their own end-of-life decisions and are dependent on others for these 
decisions. The study was limited by the fact that no people with IDs were directly involved in the different studies. People with IDs are sometimes not able to communicate in spoken language, and if they can talk, they are often unable to understand, discuss and evaluate the consequences of a medical decision. This does not relieve physicians, representatives and paid care staff from the obligation to make every effort to involve them in the decisions, and ways should be sought to put this into practice. The study on the prevalence of end-of-life decisions was limited by the fact that it took place within one care facility. In addition, our qualitative studies only involved ID physicians and no general practitioners. This means that the results from this study cannot be generalized to situations of people with IDs who are living in the community and are cared for by general practitioners.

\section{Reflections}

The studies in this thesis have demonstrated that end-of-life decisions for people with IDs are an important issue. It emerged that ID physicians were not always transparent about their responsibility in end-of-life decisions, although they thought that they had made themselves clear about their role as decision makers. Only when we interviewed the representatives and paid care staff after the deaths of people with IDs did it become evident that the role of the physician as the decision maker was not as clear to the representatives and paid care staff as the ID physicians had thought. The fact that the ID physicians (and the paid care staff) allocated a very important role to the representatives in the decision-making process has doubtlessly contributed to the lack of clarity about who is ultimately responsible. The representatives deliberated and took upon themselves the burden of making a decision, and it was only after the deaths of their loved ones that they understood that it was the physician who was actually responsible for the end-of-life decisions.

The vulnerability of the ID physicians' role emerged where the physicians had views that differed from those of the representatives. On the one hand, the representatives attached great weight to considerations like avoiding (more) suffering, the fact that their loved ones might not understand the burden of possible interventions and treatments, and protecting their loved ones from needless medical treatment. Challenging behaviour on the part of the patients was one reason mentioned by representatives for withholding treatment, which made physicians uncertain. On the other hand, the ID physicians had the greatest affinity for the medical considerations which they had been trained to address. Quality of life and avoiding suffering were difficult themes to them, and were left to the representatives, who had developed their views about this over the years. The physicians and representatives had to work closely together throughout the process, and the 
representatives expected support from the physicians. Paid care staff were able to support the physicians in making up their mind about non-medical issues, which contributed to the decisions to be made. Although the paid care staff had no formal role in the decision-making process, they did informally steer the process as they were at the centre of the communications network linking the other parties involved.

The care for people with IDs is organized differently in other countries than in the Netherlands, where there is a tradition of specialized vocational training in ID care for physicians and nursing staff. In addition, palliative care training in ID care has evolved during the last decade. This could explain why Dutch paid care staff feel better equipped to support clients with IDs in end-of-life care than similar staff in other countries $^{3-5}$.

As regards the DNAR decisions, considerations about quality of life and avoiding suffering were just as important there as in the other end-of-life decisions. The paid care staff had every reason to ask for clear instructions regarding DNAR, as they had to know how to act. New registration systems are being tried out and discussions on end-of-life decisions are encouraged in other settings, like hospitals ${ }^{6}$. Just as in other settings, ID physicians tend to make a DNAR decision based on the condition of the patient rather than on the prognosis of resuscitation ${ }^{7}$.

Unclear roles and positions in the end-of-life decision-making processes for people with IDs are not different from decision-making for people who have to be represented for other reasons than IDs, as has been found in nursing homes and hospitals ${ }^{8-11}$. In nursing homes, physicians and other professionals were inclined to do what representatives wanted, even when they felt it was not the best option for the patient, and 'advance directives' were not always respected ${ }^{11,12}$. What exactly happens in all these decision-making processes at the end of life remains for the most part unclear in all care settings ${ }^{13}$.

The fact that people with IDs have to be represented and supported throughout their lives makes the roles of everybody involved in decision-making process different from those in other settings, and this is especially true for the role of the representatives $^{14-16}$. Over the years, they have the opportunity to grow in their role, which is different from that of parents who encounter problems at birth ${ }^{17}$ or children who have to represent their parents at the end of life ${ }^{8,12}$, and who are thus suddenly confronted with a different position vis-a-vis their parents.

Our study covered the decision-making processes involving ID physicians, not processes in which it is general practitioners or medical specialists who take the lead. General practitioners are experienced in palliative care and end-of-life decisions, but less so in advance care planning ${ }^{18}$, and ID physicians could support general practitioners in advance care planning and decision-making processes for people with IDs.

Our research findings should also be used in tailoring palliative care to the needs of people with IDs. At the closing ceremony of the 2013 European Association for 
Palliative Care (EAPC) conference, decision-making in palliative care was described as the most neglected part of palliative care and a great challenge for the future. From a European perspective, palliative care and end-of-life decisions for people with IDs will receive more attention in the near future, as the EAPC has installed a special interest group on palliative care for people with IDs, which aims to improve palliative and endof-life care for these people ${ }^{19}$. In England, a confidential inquiry into premature deaths of people with learning disabilities (CIPOLD) ${ }^{20}$ investigated the sequence of events leading to all known deaths of people with IDs. The report recommends improvements in advance health and care planning and in the management of multimorbidity and end-of-life care. Advice and education aimed the general public to draw attention to advance care planning and end-of-life decisions should include people with IDs and their representatives ${ }^{13,18}$.

Our studies show that roles are not always completely clear, and stakeholders may be uncertain about their roles. Residential care facilities seldom have written policies on end-of-life care and even less so on end-of-life decisions ${ }^{21,22}$. The Dutch Association of ID physicians has a guideline but this does not include instruments for advance care planning or decision making ${ }^{23}$. The decision-making process could be improved with the help of two instruments: advance care planning and shared decision making. Advance care planning has already been practiced to some extent in ID care ${ }^{24,25}$, but shared decision making has hardly been applied.

\section{Advance care planning and shared decision making}

If people are provided with an 'advance directive' or have given a long-term power of attorney to someone, they not only get the care they would have preferred, but they are also given less aggressive care at the end of life ${ }^{26}$. Advance directives are not a set of static decisions but need to be regularly reconsidered, as preferences may change and communication between patient and caregiver is not always easy at the end of life $^{27}$. Advance care planning may thus be regarded as a continuous process rather than as an action implemented at one given moment ${ }^{24,28}$. It seems wise to update preferences and reconsider values and ideas about quality of life in a structured way $^{29}$. The process of advance care planning appears to be more comprehensive than was thought in the past and this is even more true for people with IDs. Only a limited part of care and care decisions can be defined precisely and can be discussed in advance, such as DNAR. Other decisions, like whether to start a specific treatment, can only be taken as the question arises. By way of preparation for future decisions, it seems important to discuss with the representatives not only medical considerations, but also beliefs and opinions regarding quality of life and the burden that their loved one can be subjected to. This should be seen as preparing and practicing for end-oflife decisions. It seems important that all participants in the process share their involvement in the lives and wellbeing of people with IDs. 
Shared decision making has been developed in other types of care than that for people with $\mathrm{IDs}^{30}$, and the problems and pitfalls that were encountered when developing shared decision making in general health care should be avoided. New models for shared decision making should be developed, or existing models adjusted to situations in which a person with IDs could become involved, even those who are hardly, if at all, able to give their opinion on end-of-life decisions. The decisions for people with IDs should therefore not only be shared between physician and patient, but involve representatives and paid care staff too. Ideas on shared decision making that have been developed in general health care include ideas about the way a physician should behave. Shared decision making is not only about giving the patient the choice and accepting the outcomes. Professionals should be involved in the decision-making process in the same role as that of a friend, to guide the patients and representatives through the process of decision making in a respectful, professional and supportive manner ${ }^{31}$. Personal experiences can be used as a 'decision aid' in addition to hard facts, to produce a workable model to start shared decision making in the care for people with IDs ${ }^{32}$. In order to make a more balanced decision, physicians should try to find ways to involve the patients with IDs themselves ${ }^{33}$, as well as other stakeholders who are important to the patients. But shared decision making goes beyond simply involving the patients and/or representatives in the decision-making process. Physicians need the skills to strike a balance between interference, involvement and professional distance, and to be clear about their position and role ${ }^{34}$.

Physicians who have known a patient over a longer period of time should also rely more on their own knowledge of the patient's needs and preferences, and openly take the lead in the decision-making process ${ }^{16}$.

Advance care planning and shared decision making are a reiterative process during the lives of those people with IDs who need a great deal of care and medical intervention. Opinions and values can change over time and should be reconsidered on a regular basis.

\section{Conclusions}

End-of-life decision making should not be a once-and-for-all decision, but should be founded, even rooted, in a lifelong process of discussing what is best for a particular person with IDs. The people with IDs themselves should be involved in end-of-life care and end-of-life decisions in every possible way. Advance care planning should be seen as a continuously developing instrument in this process and certainly not as a written statement that remains valid for the rest of life. The trajectory that leads towards endof-life decisions and the sharing of this trajectory and the decisions are important to all stakeholders, and may lead to better decisions for the person with IDs who is at the 
centre of this process. The findings of our studies allow the conclusion that ID physicians should be open about their responsibility for the end-of-life decisions, based on their knowledge of the patient and on the input of representatives and paid care staff. A transparent and shared process of decision making can not only improve the end-of-life care for people with IDs but also the end-of-life decision-making process for everyone involved. Our findings underline the rights of people with IDs to a sophisticated process of end-of-life decisions. Just like the general population, people with IDs need advance care planning and shared decision making. Involving patients and representatives is important for end-of-life decision making ${ }^{35,36}$ and should become a major element of best practice.

\section{Recommendations}

Although this thesis should primarily be seen as a starting point for further research into end-of-life decision making, there are also some recommendations that can be made for and policy and practice.

\section{Recommendations for further research}

The outcomes of the present studies should be used to develop and implement an evidence-based guideline on end-of-life decision making (including DNAR) and advance care planning, as well as training programmes for physicians to deal with uncertainties regarding end-of-life decisions.

Models for shared decision making for people with IDs, their representatives and the professionals should be developed and their effects studied.

The way general practitioners cope with end-of-life decisions for people with IDs needs to be studied further. What is their role and which problems and pitfalls do they encounter? A training programme based on the outcomes of such a study could be useful for all physicians who deal with partly or wholly incapacitated patients and their next-of-kin or representatives.

Methods should be developed and studied to facilitate general practitioners consulting ID physicians for advice on general and palliative care and end-of-life decision-making for people with IDs.

There is a need for an instrument to evaluate the quality of life of people with IDs nearing the end of their lives, to be used in the decision-making process. Further studies should aim to develop such an instrument to assess quality of life. 
The role and influence of people with IDs themselves in the process of end-of-life decisions should be the subject of further study. Methods should be developed to involve people with IDs themselves, as far as possible, in evaluating their quality of life, but also to clarify their views, preferences and expectations concerning death, dying and decision making.

\section{Recommendations for policy and practice}

Health care organizations should develop a clear view regarding DNAR orders, including a written policy, and should implement a procedure for DNAR decisions.

Paid care staff should be educated about resuscitation and trained to handle DNAR procedures.

Physicians should be trained in shared decision making and advance care planning as part of their vocational training, and these subjects should also be part of the continuing education of all ID physicians.

The decision-making process should start at the moment when serious conditions are presented, which will often be long before the end-of-life phase. The major question should be 'What are the benefits of this diagnostic or therapeutic intervention for this patient at this moment and what are the consequences for the future?'

Paid care staff need to be trained in the how and why of end-of-life decisions, their own position and the opportunities they have to contribute to these important issues. Subsequently, physicians and paid care staff should support representatives and the people with IDs themselves in participating in the process of end-of-life decisions. 


\section{References}

1. Van Thiel GJ, Van Delden JJ, De Haan K, et al. Retrospective study of doctors' "end of life decisions" in caring for mentally handicapped people in institutions in The Netherlands. BMJ 1997;315:88-91.

2. Van der Heide A, Deliens L, Faisst K, et al. End-of-life decision-making in six European countries: descriptive study. Lancet 2003;362:345-50.

3. Ryan K, McEvoy J, Guerin S, et al. An exploration of the experience, confidence and attitudes of staff to the provision of palliative care to people with intellectual disabilities. Palliat Med 2010;24:566-72.

4. Wiese M, Stancliffe RJ, Balandin S, et al. End-of-life care and dying: issues raised by staff supporting older people with intellectual disability in community living services. J Appl Res Intellect Disabil 2012; 25:571-83.

5. Tuffrey-Wijne I, Bernal J, Hubert J, et al. Exploring the lived experiences of people with learning disabilities who are dying of cancer. Nurs Times 2010;106:15-8.

6. Creemers D., Bosch F., Vliet J., et al. Reanimeer maar met mate [Resuscitate, but within limits]. Medisch Contact $2013 \mathrm{Nr} 20$.

7. De Vos R, Koster RW and de Haan RJ. Impact of survival probability, life expectancy, quality of life and patient preferences on do-not-attempt-resuscitation orders in a hospital. Resuscitation Committee. Resuscitation 1998;39:15-21.

8. Dreyer A, Forde R and Nortvedt P. Autonomy at the end of life: life-prolonging treatment in nursing homes--relatives' role in the decision-making process. J Med Ethics 2009;35:672-7.

9. Nolan MT, Hughes M, Narendra DP, et al. When patients lack capacity: the roles that patients with terminal diagnoses would choose for their physicians and loved ones in making medical decisions. J Pain Symptom Manage 2005;30:342-53.

10. Weiss $\mathrm{BD}$, Berman $\mathrm{EA}$, Howe $\mathrm{CL}$, et al. Medical decision-making for older adults without family. J Am Geriatr Soc 2012;60:2144-50.

11. Dreyer A, Forde R and Nortvedt P. Life-prolonging treatment in nursing homes: how do physicians and nurses describe and justify their own practice? J Med Ethics 2010;36:396-400.

12. Kaspers PJ, Onwuteaka-Philipsen BD, Deeg DJ, et al. Decision-making capacity and communication about care of older people during their last three months of life. BMC Palliat Care 2013;12:12-1.

13. ZonMw, ed. Moet alles wat kan (Do we need to do everything that is possible?) Vagen rond medische beslissingen bij het begin en einde van het leven (Questions surrounding medical decisions at the beginning and the end of life). 2013, ZonMw: den Haag. 1-66.

14. Welie JV and Welie SP. Patient decision making competence: outlines of a conceptual analysis. Med Health Care Philos 2001;4:127-38.

15. Welie SP. Criteria for patient decision making (in)competence: a review of and commentary on some empirical approaches. Med Health Care Philos 2001;4:139-51.

16. Welie SP, Dute J, Nys $\mathrm{H}$, et al. Patient incompetence and substitute decision-making: an analysis of the role of the health care professional in Dutch law. Health Policy 2005;73:21-40.

17. De Vos MA, Van der Heide A, Maurice-Stam H, et al. The process of end-of-life decision-making in pediatrics: a national survey in the Netherlands. Pediatrics 2011;127:1004-1012.

18. Maasen H. Bespreek reanimatie tijdig met patiënt (Discuss DNAR with the patient, at an early stage). Medisch Contact 2013;14:706-707.

19. http://www.eapcnet.eu/Themes/Specificgroups/Peoplewithintellectualdisabilities.aspx. Palliative care for people with intellectual disabilities: Best practice guidelines and core standards ( cited May 17th 2013)

20. Heslop P, Confidential Inquiry into premature deaths of people with learing disabilities. 2013, Norah Fry Research Centre: Bristol UK.

21. D'Haene I, Pasman HR, Deliens L, et al. End-of-life care policies in Flemish residential care facilities accommodating persons with intellectual disabilities. J Intellect Disabil Res 2010;54:1067-77.

22. Haverkate I and Van der Wal G. Policies on medical decisions concerning the end of life in Dutch health care institutions. JAMA 1996;275:435-9. 
23. NVAVG. Medische Beslissingen rond het levenseinde bij mensen met een verstandelijk handicapt (Medical end-of-life decisions for people with intellectual disabillities). Guideline 2008

24. Kingsbury LA. People Planning Ahead. 2009, Washington: AAIDD.

25. Friedman RI. Use of advance directives: facilitating health care decisions by adults with mental retardation and their families. Ment Retard 1998;36:444-56.

26. Silveira MJ, Kim SY and Langa KM. Advance directives and outcomes of surrogate decision making before death. N Engl J Med 2010;362:1211-8.

27. Fried TR and O'Leary JR. Using the experiences of bereaved caregivers to inform patient- and caregiver-centered advance care planning. J Gen Intern Med. 2008; 23: 1602-7. doi: 10.1007/s11606008-0748-0. Epub 2008 Jul 30.

28. Sudore RL and Fried TR. Redefining the "planning" in advance care planning: preparing for end-of-life decision making. Ann 2010; 153: 256-61.

29. McMahan RD, Knight SJ, Fried TR, et al. Advance Care Planning Beyond Advance Directives: Perspectives From Patients and Surrogates. J Pain Symptom Manage 2012;3924:00504-0.

30. Charles C, Gafni A and Whelan T. Shared decision-making in the medical encounter: what does it mean? (or it takes at least two to tango). Soc Sci Med 1997;44:681-92.

31. Entwistle VA, Carter SM, Cribb A, et al. Supporting patient autonomy: the importance of clinicianpatient relationships. J Gen Intern Med 2010;25:741-5.

32. Entwistle VA, France EF, Wyke S, et al. How information about other people's personal experiences can help with healthcare decision-making: a qualitative study. Patient Educ Couns 2011;85:8.

33. Tuffrey-Wijne I, Bernal J, Butler G, et al. Using Nominal Group Technique to investigate the views of people with intellectual disabilities on end-of-life care provision. J Adv Nurs 2007;58:80-9.

34. Cribb A and Entwistle VA. Shared decision making: trade-offs between narrower and broader conceptions. Health Expect 2011;14:210-9.

35. Evans N, Pasman HR, Vega Alonso T, et al. End-of-life decisions: a cross-national study of treatment preference discussions and surrogate decision-maker appointments. PLoS One 2013;8:5.

36. Meeussen K, Van den Block L, Echteld M, et al. Advance care planning in Belgium and The Netherlands: a nationwide retrospective study via sentinel networks of general practitioners. J Pain Symptom Manage 2011;42:565-77. 



\section{Summary}
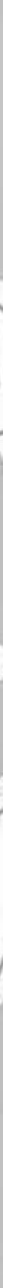


\section{Background}

End-of-life decisions are important for all people, as is illustrated by the increasing numbers of such decisions in Western countries. End-of-life decisions are defined as those decisions at the end of life which may shorten life, but are not aimed at shortening a patient's life. They include withdrawing or withholding treatment, administering treatments to relieve symptoms with possible life-shortening sideeffects, and ending a patient's life with or without their request. People with IDs are often unable to decide for themselves regarding these matters, and need the help of representatives, often next-of-kin. In addition, they tend to have more health problems than people without IDs.

At the start of this research project, barely any literature was available on the topic of end-of-life decisions for people with IDs. There was some information about the prevalence of such decisions, but not about the process of decision making.

\section{Research questions}

This project was initiated because we wanted to find out how often end-of-life decisions were being made, what kind of end-of-life decisions were made and the role and influence of the various participants in the process of end-of-life decisions for people with IDs.

The following research questions were addressed:

- What is the prevalence and nature of end-of-life decisions for people with IDs?

- How does the process of end-of-life decisions work?

- Who plays which role in the process?

- Which considerations are important in the decision-making process?

- What are the problems and pitfalls regarding the issuing of Do Not Attempt Resuscitation (DNAR) orders from the perspective of ID physicians?

\section{Chapter 2}

\section{Prevalence and nature of end-of-life decisions for people with IDs}

A retrospective study of medical files of people who died in a Dutch centre providing residential care for 335 people with IDs demonstrated that an end-of-life decision had been recorded for $57 \%$ of the deceased. Cases are described to illustrate the nature of 
these decisions. However, no information was found about the actual process of endof-life decision making. There was no evidence in the notes that any of the people with IDs were asked to give their own opinion about the end-of-life decision.

\section{Roles, perspectives and considerations of various stakeholders in the process of end-of-life decisions}

This qualitative study, carried out in the Netherlands, involved semi-structured interviews with ID physicians, representatives and paid care staff made after the deaths of ten patients with IDs that had involved end-of-life decisions. The interviews were recorded digitally, transcribed verbatim and analysed using Grounded Theory procedures.

\section{Chapter 3}

\section{Perspective of the physicians}

Physicians reported that they extensively involved representatives and paid care staff in the decision-making process. To this end, they tried to maintain good working relationships and allocated to the representatives the position of the person who had to evaluate the quality of life of their loved one. In their view, knowledge of a patient's vulnerabilities is needed to make decisions based on the needs and preferences and the medical life story of patients who are not (or not fully) able to decide.

\section{Chapter 4}

\section{Perspective of the representatives}

Sixteen patient representatives (most family members) were interviewed after the deaths of their loved ones.

The representatives felt highly responsible for the decisions they had made. They had not involved the patients themselves in the end-of-life decision making process, nor any other professionals than the doctor. Patient representatives had developed ideas about quality of life, about prevention of suffering and about the ability of their loved one to understand the burden of possible interventions. They wanted support from the ID physician and they regretted they had not known that it was the ID physicians who were ultimately responsible for the end-of-life decisions. 


\section{Chapter 5}

\section{Perspective of the paid care staff}

The position of the paid care staff was characterized by the fact that they considered themselves to be at the centre of the communication network during the end-of-life period of the people with IDs they cared for. They were confident about their own opinion as they were familiar with the patient's complete picture. They did feel responsible for the end-of-life care, but not for the end-of-life decisions. The paid care staff reported being unclear about who had the responsibility for the end-of-life decisions.

\section{Chapter 6}

Problems and pitfalls of issuing a DNAR order for people with IDs, from the viewpoint of ID physicians

To clarify the problems and pitfalls of DNAR decision making for people with IDs, we interviewed 40 Dutch ID physicians. The semi-structured interviews were recorded and transcribed and analysed in the same way as in the studies discussed above. It appeared that medical considerations were the main factors contributing to the decision-making process on DNAR orders, rather than the expected success rate of resuscitation. The evaluation of the patient's quality of life and possible suffering due to challenging behaviour was left to the representatives. The physicians wanted to prevent conflicts with representatives, and felt they were vulnerable, so they said they wanted a more solid and clearly defined legal position. The procedure of issuing a DNAR order and the embedding of this procedure in the health care organization were important for the ID physicians.

\section{Chapter 7}

\section{General discussion}

This thesis has examined how various stakeholders participate in the process of endof-life decisions for people with IDs. The process proved to be characterized by incomplete knowledge about the roles and input of participants and by uncertainty. The different types of participants need different types of support for their role in this process. It seems important that participants in the process share their involvement in the lives and wellbeing of people with IDs and share their opinions on their quality of 
life. Physicians need the skills to strike a balance between interference, involvement and professional distance, and to be clear about their position and role. Regular discussions with everyone involved, including the people with IDs themselves, can improve everyone's awareness of the others' motives in end-of-life decisions and can clarify mutual expectations.

Two instruments that can be used to support the decision-making process for people with IDs are advance care planning and shared decision making. Advance care planning should not be seen as one particular action taken at one particular moment, but as a continuous process. Shared decision making still leaves room for improvement, and there are no evidence-based models available for sharing decisions in the care for people with IDs. Both advance care planning and shared decision making should be considered not only at the end of life but at each stage where decisions have to be made that may affect survival. As a consequence, this process needs continuous finetuning and refining, and requires participants who know their roles and have the skills required for this complex process.

\section{Conclusion}

The studies in this thesis have demonstrated that end-of-life decisions for people with IDs are an important issue. The roles and responsibilities of the various participants in the end-of-life decision-making process for people with IDs turned out not to be fully clear to everyone involved, with uncertainty and conflicts arising particularly as regards evaluating the quality of life. The representatives and paid care staff were often not fully aware that it was the ID physician who was ultimately responsible for the end-of-life decisions, and this unawareness sometimes imposed a burden on the representatives. Issuing a DNAR decision did not necessarily lead to its implementation, and the ID physicians considered themselves to be dependent on the health care organization for implementing the decision.

\section{Recommendations}

\section{For research}

- An evidence-based guideline on end-of-life decision making should be developed, as well as a guideline on DNAR.

- Models for shared decision making for people with IDs, their representatives and the professionals should be developed, and their effects studied. 
- The way general practitioners cope with end-of-life decisions for people with IDs should be examined in further studies.

- Methods should be developed to facilitate general practitioners consulting ID physicians about palliative care for people with IDs.

- An instrument should be developed to assess the quality of life of people with IDs who cannot express themselves and are nearing the end of their life.

- Methods should be developed to involve people with IDs in the process of end-oflife decision making and in the development of a quality-of-life instrument.

\section{For policy and practice}

- Health care organizations should develop and implement a sound procedure on DNAR and should train paid care staff about making the decision as to whether to resuscitate or not at the critical moment.

- Physicians should be trained in advance care planning and shared end-of-life decision making. Physicians also need to be trained to deal with the uncertainties associated with end-of-life decision making.

- Paid care staff need to be trained in the how and why of end-of-life decisions, their own position and the opportunities they have to contribute to these important issues.

- $\quad$ The decision-making trajectory should start long before the end-of-life phase. 



\section{Samenvatting}

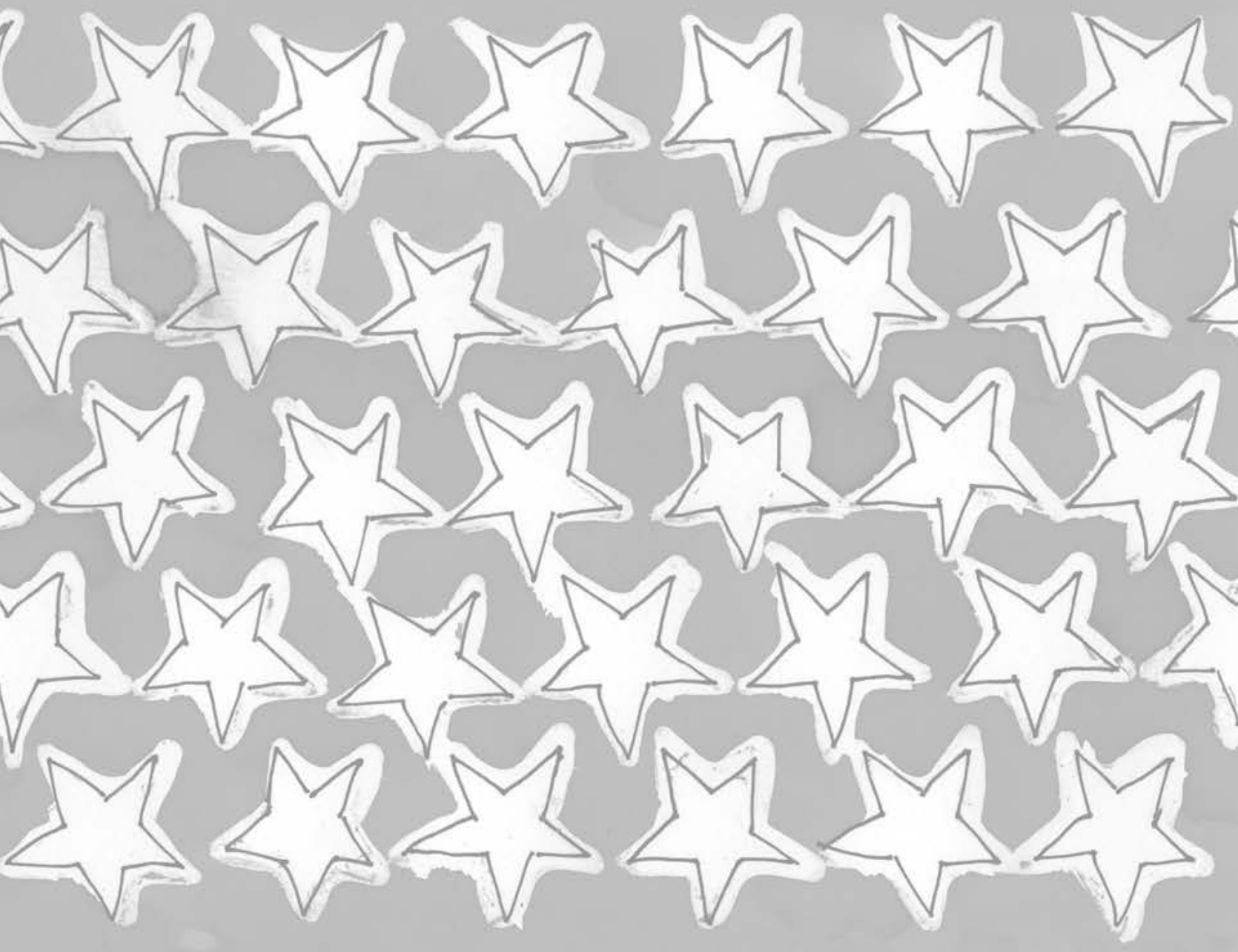




\section{Achtergrond van het onderzoek}

Beslissingen rond het levenseinde zijn belangrijk voor de meeste mensen en dat wordt geillustreerd door het feit dat in de Westerse wereld in een groot aantal overlijdensprocessen dit soort beslissingen worden genomen. Beslissingen rond het levenseinde zijn beslissingen aan het einde van het leven die het leven mogelijk bekorten, maar die dit niet als doel hebben. Het gaat dan over een drietal beslissingen namelijk (1) het stoppen of niet starten van een behandeling (2) de levensbekortende effecten van een behandeling die als doel heeft om symptomen te bestrijden (3) beëindigen van het leven wel of niet op iemands eigen verzoek.

Mensen met een verstandelijke beperking hebben vaak hulp nodig bij het nemen van moeilijke beslissingen en als dit het geval is dan zeker bij beslissingen rond het levenseinde. Daarbij komt het feit dat zij meer gezondheidsproblemen hebben dan mensen zonder een verstandelijke beperking.

Bij de start van dit onderzoek was er nauwelijks literatuur te vinden over hoe beslissingen rond het levenseinde genomen werden bij mensen met een verstandelijke beperking. Er was wel iets bekend over de prevalentie, maar niet over het proces van beslissen.

\section{Onderzoeksvragen}

Dit project is gestart omdat we wilden weten wat de rol en invloed was van de verschillende deelnemers in het proces van beslissen, hoe vaak beslissingen rond het levenseinde werden genomen en welk soort beslissingen er werden genomen.

De volgende onderzoeksvragen werden geformuleerd:

- Wat is de prevalentie en de aard van beslissingen rond het levenseinde bij mensen met een verstandelijke beperking?

- Hoe verloopt het proces van beslissen?

- Wie speelt welke rol in dit proces?

- Welke afwegingen zijn belangrijk in het proces van beslissen?

- Welke problemen en valkuilen ervaren AVG's (artsen voor mensen met een verstandelijke beperking) bij het nemen van niet reanimatie beslissingen?

\section{Hoofdstuk 2}

De prevalentie en het soort beslissingen rond het levenseinde bij mensen met een verstandelijke beperking. 
Er werd een dossier studie gedaan van mensen die gedurende een periode van 5 jaar overleden waren in een Nederlands instituut met 335 mensen met een verstandelijke beperking. Hieruit bleek dat er een beslissing rond het levenseinde was genomen bij $57 \%$ van degene die overleden waren. Het soort beslissingen werd geillustreerd met het beschrijven van casus. Er werd geen informatie in de dossiers gevonden over hoe het proces van beslissen was verlopen en wie welke rol speelde noch of de overledene zelf om een mening was gevraagd.

De rollen, gezichtpunten en overwegingen van de verschillende deelnemers in het proces van beslissingen rond het levenseinde.

In deze kwalitatieve studie werden, na het overlijden van tien mensen met een verstandelijke beperking, interviews gedaan met degenen die betrokken waren in het proces van beslissen, namelijk met AVG's, wettelijk vertegenwoordigers en de meest belangrijke verzorgenden. De halfgestructureerde interviews over het proces van beslissen, werden digitaal geregistreerd, letterlijk uitgetypt en geanalyseerd volgens de methode van Grounded Theory.

\section{Hoofdstuk 3}

\section{Het gezichtpunt van de artsen}

Artsen vonden de mening van wettelijk vertegenwoordigers en de verzorgers uitermate belangrijk voor de te nemen beslissingen en betrokken hen bij het traject van beslissen. Om tot een goed proces van beslissen te komen, investeerden ze in de relatie met de wettelijk vertegenwoordigers. De wettelijk vertegenwoordigers kregen de ruimte om over de kwaliteit van leven van de naaste te oordelen. De artsen lieten dit zwaar meewegen in hun beslissing evenals de medische voorgeschiedenis, de behoeften en voorkeuren van de patiënt en de kwetsbaarheid van de patiënt.

\section{Hoofdstuk 4}

\section{Het gezichtpunt van de wettelijk vertegenwoordigers}

Zestien wettelijk vertegenwoordigers (meest familieleden) werden geïnterviewd na het overlijden van hun naaste met een verstandelijke beperking. Het bleek dat de wettelijk vertegenwoordigers zich zeer verantwoordelijk voelden voor de genomen beslissingen rond het levenseinde. Behalve de dokter hadden zij niemand betrokken bij deze beslissingen, ook de patiënt zelf niet. De wettelijk vertegenwoordigers 
hadden een duidelijk idee over de kwaliteit van leven, zij wilden graag meer lijden voorkomen en waren van mening dat hun naaste de belasting van onderzoek en behandeling niet konden begrijpen. Het was genoeg geweest. Ze hadden vooraf heel graag geweten dat de dokter verantwoordelijk was voor de beslissingen die genomen moesten worden en zouden zich dan beter gesteund hebben gevoeld.

\section{Hoofdstuk 5}

\section{Het gezichtpunt van de verzorgenden}

De verzorgenden zagen voor zichzelf een rol weggelegd in het centrum van communicatie tijdens de zorg rond het levenseinde voor hun patiënten met een verstandelijke beperking. Zij waren ervan overtuigd dat ze wisten wat goed was omdat ze de patiënt door en door kenden. Zij voelden zich verantwoordelijk voor de zorg rond het levenseinde, maar niet voor de beslissingen rond het levenseinde. Voor de verzorgenden was het niet helder wie er verantwoordelijk was voor de beslissingen rond het levenseinde.

\section{Hoofdstuk 6}

De problemen en valkuilen die dokters ervaren bij het afspreken van niet reanimeren voor mensen met een verstandelijke beperking.

Om de problemen en valkuilen te onderzoeken bij het maken van niet reanimatie afspraken voor mensen met een verstandelijke beperking, werden er 40 Nederlandse AVG's geïnterviewd.

De halfgestructureerde interviews werden opgenomen, uitgeschreven en geanalyseerd zoals eerder in dit hoofdstuk beschreven. Medische redenen waren de belangrijkste overwegingen bij het maken van niet reanimatie afspraken, meer dan het slagingspercentage van de reanimatie. Het beoordelen van de kwaliteit van leven werd overgelaten aan de wettelijk vertegenwoordigers. Dat ouders het lijden van hun kind aan gedragsproblemen ervoeren als een reden voor een niet reanimatie afspraak vonden artsen moeilijk. De artsen wilden conflicten met de wettelijk vertegenwoordigers vermijden en voelden zich daarbij kwetsbaar. Om deze reden wilden ze een meer stevige en beter omschreven wettelijke positie. De procedure voor een niet reanimatie afspraak en de verankering in de zorgorganisatie waren belangrijk voor de AVG's. 


\section{Hoofdstuk 7}

\section{Algemene discussie}

In dit proefschrift werd onderzocht welke rol de verschillende deelnemers spelen in het proces van beslissingen rond het levenseinde bij mensen met een verstandelijke beperking. Het proces werd gekenmerkt door onzekerheid en door onvolledige kennis over de rol en de bijdrage van betrokkenen. De verschillende deelnemers hebben elk andere ondersteuning nodig voor hun rol in dit proces. Het is belangrijk dat zij hun betrokkenheid delen bij het leven en welbevinden van de mensen met een verstandelijke beperking en vooral hun ideeën en mening delen over de kwaliteit van leven. Artsen hebben vaardigheden nodig om een evenwicht te vinden tussen betrokkenheid en professionele distantie en moeten duidelijk zijn over hun positie en hun rol. Een dialoog met alle betrokkenen, waar mogelijk ook met de persoon met de verstandelijke beperking zelf, kan duidelijk maken waar anderen aan denken, wat hun ideeën en motieven zijn en kan verwachtingen naar elkaar toe verhelderen.

Twee instrumenten kunnen gebruikt worden om het proces van beslissen te verbeteren en te vergemakkelijken namelijk advance care planning en gedeelde besluitvorming. Advance care planning moet niet gezien worden als eenmalige actie om beslissingen te nemen en vast te leggen, maar als een proces waar steeds aan moet worden gewerkt. Gedeelde besluitvorming als methode staat nog in de kinderschoenen in de zorg voor mensen met een verstandelijke beperking en er zijn nog geen wetenschappelijk onderbouwde modellen. Zowel advance care planning als ook gedeelde besluitvorming moeten niet alleen aan het einde van het leven aan de orde komen, maar moeten veel eerder als instrumenten worden ingezet om belangrijke beslissingen voor te bereiden die invloed kunnen hebben op kwaliteit van leven. Om dit te bereiken moet het proces van beslissen steeds worden bijgesteld en afgestemd en moeten de betrokkenen hun rol kennen en de vaardigheden hebben voor dit ingewikkelde proces van beslissen voor een ander.

\section{Conclusie}

In dit proefschrift is duidelijk gemaakt dat beslissingen rond het levenseinde voor mensen met een verstandelijke beperking belangrijk zijn. De rollen en verantwoordelijkheden van de deelnemers aan dit proces zijn niet helemaal duidelijk. Het gevolg is onzekerheid en conflicten in het bijzonder bij het evalueren van de kwaliteit van leven. De wettelijk vertegenwoordigers en verzorgenden waren vaak niet op de hoogte van het feit dat de dokter uiteindelijk verantwoordelijk is voor de beslissing en dit was belastend voor de wettelijk vertegenwoordigers. Het afspreken van niet 
reanimeren, leidde niet per definitie tot implementatie van de afspraak en de AVG's voelden zich erg afhankelijk van de organisatie waarin ze werkten.

\section{Aanbevelingen voor onderzoek}

- Een evidence based richtlijn moet worden ontwikkeld voor het nemen van beslissingen rond het levenseinde voor mensen met een verstandelijke beperking evenals een richtlijn voor niet reanimeren.

- Een methode voor gedeelde besluitvorming voor mensen met een verstandelijke beperking, hun vertegenwoordigers en de professionals moet worden ontwikkeld en geëvalueerd.

- De manier waarop huisartsen omgaan met beslissingen rond het levenseinde bij mensen met een verstandelijke beperking moet worden onderzocht.

- Er zou een methode moeten worden ontwikkeld waarmee huisartsen AVG's kunnen consulteren in verband met palliatieve zorg voor mensen met een verstandelijke beperking.

- Er dient een instrument te worden ontwikkeld om kwaliteit van leven te meten aan het einde van het leven van mensen met een ernstige verstandelijke beperking die zich zelf niet kunnen uitdrukken.

- Een werkwijze moet worden ontwikkeld om mensen met een verstandelijke beperking te betrekken bij beslissingen rond het levenseinde en bij het ontwikkelen van een kwaliteit van leven instrument.

\section{Aanbevelingen voor beleid en praktijk}

- Organisaties in de gezondheidszorg moeten een duidelijk (niet) reanimatie beleid ontwikkelen en implementeren. Het verzorgend personeel moet getraind worden om als reanimatie aan de orde is te weten hoe ze moeten handelen.

- Artsen moeten worden getraind in advance care planning en in gedeelde besluitvorming. Artsen moeten ook worden getraind in het omgaan met de onzekerheden die horen bij beslissingen rond het levenseinde.

- Verzorgenden moeten weten hoe beslissingen rond het levenseinde worden genomen, wat hun eigen positie is en wat hun bijdrage kan zijn.

- Het traject van beslissen moet in de zorg voor mensen met een verstandelijke beperking, ver voor het levenseinde starten. 



\section{List of publications}

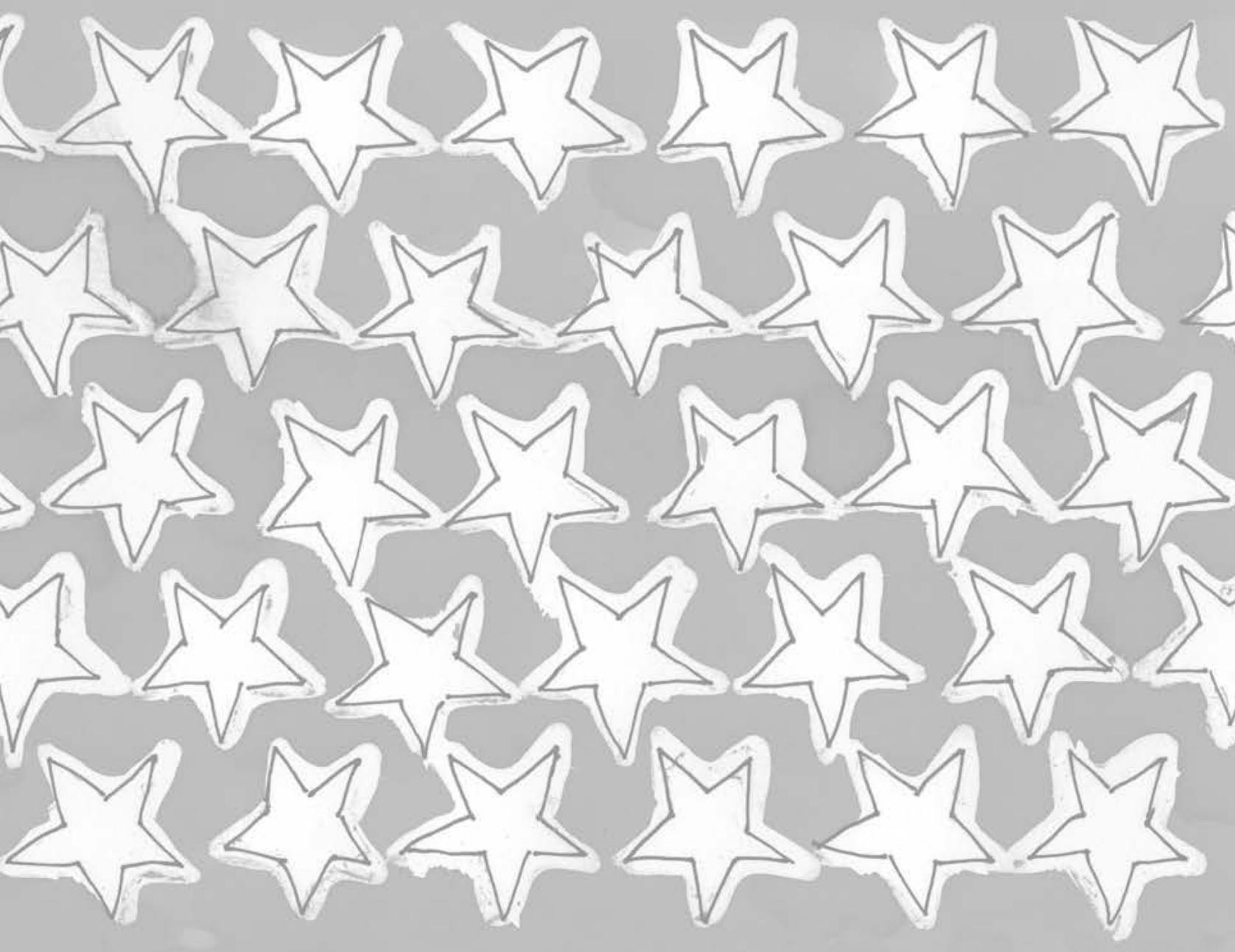




\section{List of publications}

Wagemans A, Zielhuis G. Een gedifferentieerd vaccinatiebeleid tegen hepatitis-B in een zwakzinnigeninstituut. Ned Tijdschr Geneeskd. 1985;129:1325-8.

Wagemans A, Krom de M, Lugt van der P. Epilepsiebehandeling bij zwakzinnigen: evaluatie van een veranderd beleid. Epilepsiebulletin december 1987:21-3.

Sijpkes P, Wagemans A, Lindeman E, Verstappen F. Evaluating physical therapy in subjects with mental retardation and cerebral palsy. Eur J Mental Disability. 1996;10: 35-42.

de Die-Smulders CE, Engelen JJ, Schrander-Stumpel CT, Govaerts LC, de Vries B, Vles JS, Wagemans A, Schijns-Fleuren S, Gillessen-Kaesbach G, Fryns JP. Inversion duplication of the short arm of chromosome 8: clinical data on seven patients and review of the literature. Am J Med Genet. 1995;59:369-74.

Wagemans AMA, Fiolet JF, van der Linden ES, Menheere PP. Osteoporosis and intellectual disability: is there any relation? Journal of Intellectual Disability Research. 1998;42:370-4.

Mergler S, Wagemans AM,. Lindeman JH. Onderzoeksprogramma chronisch zieken, 1999, onder redactie van Heleen Evenhuis, hoofdstuk over fracturen en osteoporose.

Verhoeven WM, Moog U, Wagemans AM, Tuinier S. Wolf-Hirschhorn (4p-)syndrome in a near adult with major depression; succesful treatment with citalopram; Genetic Counseling. 2002;13:297-301.

Wagemans AM, Cluitmans JJ. Falls and fractures: a major health risk for adults with intellectual disabilities in residential settings. Journal of Policy and Practice in Intellectual Disabilities. 2006;3:136-8.

Schrander-Stumpel CT, Sinnema M, Van den Hout L, Maaskant MA, Van Schrojenstein Lantman-de Valk HM, Wagemans A, Schrander JJ, Curfs LM. Healthcare transition in persons with intellectual disabilities. General issues, the Maastricht model and PraderWilli syndrome. Am J Med Genet C Semin Med Genet. 2007;145C:241-7.

Stoffelen JM, Buntinx WH, Wagemans AM, van Schrojenstein Lantman-de Valk HM, Curfs LMG. Palliatieve zorg voor mensen met een verstandelijke beperking in de praktijk Nederlands Tijdschrift voor de Zorg aan mensen met een verstandelijke beperking. 2008;34. 
Wagemans A, van Schrojenstein Lantman-de-Valk H, Tuffrey-Wijne I, Widdershoven G, Curfs L. End-of-life decisions: an important theme in the care for people with intellectual disabilities.J Intellect Disabil Res. 2010;54:516-24.

Paulussen AD, Stegmann AP, Blok MJ, Tserpelis D, Posma-Velter C, Detisch Y, Smeets EE, Wagemans A, Schrander JJ, van den Boogaard MJ, van der Smagt J, van Haeringen A, Stolte-Dijkstra I, Kerstjens-Frederikse WS, Mancini GM, Wessels MW, Hennekam RC, Vreeburg M, Geraedts J, de Ravel T, Fryns JP, Smeets HJ, Devriendt K, SchranderStumpel CT. MLL2 mutation spectrum in 45 patients with Kabuki syndrome. Hum Mutat. 2011;32:E2018-25.

Wagemans AM, van Schrojenstein Lantman-de Valk HM, Proot IM, Metsemakers J, Tuffrey-Wijne I, Curfs LM. "The factors affecting end-of-life decision making by physicians of patients with intellectual disabilities in the Netherlands: a qualitative study" J Intellect Disabil Res. 2013;57:380-9.

Wagemans AM, Van Schrojenstein Lantman-de Valk HM, Proot IM, et al. End-of-life decisions for people with intellectual disabilities, an interview study with patient representatives. Palliat Med. 2013;27:765-71.

Wagemans AM, van Wijmen, van Schrojenstein Lantman-de Valk HM. "Als een gehandicapt kind lijdt...". Medisch Contact. 2013;4:227-9. 


\section{Dankwoord}
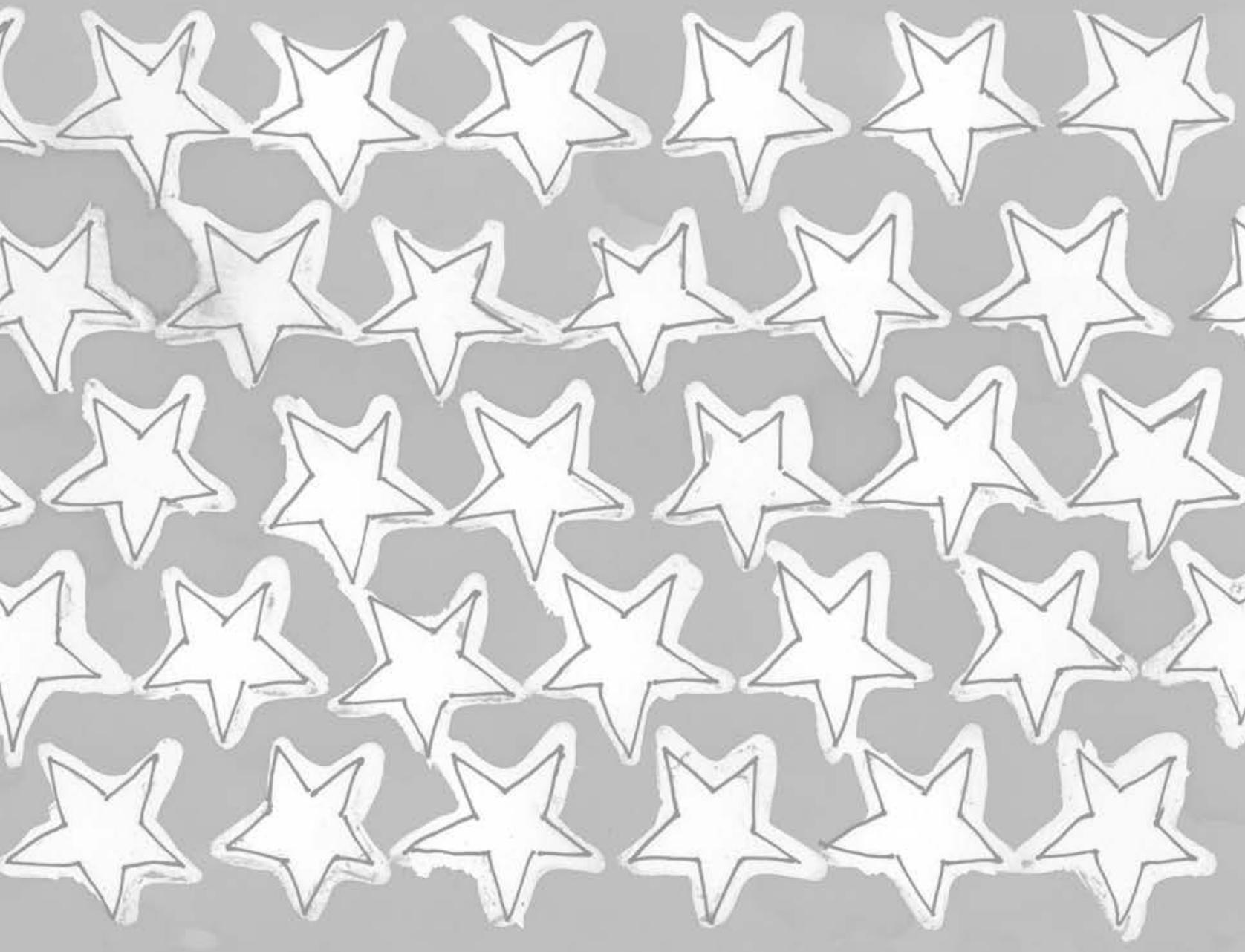


\section{Dankwoord}

\section{Dank aan}

alle cliënten van Maasveld en hun familieleden die mij geleerd hebben dat de werkelijkheid van het beslissen voor een ander ingewikkeld is, moeilijk en weerbarstig en dat er vaak geen goede beslissingen zijn.

de begeleiders en verpleegkundigen van Maasveld, die met hart en ziel bij hun werk betrokken zijn en zich afvragen wat het beste is voor hun cliënten.

de raad van bestuur van de Koraalgroep die mij de gelegenheid heeft gegeven om dit onderwerp uit te diepen, Chrik Diemel en Hank van Geffen.

de opeenvolgende directies van Maasveld die dit plan hebben gesteund, ook al was het soms moeilijk om de fondsen te vinden.

promotor professor Leopold Curfs, die mij op het 125 jarig bestaan van de stichting Sint Anna (tegenwoordig Koraalgroep) heeft gemotiveerd op het onderwerp palliatieve zorg verder uit te werken. Doelgericht werkt hij aan het op de kaart zetten van deze onderzoekslijn van het Gouverneur Kremers Centrum.

promotor professor Henny van Schrojenstein Lantman- de Valk, nooit moe om weer een versie na te kijken of mij te motiveren om toch maar naar een symposium te gaan. Henny, dank, je was voor mij een grote steun.

promotor professor Job Metsemakers, gastvrij voor "kleine" vakken zoals het AVG vak en een koersvast en betrouwbaar promotor.

de leden van de leescommissie die het manuscript zorgvuldig hebben bestudeerd.

dr Ireen Proot, geduldig, secuur, mijn onvolprezen begeleider op gebied van kwalitatief onderzoek. Onze eerste bijeenkomst op het terras van Cubico in Maastricht op een "goede" vrijdag in 2007 was de start van een zeer prettige samenwerking.

dr Irene Tuffrey-Wijne, gedreven onderzoeker op gebied van palliatieve zorg voor mensen met een verstandelijke beperking, ervaren in het helder beschrijven waar het in een artikel om draait.

Wiesje Bressers, bijna klaar met de opleiding tot AVG en degene die een groot deel van het NR onderzoek heeft gedaan. 
professor Frans van Wijmen, altijd bereid tot praktische adviezen in de dagelijkse medische praktijk, maar ook degene die mij een jaar of zes geleden adviseerde een plan te maken voor de promotie, dit uit te werken, een einddatum vast te stellen en aan de slag te gaan.

professor Guy Widdershoven die eveneens aan de wieg van dit onderzoek heeft gestaan en belangstelling bleef tonen.

professor Joep Geraedts en professor Harry Crebolder die zich beiden het vuur uit de sloffen hebben gelopen voor de academisering van Maasveld en de Koraalgroep.

Hans Fiolet die mij altijd met raad en daad heeft bijgestaan bij het beslissen voor mijn patiënten, jij hebt me geleerd dat niet alles moet wat kan.

de collega's van de regionale toetsgroep die enthousiast hebben meegewerkt aan de interviews.

alle lieve en aardige mensen van de afdeling Huisartsgeneeskunde die ervoor hebben gezorgd dat ik me thuis voelde.

het A-team van Maasveld, volgens mijn jongste zoon, de knappe, blonde en hoogopgeleide dokters van mama, te weten Anke, Anique en Aloise (Wiesje), die mij afgelopen jaren de mogelijkheid en ruimte gegeven hebben te doen wat er moest gebeuren om dit project tot een goed einde te brengen.

mijn gezin, de kern van mijn bestaan: Joep, tolerant, liefdevol en steunend. Matthijs die al heel jong met mij driehonderd dossiers lichtte voor het artikel over vallen en fracturen en nu mijn ICT ondersteuner is (en nog veel meer). Daan, de zeeman die het van een afstand bekijkt en mij met twee voeten op de grond zet en Caspar, zorgzaam en betrokken.

mijn ouders: mijn moeder die mijn zus en mij al heel jong ervan heeft doordrongen dat we op eigen benen moesten staan en mijn vader die het gymnasium eigenlijk niet geschikt vond voor een meisje, maar er zich onmiddellijk bij neerlegde toen dat meisje er toch heen wilde vanwege de mooie oude verhalen.

Kortom, ik heb geboft met de mensen om me heen. 


\section{Curriculum Vitae}

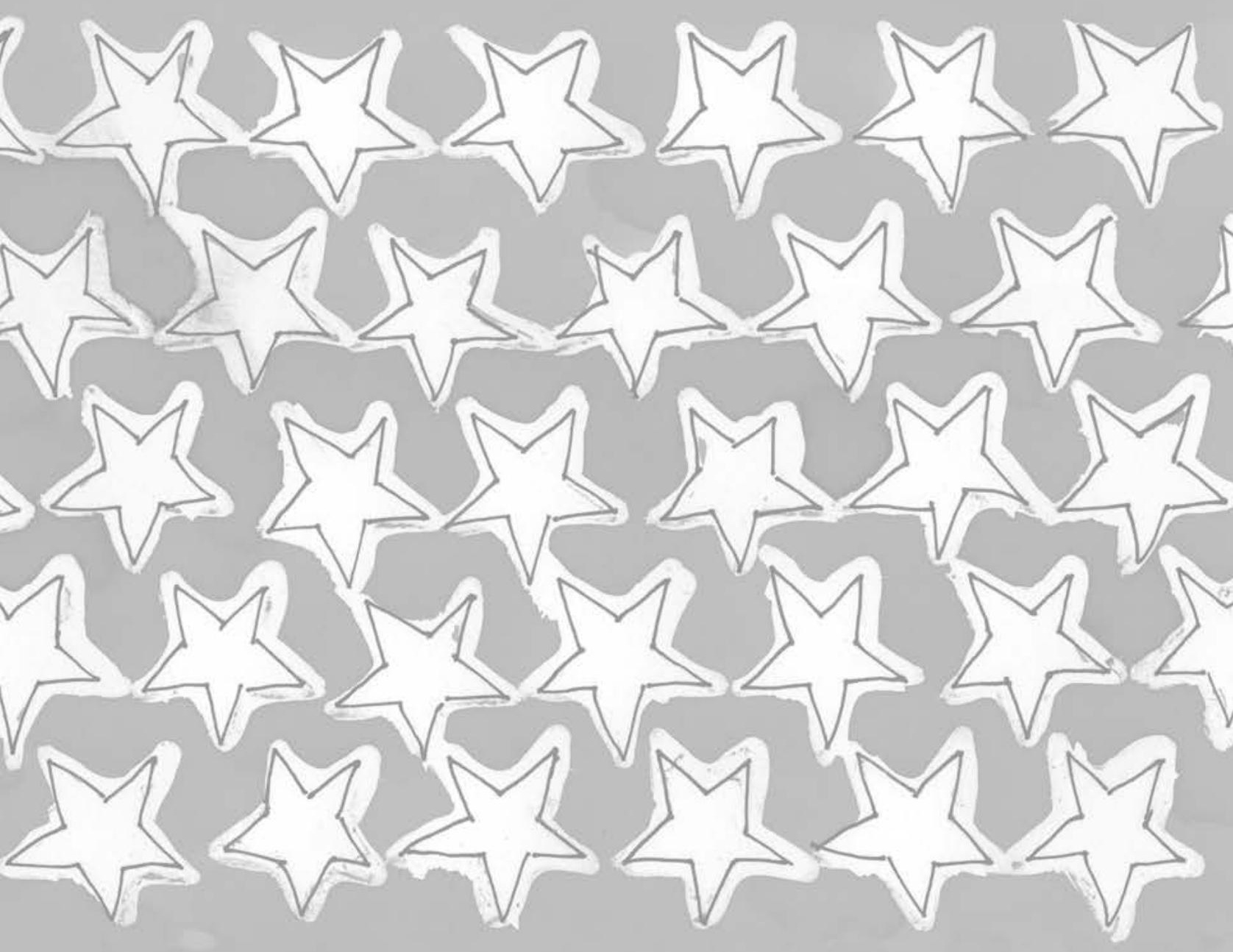




\section{Curriculum Vitae}

Annemieke Wagemans werd geboren op 27 juni 1955 in Weert, volgde het gymnasium bij de zusters Ursulinen in Roermond, en de studie geneeskunde aan de Radboud universiteit in Nijmegen.

Ze kwam in 1980 als basisarts in dienst van de Stichting Sint Anna, de huidige Koraalgroep, werkte eerst bij Sint Anna in Heel en vanaf 1984 bij Maasveld in Maastricht. In 1981 trouwde ze met Joep Cluitmans en samen kregen ze drie jongens, Matthijs, Daan en Caspar.

Van 1982-1984 volgde ze de opleiding sociale geneeskunde, tak jeugdgezondheidszorg, aan de universiteit van Nijmegen. In 2000 werd het specialisme AVG (Arts voor Verstandelijk Gehandicapten) een zelfstandig specialisme en werd Annemieke als zodanig geregistreerd. Vervolgens werd ze opleider voor AVG's.

Van 2002 tot 2008 zat ze in het bestuur van de Nederlandse Vereniging voor Artsen voor Verstandelijk Gehandicapten (NVAVG).

Ze was lid van de taakgroep "Beslissingen rond het levenseinde", die een NVAVG richtlijn publiceerde in 2007. In datzelfde jaar startte ze met het onderzoek naar beslissingen rond het levenseinde bij het Gouverneur Kremers Centrum. Voor dit onderzoek werd de vakgroep Huisartsgeneeskunde van de Universiteit Maastricht haar thuisbasis.

Vanaf 2005 vertegenwoordigt ze Maasveld in het netwerk palliatieve zorg Heuvelland. Verder heeft ze een aanstelling bij het academisch ziekenhuis Maastricht bij de vakgroep Klinische Genetica. Hier doet ze een spreekuur voor volwassen mensen met een verstandelijke beperking sinds 2004 en een multidisciplinair spreekuur voor volwassen mensen met het Downsyndroom sinds 2012.

Annemieke is adviseur voor de METC van het MUMC+ voor onderzoek bij wilsonbekwame mensen sinds 2006.

In 2012-2013 heeft ze deelgenomen aan de voorbereiding van het beleidsstuk "Omgaan met vragen voor levensbeëindiging van wilsonbekwame mensen met een verstandelijke beperking" door de Adviesgroep Ethiek van de NVAVG. Sinds kort doet ze consultaties voor de Levenseinde kliniek wanneer er vragen zijn betreffende mensen met een verstandelijke beperking. 
